\title{
Communication and reasoning on clinical teaching teams : the genres that shape care and education
}

Citation for published version (APA):

Goldszmidt, M. A. (2015). Communication and reasoning on clinical teaching teams : the genres that shape care and education. [Doctoral Thesis, Maastricht University]. Datawyse / Universitaire Pers Maastricht. https://doi.org/10.26481/dis.20150902mg

Document status and date:

Published: 01/01/2015

DOI:

10.26481/dis.20150902mg

Document Version:

Publisher's PDF, also known as Version of record

\section{Please check the document version of this publication:}

- A submitted manuscript is the version of the article upon submission and before peer-review. There can be important differences between the submitted version and the official published version of record.

People interested in the research are advised to contact the author for the final version of the publication, or visit the DOI to the publisher's website.

- The final author version and the galley proof are versions of the publication after peer review.

- The final published version features the final layout of the paper including the volume, issue and page numbers.

Link to publication

\footnotetext{
General rights rights.

- You may freely distribute the URL identifying the publication in the public portal. please follow below link for the End User Agreement:

www.umlib.nl/taverne-license

Take down policy

If you believe that this document breaches copyright please contact us at:

repository@maastrichtuniversity.nl

providing details and we will investigate your claim.
}

Copyright and moral rights for the publications made accessible in the public portal are retained by the authors and/or other copyright owners and it is a condition of accessing publications that users recognise and abide by the legal requirements associated with these

- Users may download and print one copy of any publication from the public portal for the purpose of private study or research.

- You may not further distribute the material or use it for any profit-making activity or commercial gain

If the publication is distributed under the terms of Article $25 \mathrm{fa}$ of the Dutch Copyright Act, indicated by the "Taverne" license above, 



\title{
Communication and Reasoning on Clinical Teaching Teams
}

\author{
The Genres that Shape Care and Education
}


The research reported here has been carried out at Du Maastricht University in Learning!

In the School of Health Professions Education

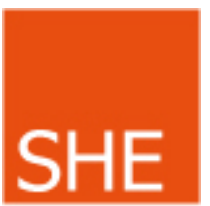

(C) copyright M. A. Goldszmidt, Maastricht 2015

Printing: Datawyse | Universitaire Pers Maastricht

ISBN 9789461594648 


\title{
Communication and Reasoning on Clinical Teaching Teams
}

\section{The Genres that Shape Care and Education}

\author{
DISSERTATION \\ to obtain the degree of Doctor at Maastricht University, \\ on the authority of the Rector Magnificus Prof.dr. L.L.G. Soete, \\ in accordance with the decision of the Board of Deans, \\ to be defended in public on Wednesday $2^{\text {nd }}$ September 2015, at 10:00 hours \\ by
}

Mark Andrew Goldszmidt 


\section{Supervisors}

Prof.dr. T. Dornan

Prof.dr. L. Lingard, Faculty of Medicine, University of Western Ontario

Prof.dr. J.J.G. van Merriënboer

Prof.dr. G. Bordage, College of Medicine, University of Illinois at Chicago

\section{Assessment Committee}

Prof.dr. A.J.J.A Scherpbier (chair)

Dr. A. de la Croix, VUmc, Amsterdam

Prof.dr. F. Scheele, VUmc Amsterdam

Prof.dr. F.W.J.M. Smeenk

Dr. R.E. Stalmeijer 


\section{Table of Contents}

$\begin{array}{ll}\text { Preface } & 7\end{array}$

Chapter 1 Introduction 9

$\begin{array}{lll}\text { Chapter } 2 & \text { Rhetorical Genre Theory } & 21\end{array}$

Chapter 3 Progressive collaborative refinement on teams: implications for 35 communication practices

Published as: Goldszmidt, M., Dornan, T., and Lingard, L. Progressive collaborative refinement on teams: implications for communication practices. Med Educ 48(3), 301-314. 2014.

Chapter 4 Attending Physician Variability: A Model of Four Supervisory Styles Published as: Goldszmidt, M., Faden, L., Dornan, T., Merriënboer, J., Bordage, G., and Lingard, L. Attending Physician Variability: A Model of Four Supervisory Styles. Acad Med 2014 (in press; accepted for publication October 23, 2014).

Chapter 5 Taking a Detour: Positive and Negative Effects of Supervisors' Interruptions During Admission Case Review Discussions Published as: Goldszmidt, M., Aziz, N., Lingard, L. Taking a Detour: Positive and Negative Effects of Supervisors' Interruptions During Admission Case Review Discussions. Acad Med 87(10), 1382-1388. 8-21-2012.

Chapter 6 Developing a Unified List of Physicians' Reasoning Tasks During Clinical Encounters

Published as: Goldszmidt, Mark, Minda, John Paul, and Bordage, Georges. Developing a Unified List of Physicians' Reasoning Tasks During Clinical Encounters. Acad Med 88(3), 390-397. 2013.

Chapter 7 Discussion: The Genres of Collaboration

Summary

Samenvatting

Valorization

Acknowledgments

Curriculum vitae 

Preface 
Since the beginning of my career as a general internist, I have always worked in academic health sciences centres. Most of my clinical time is spent working on inpatient, internal medicine, clinical teaching units (CTUs). Typically, this means supervising a diverse group of learners at various levels of training while they provide care for some of the sickest and most complex patients admitted to the hospital. Since the first time I took on a supervisory role as a resident in the mid 1990's, I have searched for research and theories that could help guide my practice and teaching of medicine. Key literatures that have fascinated and supported me over the years relate to communication skills and theories, supervisory practices, clinical reasoning, and expertise. While all four of these literatures have helped me reflect on my practice and guide my teaching, I constantly struggled because I feel that there are too many areas of practice that go unaddressed in these literatures. For example, the communication literature largely ignores the issue of integrating reasoning and communication; the supervision literature often ignores the impact of context on practice; and the clinical reasoning and expertise literatures in medicine are limited by their almost exclusive focus on the process of diagnosis.

The four empirical studies that comprise this dissertation represent the beginnings of my journey ${ }^{1}$ to address these gaps. What they share in common is a focus on providing clinician-educators with some of the knowledge that they will need to supervise and teach in the clinical setting. They also have insights for students, faculty developers, and researchers. For the most part, the studies provide insights into new questions and new ways of studying the delivery of clinical care in the context of teaching teams. In particular, they challenge us to reconsider the components of clinical reasoning and communication necessary for the delivery of high quality team-based care.

Most of my studies were published in medical education journals. Due to word limit restrictions, I was not always able to fully describe the context for the studies or their theoretical underpinnings. Therefore, in chapter 1 I will describe the clinical context for my research. This will be followed in Chapter 2 by a presentation of rhetorical genre theory and how it influenced my research.

1 Because this is a dissertation, I am writing in the first person. However, I want to acknowledge the collaborative nature of this research and the importance of my research team. For the most part, when referring to the studies themselves, the "I" statements should be read as "we". 
CHAPTER 1

Setting the Stage 
In order to understand the context for my work, it is important to review some of the current issues in academic, internal medicine practice. In this chapter, I will first describe the patient population and clinical setting. I will then provide a general overview of the studies included in this dissertation. In each section, I will discuss some of the key literature and, where relevant, how the local context of my studies relates to what is described in the literature. I will also identify some of the gaps that the studies in this dissertation address.

\section{The Complex Patient}

Social and medical advances have led to an aging population of patients who live with multiple chronic medical conditions. While approximately $62 \%$ of people over the age of 65 suffer from chronic conditions including diabetes, hypertension, chronic heart and lung disease, and mental illness, most receive their health care in a system that is focused primarily on the management of acute medical problems ${ }^{1}$, 2. While internal medicine practice in Canada deals with a wide range of patients aged 18 and older, patients admitted to hospital under internal medicine are typically older and the majority suffer from at least three chronic medical conditions. Not infrequently, many have multiple challenges in caring for themselves independently. Patients admitted to the hospitals where my studies took place are typical of this older patient population.

Patients with multiple, most often chronic medical problems present challenges in acute care settings. Studies indicate that when these patients are admitted to hospital on an emergency basis, medical teams don't always take into account their chronic active problems ${ }^{3,4}$ but instead focus almost exclusively on their acute problem(s). Hayward et al.'s study of chart audits identified that the majority of substantive medical errors are errors of omission, where patients with chronic medical conditions receive inadequate investigations and treatments for their chronic active problems ${ }^{3}$, which will often result in re-admission. For example, as many as $83 \%$ of patients presenting to hospital with congestive heart failure will be re-admitted, with more than 50\% having multiple admissions, usually for a secondary, pre-existing, non-cardiac related medical condition ${ }^{4,5}$. Similarly, over the course of a year at our centre, $80 \%$ of internal medicine patients will be admitted on more than one occasion for pre-existing problems ${ }^{6}$. Dubbed the "sins of omission", this failure to consider a patient's chronic active issues when managing their acute illness has been considered one of the "greatest threats to patient safety" ${ }^{3}$. To date, little is known about how such omissions occur and why they persist. 


\section{The Clinical Teaching Unit (CTU) Team Structure, Communication and Teaching Practices}

The challenge of caring for complex patients is heightened by the structure of the inpatient medical team, in Canada referred to as a Clinical Teaching Unit (CTU) team. A CTU team is staffed by a multi-layered group consisting of junior trainees (senior medical students and junior residents), senior residents and their faculty supervisors. In all but one of the studies in this dissertation, the setting was a typical academic, acute care hospital, internal medicine CTU. In the primary study setting there are three CTU teams functioning simultaneously. In other Canadian CTUs, configurations may vary, but each academic hospital typically has between 14 internal medicine CTU teams. Typically, each team is supervised by a faculty member referred to as the attending physician. In other countries these may be referred to as the consultant or supervisor. While the exact role may vary among different academic centres, the attending physician holds ultimate medical-legal responsibility for all patients admitted to the team and is expected to see all patients and review all care decisions. With few exceptions, the attending is also responsible for teaching and evaluating the trainees on the team. To varying degrees, attendings also share the responsibilities of teaching and supervision with the senior medical resident. Similar to their European counterparts (registrars), these residents - who are always second or third-year residents in the core internal medicine program - are typically responsible for the day-to-day management of the team. Although there are overlapping roles between attendings and senior residents, I am unaware of any research that has explored how the two configure and share their responsibilities on the CTU team.

In the primary study setting, each team had 2 senior medical residents; one second-year and one third-year resident. The teams also have 4-8 junior trainees typical consisting of 2-4 senior medical students who are called clinical clerks and 2-4 first-year (junior) residents. The junior residents can be in internal medicine or other programs such as family medicine, surgery, or radiology. In most Canadian hospitals, there are only slight differences in the roles of the medical students and junior residents. In common, all junior trainees are given responsibility for admitting patients to the team, seeing several patients each day in follow-up, writing the clinical notes on those patients, and then reviewing these with the senior medical resident and/or the attending physician and the rest of the team. Typically, junior residents follow more patients than medical students (5-8 vs. 3-5). Junior residents also have the ability to sign their own patient care orders whereas medical students require a co-signature from a resident. It should be noted that the role of the medical student in the Canadian context is very different from their 
counterparts in the United States and in many European settings where they often play more observer-type roles.

In the settings studied, each of the three CTU teams takes turns receiving new admissions, with each admitting a third of all referred patients in any given 24-hour period. In other hospitals, approaches vary with some taking turns according to the day of the week or the time of day - daytime vs. nighttime. The majority of patients are admitted from the emergency room. Approximately two thirds of new patients are admitted overnight during the on-call period; trainees in our program typically do a 10-hour work day followed by an on-call overnight period every 4-6 days. Oncall days therefore include total shift durations of approximately 26 hours. While many Canadian programs use a similar system, some have moved to night float systems where the on-call team is a completely different set of trainees from the daytime team. In the settings where I used direct observation, (chapters $3 \& 5$ ), the on-call team consisted of one senior resident and one junior trainee from each of the three teams. In terms of case review, cases admitted on-call are typically not reviewed with the attending until morning when morning presentations of new patients are given by the admitting post-call junior trainee. Given that there is only one on-call senior resident, they are only for their own team's reviews. This means that for two teams, the junior trainee will be the only one present who already knows the patient during the morning case presentations.

The provision of care by the CTU team is dependent on a series of interrelated communication practices including oral case review and written documentation. One of the key sections of the written documentation is known as the assessment and plan, although this term draws attention to the product rather than the process. The process of assessing and planning on the CTU team is fundamentally dependent on two communication practices: oral case review and daily written documentation in the chart. Oral case reviews allow more senior team members to evaluate the data that junior team members have gathered about the patient at admission and to guide the plan for patient care. After assessing the patient and writing an admission note, trainees typically review the note with the senior resident on-call. Subsequently, typically the next morning, they present to the attending physician and other team members who typically include the team's senior resident and all of the junior trainees. Case reviews then occur, as needed, throughout the patient's admission process, often in abbreviated form. Documentation, in the form of admission notes, progress notes, orders and discharge summaries, is done by the junior trainees on a daily basis. At the centres studied, clinical documentation and orders are paper based with the exception of the discharge summary that is dictated by the junior trainees, co-signed by the attending physicians, and placed in the electronic medical record.

These communication practices serve two goals: trainee education and patient care. Although the educational aspects of case review have received research attention $^{7-11}$, studies have not considered the relationship between case review and 
documentation practices, which, as discussed, are largely delegated to junior trainees. Further, no studies have endeavored to trace how the case review and documentation practices are combined to shape the team's actual decision making and delivery of care. While researchers acknowledge that case review is both a supervisory and a clinical practice ${ }^{9}$, studies have not previously concretely traced its implications for the team's (not just the trainee's) characterization of the patient's problems and the clinical plans to address those problems.

The transfer of care responsibility among changing team members is increasingly the norm in North America and has been shown to increase patients' risks of experiencing adverse events ${ }^{12-14}$. As is typical of academic centres in North America, attendings in our studies rotate every 2 weeks, residents rotate every 4-8 weeks and medical students every 6 weeks. Because of post-call absences and absences for trainee teaching or out of sequence rotation changes, the actual team membership is highly variable, thus creating fragmented teams. The degree of fragmentation has been well described in similar settings at other academic institutions ${ }^{15,16}$. A critical implication of this fragmented team structure is the necessity for multiple transfers of information between individuals, a phenomenon referred to as 'handover'. Lack of key information that may only be available from handover can lead to uncertainty during subsequent decision making, which in turn can lead to inefficient or suboptimal care ${ }^{17}$.

Another important transition takes place at the time of the patient's discharge from the hospital. In a study of discontinuity between inpatient CTU and ambulatory care, nearly $50 \%$ of patients had errors related to follow-up regarding ordered tests, planned work-up not being completed and medication errors. ${ }^{13}$ of these errors, many were related to inadequate communication and resulted in increased hospital readmission rates ${ }^{13}$. The role of written documentation is therefore particularly important at discharge, where it has been shown that preventable errors arise as a result of omissions of key information 13, 18-20. The issue that has not been addressed is the extent to which these omissions may arise as a result of the inadequacy of the admitting case review and inpatient case characterizations and documentation practices.

Emerging research suggests that, in addition to team fragmentation, the setting itself may also influence communication in ways that may cause safety threats $^{21,22}$. Hoff, Pohl and Bartfield (2006) have shown that teaching teams may structure their interactions in ways that conflict with the goals of continuous quality improvement ${ }^{23}$. They reported that case review discussions tend to focus on what individual learners know and fail to recognize the team processes involved in errors or near misses. Bernabeo et al. (2011) showed that, due to short rotations, trainees may feel a lack of ownership for the patients they care for, which may influence their approach to workload 12; for example, they found that some residents use workarounds - strategies that circumvent but don't address the underlying problem - such as writing fewer progress notes or focusing handover 
discussions on tasks to be done rather than as an opportunity to discuss the patient and their progress.

One of the dominant theories addressing the issue of student participation in the clinical setting comes from the work of Lave and Wenger (1991) on situated learning ${ }^{24}$. According to their theory, junior members of a team begin by taking on legitimate but peripheral roles. Over time, they increasingly take on more central roles. For this to take place safely and effectively there is a need for a stable community of practice for the junior members to join. As already noted, the CTU team membership varies considerably within short periods of time and thus presents additional challenges. Moreover, in many ways, as will be shown from some of the studies in this dissertation, the junior members of the teams are given roles that are very central to the teams' work such as clinical documentation. While oversight practices exist to safeguard patients 7,25 , clinical documentation is not always attended to in a way commensurate with its importance in practice.

In addition, the notion of team competence is highly relevant to the practices of the CTU team ${ }^{26,27}$. The care of the patients admitted to the CTU is not provided by a single individual or even by a series of individuals each handing over to the next in a linear sequence. Rather, care is provided by multiple individuals both simultaneously and distributed over time in complex, non-linear relationships. Research to date on the CTUs has largely ignored this issue.

In summary, the CTU is a setting in which attending physicians support the education of medical students and residents by actively sharing patient care. As such, the quality of care is heavily reliant on the team's collective competence. While individual competence clearly plays a critical role, scheduling constraints that lead to frequent changes in team membership, put a heavy burden on the team's ability to use their communication practices to support collective care. Other challenges of this situated learning environment include the varying levels of learner experience, the dual roles of education and patient care, and patient complexity. To date, studies have largely focused on the types of care gaps that arise ${ }^{1-5,12-22}$ and on best practices in teaching ${ }^{7-11}$. Similarly, studies addressing the team's communication practices have typically focused on isolated elements of communication $7-9,13,17-20,23,25$. Thus there is a research need for a more nuanced study at how the team's communication practices both support and constrain trainee education and the team's collective competence in providing quality patient care. The studies in this dissertation are all part of a research program focused on determining how team communication practices support and constrain both trainee education and patient care. 


\section{A General Outline of the Work}

The aim of my research program is to inform, and hopefully improve, trainee education and clinical practice by understanding the complex environments where clinicians and trainees interact to provide care and learn as teams. The studies in this dissertation are the first step in that program. At its highest level, my goal in the dissertation research was to explore the CTU communication practices and the ways in which they currently support and constrain the team's ability to provide appropriate and safe patient care and high quality trainee education. In the following paragraphs I will provide a brief overview of the dissertation chapters and their relationship to each other.

As can be seen in Figure 1.1, the CTU communication system is composed of both oral and written practices. From the perspective of this dissertation, each of these practices can be called genres: they have recurring structures, use language to serve shared purposes and achieve particular social actions and are recognized as distinct practices by the members of the teams using them. This definition of genre is at the heart of this dissertation, which uses the lens of Rhetorical Genre Theory (RGT) to explore the CTU context. Due to the nature of the four publications that make up the core of this dissertation - they were published for a medical education and clinical audience - it was not always possible, or appropriate, to fully explore the connection between RGT and the study findings. The focus of Chapter 2 is therefore an introduction to RGT. Specifically, Chapter 2 focuses on providing those unfamiliar with the theory with a definition of RGT and some of the core RGT concepts. In Chapter 7 (Discussion), I then return to two of these concepts, exigence and intertextuality, and explore what additional insights they provide on the four studies' findings. I also discuss in Chapter 7 the implications of the study results for both practice and medical education research. 


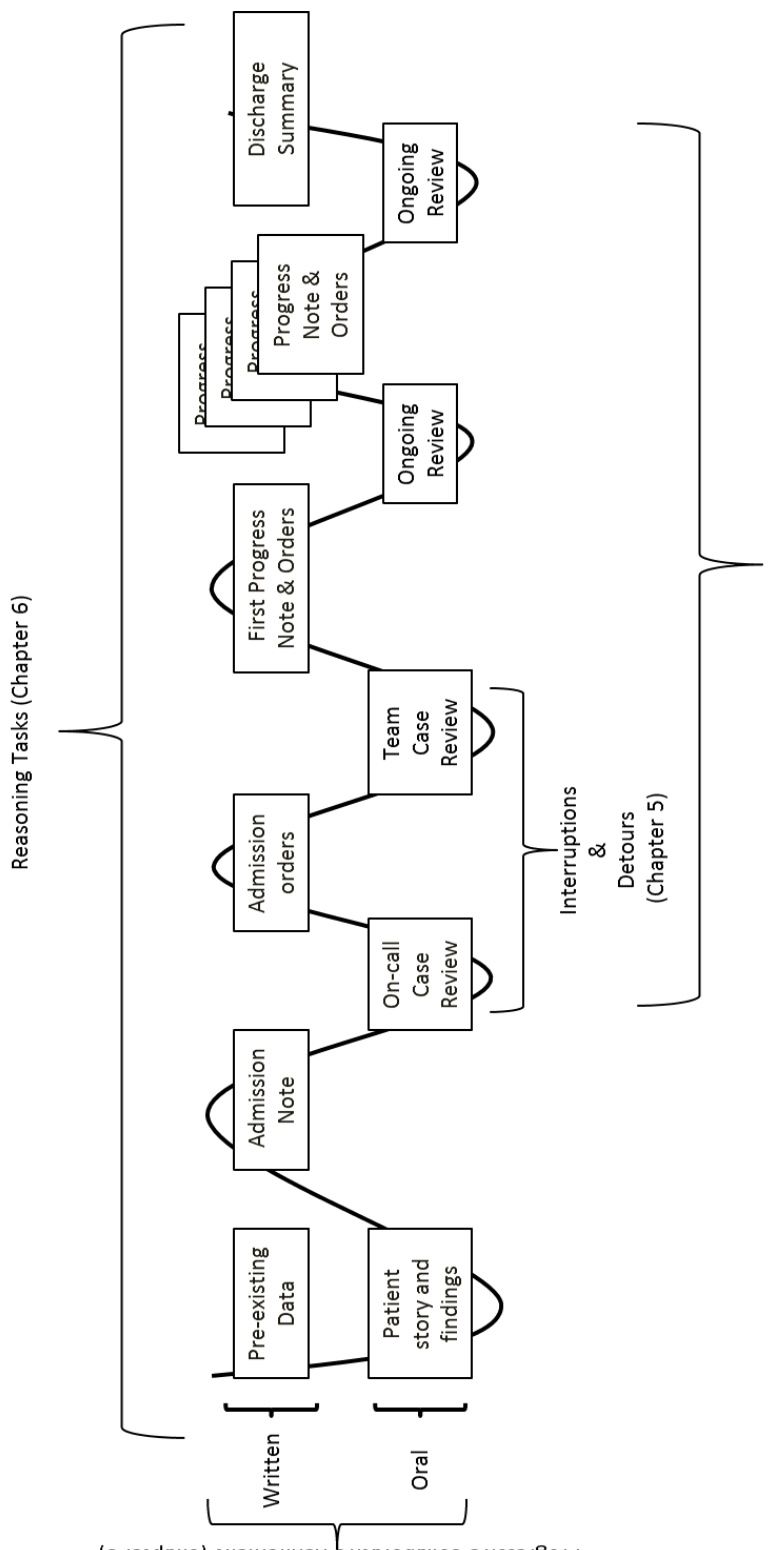

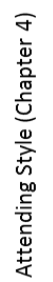


Figure 1.1 also depicts the relationship between each of the four studies and the CTU genre system. In the centre of the figure is the CTU genre system. In the figure, the basic connections between the oral and written genres are depicted. The first study, reported in Chapter 3 and entitled "Progressive Collaborative Refinement on Teams: Implications for Communication Practices" focuses on this CTU genre system and how it supports and, at times, constrains the team's ability to provide safe and effective patient care. Further, I identify one of the key characteristics of what an effective communication system should achieve: "progressive collaborative refinement" (PCR). That is, from the start of a patient's admission through to their discharge from hospital, the team's communications (oral and written) should capture the full progression of thinking that the team went through regarding all of the patient's active problems. For example, as investigation results become available, new information comes to light and more senior members of the team help junior members to elaborate an understanding of the problems and plans, these should be documented and fed forward such that the next care providers are able to continue to support the patient's care.

The second study reported in Chapter 4, "Exploring Variability in Attending Physician Practice: A Model of Four Supervisory Styles", arose in response to a pivotal finding from the first study. As part of the observations of case review practices, I identified considerable variation in how attending physicians conducted case review. In order to further explore this variability, I used an interview-based study to ask attending physicians to reflect on their supervisory practices. This also allowed me to explore aspects of supervisory practice that were not captured in the original study, including attendings' pre and post-review practices, their perceptions of the affordances and constraints of the CTU context, and their underlying assumptions about teaching, learning, and patient care.

The third study reported in Chapter 5, entitled "Taking a Detour: Positive and Negative Effects of Supervisors' Interruptions During Admission Case Review Discussions", was designed to qualitatively explore the impact of interruptions on the quality of admission case review and the ability of the team to present and discuss the full patient case. The results from this study led me to explore both the benefits and risks associated with interrupting trainees during their case presentations. In the data analyses, interruptions were ubiquitous and had the potential to either support or hinder PCR. Moreover, it appeared that, without interruptions, trainees would receive little guidance or teaching from the more senior members of the team. The most important element, determining whether an interruption would interfere with PCR, was the type of detour it introduced. In this study, I defined detours as deviations from the standard case presentation format. In an effective detour, the presentation would be paused, the detour would arise and then the presentation would return to where it left off. Detours that interfered with PCR however were ones where the presentation did not return to where the presentation left off from the standard sequence with the consequence, at times, of 
important information not being shared. While detours could be initiated by any member of the team during case presentations, it was interruptions from the attending physician or senior resident that seemed to have the highest impact on PCR, either beneficial or detrimental. The main recommendation from these results was to time interruptions carefully and to ensure that, following an interruption, the trainee presenting the case is guided back to where he or she left off prior to it.

The final study reported in Chapter 6, entitled "Developing a Unified List of Physicians' Reasoning Tasks During Clinical Encounters", was meant to address a different gap in the understanding of PCR. While the other studies explored what PCR is and why it may or may not be supported, this study addresses the question: "PCR about what?" Prior to this study, the medical community has used a very rudimentary vocabulary for talking about clinical reasoning as a process and its content. For the most part, the study of clinical reasoning has focused mainly on diagnosis and only rarely includes management. As part of this study, I developed a list of 24 tasks that clinicians - and therefore clinical teams - could think about when they see and discuss patients. In relation to PCR, this newly assembled vocabulary can be used to explore not only whether PCR is taking place but also which reasoning tasks are being addressed during case reviews, and which ones may be only partially addressed or even completely ignored.

\section{References}

(1) Vogeli C, Shields AE, Lee TA et al. Multiple chronic conditions: prevalence, health consequences, and implications for quality, care management, and costs. J Gen Intern Med 2007;22 Suppl 3:391-395.

(2) Partnership for Solutions. Chronic Conditions: Making the Case for Ongoing Care. 2002 Dec.

(3) Hayward RA, Asch SM, Hogan MM, Hofer TP, Kerr EA. Sins of omission: getting too little medical care may be the greatest threat to patient safety. J Gen Intern Med 2005;20(8):686-691.

(4) Pitt B. Male gender, diabetes, COPD, anemia, and creatinine clearance $<30$ $\mathrm{mL} / \mathrm{min}$ predicted hospitalization after heart failure diagnosis. Ann Intern Med 2010;152(8):JC4-3.

(5) Dunlay SM, Redfield MM, Weston SA et al. Hospitalizations after heart failure diagnosis a community perspective. J Am Coll Cardiol 2009;54(18):1695-1702.

(6) Census Data. London Health Science Centre. 2015.

(7) Kennedy TJ, Lingard LA. Questioning competence: a discourse analysis of attending physicians' use of questions to assess trainee competence. Acad Med 2007;82 (10 Suppl):S12-S15.

(8) Haber RJ, Lingard L. Learning oral presentation skills: a rhetorical analysis with pedagogical and professional implications. J Gen Intern Med 2001;16(5):308314. 
(9) Lingard L, Haber RJ. Teaching and learning communication in medicine: a rhetorical approach. Acad Med 1999;74(5):507-510.

(10)Irby DM. How attending physicians make instructional decisions when conducting teaching rounds. Acad Med 1992;67(10):630-638.

(11)Irby D, Bowen JL. Time-efficient strategies for learning and performance. The Clinical Teacher 2004;1(1):23-28.

(12)Bernabeo EC, Holtman MC, Ginsburg S, Rosenbaum JR, Holmboe ES. Lost in transition: the experience and impact of frequent changes in the inpatient learning environment. Acad Med 2011;86(5):591-598.

(13)Moore C, Wisnivesky J, Williams S, McGinn T. Medical errors related to discontinuity of care from an inpatient to an outpatient setting. J Gen Intern Med 2003;646-651.

(14)Coleman EA, Berenson RA. Lost in transition: challenges and opportunities for improving the quality of transitional care. Ann Intern Med 2004;141(7):533536.

(15)Amalberti R, Auroy Y, Berwick D, Barach P. Five system barriers to achieving ultrasafe health care. Ann Intern Med 2005;142(9):756-764.

(16)Safford MM, Allison JJ, Kiefe CI. Patient complexity: more than comorbidity. the vector model of complexity. J Gen Intern Med 2007;22 Suppl 3:382-390.

(17)Arora V, Johnson J, Lovinger D, Humphrey HJ, Meltzer DO. Communication failures in patient sign-out and suggestions for improvement: a critical incident analysis. Qual Saf Health Care 2005;14(6):401-407.

(18)van Walraven C, Seth R, Austin PC, Laupacis A. Effect of discharge summary availability during post-discharge visits on hospital readmission. J Gen Intern Med 2002;17(3):186-192.

(19)van Walraven C, Seth R, Laupacis A. Dissemination of discharge summaries. Not reaching follow-up physicians. Can Fam Physician 2002;48:737-742.

(20)Epstein RM. Communication between primary care physicians and consultants. Arch Fam Med 1995;4(5):403-409.

(21)Sutcliffe KM, Lewton E, Rosenthal MM. Communication Failures: An Insidious Contributor to Medical Mishaps. Acad Med 2004;79(2):186-194.

(22)Singh H, Thomas EJ, Petersen LA, Studdert DM. Medical Errors Involving Trainees: A Study of Closed Malpractice Claims From 5 Insurers. Arch Intern Med 2007;167(19):2030-2036.

(23)Hoff TJ, Pohl H, Bartfield J. Teaching but not learning: how medical residency programs handle errors. J Organiz Behav 2006;27(7):869-896.

(24)Lave J, Wenger E. Situated learning: legitimate peripheral participation. Cambridge England: Cambridge University Press; 1991.

(25)Kennedy TJ, Lingard L, Baker GR, Kitchen L, Regehr G. Clinical oversight: conceptualizing the relationship between supervision and safety. J Gen Intern Med 2007;22(8):1080-1085.

(26)Lingard L. What we see and don't see when we look at 'competence': notes on a god term. Adv Health Sci Educ Theory Pract 2009;14(5):625-628.

(27)Lingard L. Rethinking Competence in the Context of Teamwork. In: Hodges B, Lingard L, editors. The Question of Competence. Cornell; 2012. 
CHAPTER 2

Rhetorical Genre Theory 
Before moving on to the empirical studies, I will discuss how I have used the theoretical framework of rhetorical genre theory (RGT) to guide my studies and this dissertation. Because each study was published in a different journal with its specifically intended audience, it was not always appropriate or possible to fully draw attention or explain my underlying theoretical framework. Instead, I chose language that would be best received by each journal audience, knowing that, sometimes, the language may not have been part of the standard genre lexicon of RGT. In order to address this situation, I have written this chapter as an overview of the key concepts of RGT as it relates to the work in this dissertation. This theoretical section is not intended to be a comprehensive presentation of the theoretical lineage of RGT nor the nuanced debates between key concepts within this framework. Instead, I have referenced selectively the sources that I think best represent the concept as I applied it. In order to help readers unfamiliar with RGT, I have included in Table 2.1 a set of definitions for selected key concepts, illustrated where possible with concrete examples from the CTU context. In my discussion chapter, I will return to RGT to discuss the significance and implications that arise from the set of studies in this dissertation.

Table 2.1 Definitions of selected terminology and concepts as used in rhetorical genre theory

\begin{tabular}{|c|c|c|}
\hline Term & Definition & Example \\
\hline Agency & $\begin{array}{l}\text { The ability to enact choice and } \\
\text { shape social action. }\end{array}$ & $\begin{array}{l}\text { At the conclusion of the case review } \\
\text { discussion, recognizing that he is still } \\
\text { not clear on the plans, a junior trainee } \\
\text { exerts agency and asks the attending if } \\
\text { he could outline the management } \\
\text { plans one more time }\end{array}$ \\
\hline Exigence & $\begin{array}{l}\text { A form of social motive that } \\
\text { drives how we act within a social } \\
\text { situation. }\end{array}$ & $\begin{array}{l}\text { Responding to the exigence arising } \\
\text { from the on-call team's diagnostic } \\
\text { error, the attending physician pauses } \\
\text { the case presentation to teach the } \\
\text { team. }\end{array}$ \\
\hline Genre & $\begin{array}{l}\text { The common communication } \\
\text { practices that a group develops } \\
\text { around recurrent situations that } \\
\text { enable it to achieve particular } \\
\text { actions. }\end{array}$ & $\begin{array}{l}\text { The admission orders genre is the } \\
\text { means by which physicians } \\
\text { communicate with nurses to indicate } \\
\text { which tests to do and what } \\
\text { medications to give. }\end{array}$ \\
\hline Genre Repertoire & $\begin{array}{l}\text { The full set of genres that a group } \\
\text { owns to achieve all of its } \\
\text { purposes }\end{array}$ & $\begin{array}{l}\text { All of the genres associated with CTU } \\
\text { practice including administrative, } \\
\text { patient care and education-related } \\
\text { ones. }\end{array}$ \\
\hline Genre Set & $\begin{array}{l}\text { A set of genres that are loosely } \\
\text { connected through the activities } \\
\text { and functions of a group. }\end{array}$ & $\begin{array}{l}\text { Hospital administrators and } \\
\text { physicians likely have in their } \\
\text { repertoires a set of genres that they } \\
\text { commonly use to communicate with } \\
\text { each other }\end{array}$ \\
\hline Genre System & $\begin{array}{l}\text { A genre set where all of the } \\
\text { genres are linked to a common } \\
\text { set of purposes }\end{array}$ & $\begin{array}{l}\text { The genre system of a hospital } \\
\text { admission. }\end{array}$ \\
\hline
\end{tabular}




\begin{tabular}{|c|l|l|}
\hline Intertextuality & $\begin{array}{l}\text { The interpretive relationship that } \\
\text { texts (oral, written or visual) } \\
\text { have with each other and with } \\
\text { those who read them. }\end{array}$ & $\begin{array}{l}\text { On hearing a patient's medication list, } \\
\text { a physician considers the relationship } \\
\text { of the current medications with the } \\
\text { patient's known diagnoses. }\end{array}$ \\
\hline Recontextualization & $\begin{array}{l}\text { The change in meaning that } \\
\text { arises as a writer or speaker } \\
\text { takes up someone else's ideas }\end{array}$ & $\begin{array}{l}\text { While writing a progress note, a } \\
\text { junior trainee may inadvertently } \\
\text { change how the documentation } \\
\text { reflects the team's understanding of a } \\
\text { patient's medical problem. }\end{array}$ \\
\hline Rhetorical situation & $\begin{array}{l}\text { A socially defined situation that is } \\
\text { recognizable to members of a } \\
\text { group and to which they respond } \\
\text { through discourse. }\end{array}$ & $\begin{array}{l}\text { In response to the rhetorical situation } \\
\text { of a newly admitted patient, the team } \\
\text { engages in the morning case review. }\end{array}$ \\
\hline Uptake & $\begin{array}{l}\text { The responsive social actions } \\
\text { that arise between genres such } \\
\text { that one genre creates a situation } \\
\text { that allows for a response using } \\
\text { another genre }\end{array}$ & $\begin{array}{l}\text { The admission note gives rise to a } \\
\text { progress note and a set of admission } \\
\text { orders. }\end{array}$ \\
\hline Utterance & $\begin{array}{l}\text { A unit of speech bounded by a } \\
\text { change of speaker. }\end{array}$ & $\begin{array}{l}\text { The medical student presents the } \\
\text { patient's medication list and the } \\
\text { attending responds to that utterance } \\
\text { by asking about specific dosages. }\end{array}$ \\
\hline
\end{tabular}

\section{Genre as social action}

RGT is but one of the many ways in which scholars approach genre studies. As indicated by its name, RGT localizes itself in the field of rhetoric. In 1984, in response to concerns over the lack of clarity of the definition of genre from a rhetorical perspective and criticism over the legitimacy of a rhetorical focus on genre, Carolyn Miller wrote what is largely considered to be the seminal paper Genre as Social Action - that launched the field of rhetorical genre studies ${ }^{1}$. In that paper, building on Bitzer's definition of rhetorical situation ${ }^{2}$, she defines genre as "typified rhetorical actions based in recurrent situations" 1(p.159), that is, how genres are used and the actions they do in the world. Through recurrent situations, groups develop normative, common communication practices that enable them to do their work. It is essential that a genre be recognized by the groups who use them and not just by scholars. RGT is ethnomethodological; that is, it focuses on real world practices and the genres that shape and support those practices. Genres are created by groups for groups to do shared work. To be recognized as a genre, there must be a recurrent situation, similarity of form, and shared purpose(s).

2 "A complex of persons, events, objects, and relations presenting an actual or potential exigence which can be completely or partially removed if discourse, introduced into the situation, can so constrain human decision or action as to bring about the significant modification of the exigence."2(p.6) 
In the CTU context, there are many communication practices that can be recognized as genres because of their recurrent nature, similarity of form, and shared purpose(s). Good examples of genres are those related to the patient admission process. These include the recurrent situation of writing admission orders, writing an admission note, and reviewing the case. The rhetorical or social actions of these genres, which are often related to their perceived purpose(s), are varied. They include actions that shape patient care and others that shape individual and group learning. Thus, each individual who writes orders, documents a history or gives a clinical presentation is shaping the way that patient will be cared for. Depending on the circumstance, he or she may also be shaping what they personally study and what other members of the team learn about caring for a patient such as the one they are presenting. Similarity of form within each genre also serves to shape the work and guide its users. For example, admission order forms have specific fields that must be completed and case presentations have expected formats that should be followed. There are also expectations about what is not to be included such as the social history during a case presentation ${ }^{3}$. While Miller's definition of genre may appear at first to be rule bound and ignore personal variations or agency (very simply, the ability to enact choice), this is not the case. Even within well-established genres (e.g., admission orders, case reviews), there can be wide variation in practices ${ }^{4}$. For some, these variations are rhetorical in that they are a deliberate attempt to persuade or shape a particular social action. For others, they are incidental or even accidental. For example, during case review, an attending physician may exert agency and deliberately modify the traditional approach to the case review genre to achieve a particular learning goal with the trainees that day. By contrast, due to inexperience, a trainee may omit an important section from their admission note, thus introducing variation, without any intent. In addition to individual variations, genres are highly influenced by context and culture ${ }^{5}$.

\section{Genre, culture and context}

According to Devitt (2004), a given genre needs to be understood and defined in relation to three types of contexts: situation, culture, and other genres. Consistent with Miller's definition she writes, "a genre constructs and is constructed by a notion of recurring situation, entailing participants roles, purposes, and uses of language"(p.29). However, she also adds that "a genre constructs and is constructed by cultural values, beliefs, and norms as well as by material culture" (p.29). Thus genres have a reciprocal relationship with the communities they serve; they both guide and respond to the community. Even though case review is a well-recognized genre within the broader community of CTUs across North America, depending on the degree to which they differ, there may in fact be many different genres that are all 
called case review but bear insufficient resemblance to each other to be considered the same genre. A good example of this may be found by comparing the case review genre of an academic centre with a strong culture of teaching to a centre where there is a heavier emphasis on patient care delivery. If the variations introduced as a result of these differences are great enough, the genres will be unrecognizable to the other group and can therefore be considered a different genre. However, if the variations introduced are still recognizable to the group then it can be considered to be the same genre as is typically the case when a new attending or senior resident imposes their approach to case presentation. Also important are the relationships between a given genre and other genres. As Devitt (2004) claims, "A genre constructs and is constructed by the set of existing genres surrounding it, genres used and not used by fellow participants in the society" (p.29). Depending on the hospital or even the ward where the work is being done, there may be different expectations of what sequences need to be followed, who needs to be spoken to, what forms are to be completed and where they are to be stored when done. For example, the nature of the admission note and case presentation genres will shape how orders are written and used thereby influencing the order writing genre at that particular institution.

\section{Genre repertoires, systems and sets}

Genres do not exist in isolation. In order to achieve their purpose(s), groups typically require multiple genres. Some of these will interact in a relatively linear or sequential fashion to achieve a specific purpose while others function within more complex relationships, at times addressing multiple and even competing purposes. In the RGT literature, the terminology for referring to the relationships between genres is not uniform ${ }^{5}$. Several authors in fact have used the same nomenclature with different definitions. I have chosen to use Devitt's (2004) definitions because I found hers to best align with the CTU context. She defines (a) "genres repertoire" as "the set of genres that a group owns, acting through which a group achieves all of its purposes, not just those connected to a particular activity" and (b) "genre systems" as "a genre set identifiable by those who use it that has clearly linked genres with a common purpose, and (c) genre sets as "more loosely defined sets of genres, associated through the activities and functions of a collective but defining only a limited range of actions"(p.56-57).

In the context of the CTU, the genre repertoire likely includes one or more genre systems related to patient care and several genre sets related to teaching and administrative genres. Defining membership into a system or set depends largely on perspective. For example, we could choose to create a label called 'admission genre system' that contains admission orders, on-call and attending case reviews, and admission notes. If asked, all members of the CTU team should be able to 
identify each of these genres as relating to the purpose of admitting a patient to hospital. Alternatively, we could choose to define a more inclusive genre system such as the 'CTU patient care genre system'. This genre system could then include all of the genres from the admission genre system along with other in-hospital patient care genres such as progress notes, investigation reports and handover reviews. As teaching and administrative practices are more loosely connected, they would be considered to be part of a teaching genre set and an administrative genre set but may not have their own genre systems. Because genres frequently overlap, genres such as case review may hold membership in both the admission genre system and the teaching genre set. As not all members of the CTU team share the same roles and experiences, their repertoires, while overlapping, will also be different. For example, imagine that a senior medical resident and a junior resident both see the same patient on a given day. The junior resident will likely predominantly use the progress note genre and the patient follow-up genre. The senior resident however will likely use the writing orders genre and the backstage supervision genre - a genre used by supervisors where they collect data and followup on patients without necessarily flagging that they have done so to their junior trainees ${ }^{6}$.

\section{Utterance, Intertextuality, Uptake and Recontextualization}

From a rhetorical perspective, no text (oral or written), and therefore no genre, can truly be studied in isolation ${ }^{7}$. In order to understand the relationship among texts, it is necessary to first explore each one at a more discrete level, the level of the "utterance." Considered to be one of the forefathers of RGT, literary theorist Bakhtin (1986) explains that:

...the boundaries of each concrete utterance as a unit of speech communication are determined by a change of speaking subjects, that is, a change of speakers. Any utterance - from a short (single word) rejoinder in everyday dialogue to the large novel or scientific treatise - has, so to speak, an absolute beginning and an absolute end: its beginning is preceded by the utterances of others, and its end is followed by the responsive utterance of others (or, although it may be silent, others' active responsive understanding, or finally, a responsive action based on this understanding 7 .

Thus, each utterance is preceded and followed by the subsequent utterances and actions of others. By contrast, for a genre to be considered complete, there must be a shift in rhetorical situation ${ }^{1}$. A genre can therefore contain one or multiple utterances. For example, whereas the admission note is a single utterance as the note has only one speaker, case review will likely have multiple utterances as information is presented and discussed by the CTU team members present. The terms intertextuality and uptake both refer to key ways in which utterances relate. 
Both are also essential for understanding the relationship between genres within a genre system.

My definition of intertextuality has been strongly influenced by three main sources: 1) Bazerman's chapter on intertextuality from the book What Writing Does and How it Does it 8; 2) Kristeva's paper "Nous Deux" or a (HI)story of Intertextuality ${ }^{9}$; and 3) Bakhtin's paper The Problem of Speech Genres ${ }^{7}$. Intertextuality, a term largely attributed to the poststructuralist Julia Kristeva, refers to the interpretive relationship that texts have with each other and with those who read them. Intertextual references can be explicit or implicit, intentional or unintentional, and anticipated or unexpected. This paragraph has a strong intertextual relationship with the preceding one, providing the reader with invaluable information about how to make meaning from it. Intertextual relations can have variable distances from each other; they can exist within the same text or draw on external texts well known to a particular community or discipline or separate and distinct from that community. Using this dissertation as an example, if my intentions are achieved, this chapter will hold a strong intertextual relationship with the five empirical studies of this dissertation and the discussion chapter; readers familiar with the concept of intertextuality will draw on those resources, both consciously and unconsciously, thus enhancing their ability to interpret and scrutinize this text while those less familiar will need to draw on other resources. Intertextuality is highly reliant on the person's prior knowledge. Not uncommonly, intertextual references go unrecognized by readers or listeners because of inattention, a failure to recognize the reference despite having sufficient prior knowledge, or a lack of requisite knowledge. A lack of prior knowledge does not necessarily mean that an important connection will be missed. As Kristeva theorizes, "even if the reader does not yet have the competence to point it out, he knows that there must be something outside the text able to make it into a meaningful whole and he goes to find it by a certain method, or later on finds it by accident when reading the key, or "missing" text" 9 .

Intertextual relationships are not neutral in how they shape understanding and action. While some are predominantly referential, others use and modify the original text. As a writer or speaker takes up someone else's ideas, often in a new context, they typically do so in ways that alter the original meaning. This change of meaning has been called recontextualization ${ }^{8}$. Recontextualization can be subtle, going unrecognized, and can represent fairly significant shifts in meaning. Recontextualization is highly relevant in the CTU context. For example junior trainees may, at times, unintentionally recontextualize in their progress notes ideas discussed during case review.

Genres also hold other bidirectional relations in addition to intertextuality and recontextualization. "Uptake" is the term used to refer to the responsive social actions that arise between texts. Freadman (2002) describes it as a "call and response"10. From a RGT perspective, uptake is used to describe how particular 
instances of using a genre arise as a response to antecedent - prior - genres. According to Freadman, uptakes mediate between genres, translating intended or unintended actions into realized actions ${ }^{10}$. Uptakes can occur within genres, for example by asking and responding to a question during case review (i.e., an intrageneric uptake). They can also occur between genres, for example writing a progress note following a case review (i.e., an inter-generic uptake). It is the intergeneric uptakes, that exist at the boundaries between different genres, that are most open to confusion because they are less automatic and their relationships less clear-cut ${ }^{10}$. As Bawarshi and Reiff (2010) state: "What we choose to take up and how we do so is the result of learned recognitions of significance that over time and in particular contexts become habitual. Knowledge of uptake is knowledge of what to take, how, and when, including how to execute uptakes strategically and when to resist expected uptakes" 11(p.219). Here again we see how agency plays a role in genre usage. For those wishing and willing to take a meaningful or active role in directing social actions, they can use uptake strategically to achieve their ends.

\section{Exigence and the Genre System}

One of the most interesting and important concepts in RGT is that of "genre exigence." In this dissertation, I have followed Miller's (1984) suggestion that exigence be viewed as a "social motive", a "form of social knowledge - a mutual construing of objects, events, interests and purposes that not only links them but also makes them what they are: an objectified social need"1(p. 158). Building on this point, Bawarshi and Reiff (2010) suggest that "how we define and act within a situation depends on how we recognize the exigence it offers, and this process of recognition is socially learned and maintained" through genre(P. 70). In this regard, genre knowledge is knowledge of both how and what to respond to.

Viewing exigence from this perspective - as social motive - draws our attention to a number of key issues. First, a similar situation may give rise to very different senses of exigence across individuals. Additionally, multiple exigencies may co-exist in complex relations to each other - sometimes in harmony, sometimes in tension. The attending case review genre is a good example. As demonstrated by Lingard et al., while the attending may be most concerned with the exigence of patient care, the medical student may be responding to an exigence related to assessment ${ }^{12}$. When both are in harmony, the attending's responses to a student presentation will lead to further actions that help support patient care without causing the student to adapt their presentations to avoid actions perceived to be associated with a poor assessment (e.g., rushing to avoid interruptions). When they are divergent, the student may rush the presentation to avoid interruptions that may in fact cause the attending to interrupt in order to ensure they are getting all the clinical facts ${ }^{12}$. 
Viewing exigence as social motive also draws attention to the fact they are learned through socialization. As Miller (1984) points out:

What we learn when we learn a genre is not just a pattern of forms or even a method of achieving our own ends. We learn, more importantly, what ends we may have: we learn that we may eulogize, apologize, recommend one person to another, instruct customers on behalf of a manufacturer, take on an official role, account for progress in achieving goals 1 (p. 165).

However, she also argues that we don't necessarily share the same motives. Two attendings participating in the same case review may have and respond to different exigencies. One may perceive and respond to a trainee's learning needs while the other may take actions in response to a patient's care needs. As a social motive, exigence is also strongly tied to context. For example, the circumstance of having two versus five patients to review during a fixed two-hour period of time may shape how members of the team recognize and respond to exigencies.

Consequently, studying exigence became an essential component of my study of genre systems. Failing to study exigence is tantamount to describing features but not function (e.g., describing two variations of the case review genre without describing the different social actions that ensue as a result). In addition, studying genre exigence requires direct observation regarding how different genres in a genre system are enacted by different users in a diverse set of circumstances and contexts. A related issue is that analysis requires an "extensive text-in-context inquiry" involving "description, interpretation, and explanation" 13(p209). Studying the original texts in isolation or relying on interviews or focus groups alone is inadequate for generating sufficient insights into a genre system because individuals, even experts, frequently do not recognize the social motives behind their own actions or necessarily agree with each other as to their nature or purposes ${ }^{1,13}$.

In this section, I have tried to provide an overview of key concepts and terminology in RGT. I have reviewed the focus of RGT which is on social action, and I have presented some of the key characteristics of genres, such as how they are influenced by culture and context and how they function together in systems and sets. Finally, I have reviewed some essential concepts for studying genres, that is, how to study genre relationships (intertextuality, recontextualization and uptake) and how to understand the social actions of genres (exigence and social motive). I will return to these essential concepts in my discussion in Chapter 7. In the next section, I will explore why RGT is ideal for studying the CTU communication practices. 


\section{Why Use Genre to Study CTU Communication Practices}

Genre research focuses on both the needs of systems and individuals. From a system perspective it allows us to explore how communication practices are used to support or constrain collective competence, that is, we can "learn to understand better the situations in which we find ourselves and the potentials for failure and success in acting together"1(p. 165). At the individual level, RGT research seeks to explore how genre users, as individuals and members of groups, use genre to do their work. This is true regardless of their role as trainees, supervisors or practitioners. As previously mentioned, CTU communication practices and the patient care outcomes that arise from these are the result of collective work. While it is possible to look at communication practices at the individual level, ultimately, it is not individual work that results in patient care but rather it is collective work that is mediated through the genre system through individuals. By studying this collective work through genres, it is possible to shed light on the exigencies that drive the CTU communication practices or as Miller stated the "ends we may have"1(p.165). The genre lens can also support the exploration of the CTU context and ways in which the genre system supports and, at times, constrains the delivery of high quality, safe medical care and trainee education. Because the CTU is an environment in which trainees work as well as learn it is also an excellent method for mapping the range of teacher and learner genre practices and exploring their affordances and constraints.

\section{A Note on Methodology}

RGT is not a method nor is it associated with a specific methodology. Rather, it is a theory. While there is no one methodology for doing genre research, certain methodologies lend themselves better to this effort than others. According to Paré and Smart (1994), when studying genre, there are four dimensions on which to focus: the texts (written or spoken), the composing practices, the reading practices, and the social roles of those who compose and use them ${ }^{14}$. Accordingly, ideal methodologies are those that involve naturalistic inquiry and combined observations, document analysis, and active participation of members of the community of practice being studied.

As described in chapters 3-6, I used three different methodologies in this dissertation: multiple instrumental case study ${ }^{15}, 16$, constructivist grounded theory 17 , and consensus building method. I chose the multiple instrumental case study method for the first two studies because it helped build an understanding of a specific phenomenon - case review - in the context of complex, real- world practice 15. For these first two studies, the cases were instrumental to understanding the process of case review and documentation and how they shape practice. This 
method allowed me to focus on all four dimensions highlighted by Paré and Smart (1994).

The purpose of my third study, reported in Chapter 5, was to explore the social roles of the attending physician in relation to findings from my first study. Thus, I used constructivist grounded theory (CGT) ${ }^{17}$. CGT has become increasingly used in medical education research ${ }^{18}$. In CGT, the research goals are interpretive rather than explanatory and are focused on developing theories for understanding the social worlds being studied ${ }^{17}$. While there is a process for doing grounded research, as Charmaz (2006) points out, this process is anything but linear 17 . However, there are several key features typically shared in common by CGT research, including: "an iterative process, systematic treatment of data through coding, constant comparisons, and theoretical sampling" 18(p851). CGT is based on the notion that knowledge is co-constructed and that researchers "construct our grounded theories through our past and present involvements" 17(p10). Using CGT allowed me to build from my existing understanding and experiences of the phenomena under study and to iteratively modify my approach as new insights were gained through analysis of the data.

From a genre perspective, my fourth study on clinical reasoning tasks, reported in Chapter 6, focuses on both the texts themselves and social roles. One of the limitations identified when analysing my first study in Chapter 3 was a lack of language to describe the types of issues that the medical team was addressing when they were doing case reviews. I needed a language to analyse the issues expressed in these texts and to explore the underlying social roles involved in caring for patients. I chose to use a combination of thematic literature review and consensus method. My study design was based on previously described principles for using consensus methods in health services research ${ }^{19}$. Consensus methods are typically used when there are no pre-existing publications or where existing publications are fragmented or inadequate for answering the questions ${ }^{19}$. Using consensus methods helps garner expert opinions while limiting any one expert's opinions from dominating ${ }^{19}$. Given the relative dearth of expertise related to the concept of reasoning tasks in medicine, the method I chose to use was also useful in ensuring that key concepts were not being missed or ignored.

\section{Summary}

In summary, RGT provides an exceptional lens for studying communication practices. In particular, rather than merely describing the characteristics of a genre, RGT draws attention to the social actions that a genre gives rise to. By focusing on these social actions and how they function within a system of genres, RGT can help provide deep insights into systems of practice and the nuances of context and culture that help to shape them. In this chapter, I have provided an overview of RGT 
theory and terminology and explained why RGT is an ideal theory for studying CTU communication practices. Finally, because RGT is not a methodology, I have also described the rational for choosing each of the methodologies described in the four dissertation studies found in chapters 3-6. In my chapter 7 discussion, I will be returning to RGT and how it can be used to draw all four of the dissertation studies together into a broader theory of communication practice on CTUs.

\section{References}

(1) Miller C. Genre as Social Action. Quarterly Journal of Speech 1984;70:151-167.

(2) Bitzer LF. The Rhetorical Situation. Philosophy and Rhetoric 1968;1:1-14.

(3) Lingard L, Haber RJ. What do we mean by "relevance"? A clinical and rhetorical definition with implications for teaching and learning the case-presentation format. Acad Med 1999;74(10 Suppl):S124-S127.

(4) Berkenkotter C, Huckin T. Rethinking Genre from a Sociocognitive Perspective. Written Communication 1993;10(4):475-509.

(5) Devitt AJ. Writing genres. Carbondale: Southern Illinois University Press; 2004.

(6) Kennedy TJ, Lingard L, Baker GR, Kitchen L, Regehr G. Clinical oversight: conceptualizing the relationship between supervision and safety. J Gen Intern Med 2007;22(8):1080-1085.

(7) Bakhtin MM, Holquist JM, Emerson C. Speech genres and other late essays. 1st ed. - ed. Austin: University of Texas Press; 1986.

(8) Bazerman C, Prior P. Intertextuality: How texts rely on other texts. In: Bazerman C, editor. What writing does and how it does it: An introduction to analyzing texts and textual practices. Mahway, NJ: Lawrence Erlbaum Associates; 2004. 82-96.

(9) Kristeva J. "Nous Deux" or a (Hi)Story of Intertextuality. Romantic Review 2002;93(1/2):7-13.

(10)Freadman A. Uptake. In: Coe R, Lingard L, Teslenko T, editors. The rhetoric and ideology of genre.Creskill, JN: Hampton Press; 2002. 39-53.

(11)Bawarshi AS, Reiff MJ. Genre: An introduction to history, theory, research, and pedagogy. West Lafayette, Ind: Parlor Press; 2010.

(12)Lingard L, Schryer C, Garwood K, Spafford M. 'Talking the talk': school and workplace genre tension in clerkship case presentations. Med Educ 2003;37(7):612-620.

(13)Askehave I, Swales JM. Genre identification and communicative purpose: a problem and a possible solution. Applied Linguistics 2001;22(2):195-212.

(14)Paré A, Smart G. Observing Genres in Action: Towards a Research Methodology. In: Freedman A, Medway $\mathrm{P}$, editors. Genre and the new rhetoric.London: Taylor \& Francis; 1994. 146-154.

(15) Stake R. The Art of Case Study Research. Thousand Oaks: Sage; 1995. 
(16) Yin RK. Case Study Research. Design and Methods. 4th ed. California: Sage Publications, Inc.; 2009.

(17)Charmaz K. Constructing grounded theory: a practical guide through qualitative analysis. London: SAGE; 2006.

(18)Watling CJ, Lingard L. Grounded theory in medical education research: AMEE Guide No. 70. Med Teach 2012;34(10):850-861.

(19)Jones J, Hunter D. Qualitative Research: Consensus methods for medical and health services research. BMJ 1995;311(7001):376-380. 


\section{CHAPTER 3 \\ Progressive Collaborative Refinement on Teams: Implications for Communication Practices}




\section{Abstract}

Objectives: Medical teaching teams (MTTs) must balance teaching and patient care in the face of three challenges: shifting team membership, varying levels of learners and patient complexity. To support care, MTTs rely on a combination of recurrent oral and written communication practices (genres), such as admission, progress and discharge notes. The purpose of this study was to explore how these genres influence the team's ability to collectively care for patients.

Methods:This was a multiple case study with data collected through observations and audio-recordings of 19 patient cases focusing on admission review discussions and chart documents throughout the hospitalisation. Participants included 14 medical students, 32 residents and 10 attending physicians rotating through one of three internal medicine MTTs. We used constant comparative analysis to identify recurrent patterns across the multiple cases, which were further elaborated in a return-of-findings focus group.

Results: The MTT genre system facilitated the care of patients through 'progressive collaborative refinement' (PCR): MTTs use case and data reviews to collaboratively and progressively refine their understanding of the patient's problems and develop strategies for addressing them. Progressive collaborative refinement was apparent through modifications made in the documentation. Although modifications were a necessary component, they were not sufficient: some modifications were made without refinement. We characterised incidents of failed modification as 'fragmentation'. Three types were observed: conceptualisation, documentation and continuity of care providers. In most cases, all three were present and interacted to impede PCR.

Conclusions: Progressive collaborative refinement was used by MTTs to provide the optimal care to patients. Progressive collaborative refinement was impeded by a lack of continuity of care providers and gaps between communication genres that fragmented conceptualisation and documentation. Progressive collaborative refinement can be understood as both an overarching process and a shared but unstated ideal. Through defining and describing PCR, the present findings can be used to improve communication and teaching.

Published as:

Goldszmidt, M., Dornan, T., and Lingard, L. Progressive collaborative refinement on teams: implications for communication practices. Med Educ 48(3), 301-314. 2014.

(C) John Wiley and Sons Ltd. 


\section{Introduction}

In the teaching hospital setting, internal medicine medical teaching teams (MTTs) allow staff (attending) physicians to educate residents and medical students by actively sharing patient care. ${ }^{1}$ Among the many challenges of these "situated learning environments" 2 three challenges are particularly salient: shifting team membership, varying levels of learner experience, and patient complexity. ${ }^{3,4,5,6,7} \mathrm{~A}$ combination of oral and written communication practices helps team members address these challenges. This study focuses on these communication practices and how they influence the team's ability to collectively care for patients.

In ideal situated learning environments, small numbers of new members join established communities of practice, participating legitimately and moving from more peripheral to more central roles as they learn. ${ }^{2,8,9,10}$ In contrast to this theoretically ideal arrangement, on MTTs the most senior members (attending physicians) rotate on and off the team frequently. Consequently, residents and clerks must develop clinical competence while coping with frequent changes in supervisors. $^{3}$ Another distinct feature of the MTT is that novices outnumber experienced practitioners 3,11 and take on key roles - notably, writing daily progress notes and patient care orders - from their earliest days on the team. In this study, we examined how MTT communication practices coordinate the work of a shifting roster of clinicians with various levels of expertise.

In addition to treating a patient's presenting problem(s), MTT team members must also take into account their chronic problems and pre-existing treatment plans. ${ }^{7}, 12,13,14,15$ Failing to do so can lead to errors and subsequent adverse events, prolonged hospitalization, readmission and even death. ${ }^{14,16,17,18}$ Addressing patient complexity poses a significant challenge in teaching hospitals, where the focus is often on acute care (rather than holistic, long-term care),15 where teams are often constrained by time and where practice guidelines focus on single diseases. ${ }^{15,19}$ To make this learning environment safer and more effective, it is imperative that we study how MTTs function within it. ${ }^{18,20}$

A combination of oral and written communication practices enable MTTs to function in this environment. These include the oral case review discussions that a learner has with a senior resident and attending physician following a patient encounter, as well as numerous written documents such as admission notes, progress notes, patient care orders and discharge summaries. We conceptualize these communication practices as 'genres': they have recurring structures, they serve shared purposes, and they are used in particular situations to achieve these purposes. $^{21,22}$ A body of research on healthcare genres on MTT has revealed how expert attending physicians make teaching decisions during case review; ${ }^{23}$ how medical students perceive particular case review actions such as interruptions; ${ }^{24}$ 
how residents perceive particular daily activities on teaching teams; ${ }^{25}$ the consequences of ineffective patient care handovers; 26 ; and the quality and timeliness of discharge documents. ${ }^{27}$ However, the existing research has focused exclusively on single genres, without attending to how the set of MTT genres interact, and how these interactions support the team's complex balance of teaching and patient care.

\section{Theoretical Framework}

We use the theoretical construct of the genre system to explore this interaction among MTT genres. Individual genres can be said to exist within a genre system when together they perform different but related roles in achieving a common purpose. ${ }^{21}$ For example, the case presentation, admission note and admission orders each play a synergistic role in achieving the purpose of admitting a patient to hospital. And, when combined with other forms of inpatient communication, they share the purpose of supporting hospital care and transition back into the community. Each of these genres exists in complex relationships with the other genres in the system. They can be said to be 'intertextually' connected in that they contain implicit and explicit references to one another; ${ }^{28}$ particular statements from case review or one area of the chart may have influence on those that follow and, those later entries may cause a reinterpretation of earlier ones. ${ }^{28}$ Genre theory offers the conceptual tools to examine how communication is used by individuals to accomplish action within a social unit. ${ }^{22}$ In this case, the social unit is the physician team.

The purpose of this study was to explore how the genres of MTTs influence their ability to collectively provide effective patient care in the face of the challenges of the learning environment: shifting team membership, variable expertise, and patient complexity.

\section{Methods}

A multiple, instrumental case study approach was used. In this approach, a collection of cases are selected to offer insights into complex real world phenomena. Each case is understood as a bounded system of actors and their interactions. ${ }^{29,30,31}$ We used genre systems theory to inform our sampling, bounding of the case, and analytic orientation. ${ }^{29}$ We obtained approval from the University of Western Ontario's institutional review board. 


\section{Setting}

The setting was an internal medicine ward in an academic health sciences centre. It has three MTTs, each admitting a third of all patients. Most patients are admitted overnight, when one senior resident is on-call, supported by one junior trainee (medical student or first-year resident) from each team. Cases admitted on-call are typically presented to the attending and team by the on-call junior member during morning rounds. The post-call senior is only present for their own team's reviews. Daily progress notes and discharge summaries are written by the junior trainees. At this centre, a mix of paper based and electronic records are used.

\section{Data Collection}

We collected data from the following five genres, which together constitute a case: on-call patient reviews, admission notes, morning patient reviews with the attending physician, in-hospital progress notes, and discharge summaries. We collected review data through limited descriptive observations with field notes (morning cases only) and audio-recordings that were transcribed and anonymized. Field notes were used to identify basic features of the case review context, including who was present and what they were doing at the time. Clinical documents, including de-identified copies of the patient's entire chart, were matched with the transcribed records of their case presentations to make up a case. For feasibility reasons, patient encounters and ongoing team dialogues (handover and progress review) were not collected. A single focus group interview with MTT attendings was also held during data analysis.

\section{Sample}

The sample consisted of 19 cases from three MTTs, collected over two eight-week periods (winter and summer 2010). Consistent with case study methodology, we tried to collect cases based on characteristics that would support both literal and theoretical replication (e.g. cases were selected based on characteristics that we would predict would demonstrate similar findings (literal replication) or draw attention to possible differences (theoretical replication). ${ }^{29}$ As such, the weeks were purposively selected to capture different stages of training and to observe a broad sample of attendings and to capture variations in group cultures and team dynamics. We also purposively included a mix of junior trainees (medical students vs. first year residents), admission dates (weekend vs. weekday) and junior-senior pairings (same team vs. different team). With regards to selection of patients, they were included by convenience. Based on the above criteria, each week, several overnight periods of data collection were selected. All patients admitted by the 
participating junior-senior pairing were included. The cases captured a wide range of patient ages and clinical presentations (see Table 1 for details). Twelve of the cases included patients who were admitted by medical students and seven by firstyear residents. In 11 cases, the senior was on the same team as the junior and was therefore present for the next morning review.

Each case included on average 12 (range 5-28) pages of admission review transcripts, 45 (19-128; SD 33) pages of clinical documentation and up to 2 hours of observation during morning reviews. The mean number of documented clinical notes per case was 9.5 (2-25; SD 7) and the mean length of stay was 7.5 (2-22; SD 6.4) days. In total there were 14 medical students, 19 first-year residents, 13 senior residents and 10 attending physicians.

\section{Data analysis}

Analysis involved exploring patterns that recurred across multiple cases, using a constant comparative analytical approach both within and across cases. ${ }^{30}$ Several cases were read recursively by two researchers (LL and MG) to develop a preliminary coding structure. This preliminary coding structure was reflective of complexities in the data, focusing on the intertextual connections across genres within the case (e.g. the content of the overnight and morning case reviews as well as the admission note, progress notes and discharge summary). These codes were refined by applying them to subsequent cases in the data set and revising the code definitions. Because each case consisted of multiple overlapping sources of interdependent data that were sequentially produced, narrative summaries were created for each case as part of the coding process. ${ }^{16}$ Such summaries have been used to attend to complexity while distilling patterns within the data. ${ }^{29,32}$ Two internists (MG, TD) independently coded one-third of the summaries to further test and refine the coding definitions. Coding discrepancies between researchers were handled by returning to the raw study data and discussing and refining code definitions and narrative descriptions to ensure consistency of narrative creation, interpretation, and coding. The remainder of the cases $(n=13)$ then had narratives created and coded by one of the researchers (MG) who entered these in NVivo 9TM qualitative data analysis software. ${ }^{33}$ Finally, in order to develop the final model, all instances of each code was reviewed individually and by the research team as a group.

Both data and investigator triangulation were used to ensure rigor and increase authenticity in the research design. ${ }^{29,34,35}$ The coding team consisted of two experienced MTT clinicians - one local practitioner (MG) and one who had practiced at another centre (TD) - as well as a non-clinician with expertise in medical team communications (LL). 


\section{Focus Group}

To verify and elaborate study findings, a 1.5 hour return-of-findings focus group session was held with four experienced MTT attending physicians who were not part of the original sample. The research team felt that their history of work on the MTTs positioned them to offer additional insights into the findings. Key themes were shared and participants were asked whether they accurately captured MTT issues. The group both shared their own examples of each theme, and then commented on examples of each theme from the data set. They were also asked to comment on the extent to which these instances mattered clinically. This session was audio-recorded, transcribed, and included in the final analysis.

Table 1. Patient summaries of the 19 cases analyzed

\begin{tabular}{|c|c|c|c|c|c|c|c|c|}
\hline ID & $\begin{array}{c}\text { Age } \\
\text { Range* }\end{array}$ & $\begin{array}{l}\text { Reason for } \\
\text { Admission }\end{array}$ & Other Active Issues & $\begin{array}{l}\text { Length } \\
\text { of Stay } \\
\text { (days) }\end{array}$ & $\begin{array}{c}\text { Number of } \\
\text { Documenters }\end{array}$ & $\begin{array}{l}\% \text { of Notes by } \\
\text { the Same } \\
\text { Documenter }\end{array}$ & $\begin{array}{c}\text { \% by } \\
\text { Admitting } \\
\text { Junior } \\
\text { Resident }\end{array}$ & $\begin{array}{l}\text { Total \# } \\
\text { of Notes }\end{array}$ \\
\hline 1 & $90-100$ & $\begin{array}{l}\text { Dehydration } \\
\text { secondary to } \\
\text { diarrhea }\end{array}$ & $\begin{array}{l}\text { End Stage Dementia, Acute } \\
\text { Renal Failure, } \\
\text { Hypernatremia, Palliation }\end{array}$ & 3 & $3-6^{* *}$ & 17 & 17 & 6 \\
\hline 2 & $80-90$ & $\begin{array}{l}\text { UTI and fall with } \\
\text { knee trauma }\end{array}$ & $\begin{array}{l}\text { Query syncope, atrial } \\
\text { fibrillation, dementia, } \\
\text { Delirium, Hypokalemia, }\end{array}$ & 11 & 4 & 50 & 50 & 12 \\
\hline 3 & $20-30$ & $\begin{array}{l}\text { Febrile } \\
\text { Neutropenia }\end{array}$ & $\begin{array}{l}\text { Dermatomyositis, } \\
\text { gastroenteritis, pancytopenia, } \\
\text { B12 deficiency, Iron } \\
\text { Deficiency, Feeding tube }\end{array}$ & 9 & 3 & 50 & 13 & 8 \\
\hline 4 & $90-100$ & $\begin{array}{l}\text { Acute Renal } \\
\text { Failure and } \\
\text { Hypernatremia } \\
\text { secondary to } \\
\text { dehydration }\end{array}$ & $\begin{array}{l}\text { Urinary Tract Infection, } \\
\text { Dementia, Delirium, } \\
\text { Hypotension, Bradycardia, } \\
\text { Anemia, Conjunctivitis }\end{array}$ & 10 & 6 & 33 & 17 & 12 \\
\hline 5 & $60-70$ & $\begin{array}{l}\text { Aspiration } \\
\text { Pneumonia }\end{array}$ & $\begin{array}{l}\text { Dementia with behavioural } \\
\text { issues }\end{array}$ & 2 & 2 & 50 & 50 & 2 \\
\hline 6 & $70-80$ & Pneumonia & $\begin{array}{l}\text { Metastatic non-small cell } \\
\text { carcinoma, Gastro-intestinal } \\
\text { Bleed, Malnutrition, } \\
\text { Hypokalemia, } \\
\text { Hypomagnesimia }\end{array}$ & 9 & 5 & 25 & 8 & 12 \\
\hline 7 & $60-70$ & Gout & $\begin{array}{l}\text { Type II diabetes, atrial } \\
\text { fibrillation on Coumadin, } \\
\text { Sleep apnea, Pulmonary } \\
\text { HTN, COPD, hypokalemia }\end{array}$ & 4 & 3 & 50 & 33 & 6 \\
\hline 8 & $60-70$ & Pancreatitis & $\begin{array}{l}\text { Alcohol withdrawal, narcotic } \\
\text { dependency, dilated biliary } \\
\text { duct, type II diabetes, } \\
\text { Hypothyroidism }\end{array}$ & 9 & 4 & 50 & 50 & 12 \\
\hline 9 & $70-80$ & $\begin{array}{l}\text { Drug induced } \\
\text { rash and } \\
\text { Hyponatremia }\end{array}$ & $\begin{array}{l}\text { Tricuspid regurgitation with } \\
\text { pedal edema, atrial } \\
\text { fibrillation on Coumadin, type } \\
\text { II Diabetes }\end{array}$ & 3 & 2 & 60 & 60 & 5 \\
\hline 10 & $80-90$ & Cellulitis of foot & $\begin{array}{l}\text { Atrial fibrillation on } \\
\text { Coumadin, diarrhea, Angina, } \\
\text { peripheral edema, type II } \\
\text { Diabetes, Hyponatremia, } \\
\text { Hypothyroidism }\end{array}$ & 16 & 8 & 24 & 18 & 17 \\
\hline
\end{tabular}




\begin{tabular}{|c|c|c|c|c|c|c|c|c|}
\hline 11 & $60-70$ & $\begin{array}{l}\text { COPD } \\
\text { Exacerbation } \\
\text { secondary to } \\
\text { pneumonia }\end{array}$ & $\begin{array}{l}\text { Anemia, elevated Creatinine } \\
\text { Kinase, Type II Diabetes, } \\
\text { Nausea and Depression }\end{array}$ & 8 & 4 & 33 & 22 & 9 \\
\hline 12 & $80-90$ & $\begin{array}{l}\text { Decrease Level of } \\
\text { Consciousness } \\
\text { and Urinary } \\
\text { Tract Infection }\end{array}$ & $\begin{array}{l}\text { Pneumonia, Dementia, Acute } \\
\text { renal Failure, Hypotension, } \\
\text { Anemia (query } \\
\text { Gatrointestinal bleed) }\end{array}$ & 3 & 4 & 40 & 20 & 5 \\
\hline 13 & $80-90$ & $\begin{array}{l}\text { Acute on chronic } \\
\text { Anemia }\end{array}$ & $\begin{array}{l}\text { Query Pneumonia, Coronary } \\
\text { Artery Disease, Diabetes, new } \\
\text { heart murmur, prostate } \\
\text { Cancer }\end{array}$ & 3 & 1 & 100 & 100 & 2 \\
\hline 14 & $50-60$ & $\begin{array}{l}\text { Infected Diabetic } \\
\text { Foot Ulcer }\end{array}$ & $\begin{array}{l}\text { Type } 1 \text { Diabetes, COPD, } \\
\text { Congestive Heart Failure, } \\
\text { Nausea and Vomiting, elevate } \\
\text { INR, Hypokalemia }\end{array}$ & 5 & 3 & 33 & 33 & 6 \\
\hline 15 & $50-60$ & $\begin{array}{l}\text { Aspiration } \\
\text { Pneumonia with } \\
\text { secondary } \\
\text { empyema }\end{array}$ & $\begin{array}{l}\text { Narcotic abuse and overdose, } \\
\text { hypotension, COPD, Acute } \\
\text { Renal Failure, iron deficiency } \\
\text { anemia, tricuspid } \\
\text { regurgitation }\end{array}$ & 22 & 6 & 40 & 40 & 25 \\
\hline 16 & $80-90$ & $\begin{array}{l}\text { Sepsis secondary } \\
\text { to Urinary Tract } \\
\text { Infection and } \\
\text { Bacteremia }\end{array}$ & $\begin{array}{l}\text { Bladder cancer, Acute renal } \\
\text { failure, hydronephrosis, } \\
\text { Congestive Heart Failure, } \\
\text { Gastrointestinal bleeding, } \\
\text { atrial fibrillation on coumadin }\end{array}$ & 6 & 4 & 50 & 50 & 8 \\
\hline 17 & $70-80$ & $\begin{array}{l}\text { Partial Small } \\
\text { Bowel } \\
\text { Obstruction }\end{array}$ & $\begin{array}{l}\text { IgA Multiple Myeloma with } \\
\text { Gastrointestinal tract } \\
\text { involvement, Acute renal } \\
\text { failure, Anemia, B12 } \\
\text { deficiency, Angina, } \\
\text { Congestive Heart Failure, } \\
\text { Hypotension, Hypokalemia, } \\
\text { chronic pain }\end{array}$ & 14 & 5 & 32 & 21 & 19 \\
\hline 18 & $60-70$ & $\begin{array}{l}\text { Pneumonia with } \\
\text { parapneumonic } \\
\text { effusion }\end{array}$ & $\begin{array}{l}\text { Type II Diabetes, Atrial } \\
\text { Fibrillation on ASA, } \\
\text { Obstructive Sleep Apnea, } \\
\text { Cardiomegaly }\end{array}$ & 3 & 3 & 63 & 13 & 8 \\
\hline \multirow[t]{4}{*}{19} & $70-80$ & $\begin{array}{l}\text { Post-operative } \\
\text { Pulmonary } \\
\text { Embolus }\end{array}$ & $\begin{array}{l}\text { New onset atrial fibrillation, } \\
\text { Acute renal failure, Cellulitis, } \\
\text { Urinary tract infection, } \\
\text { hypothyroidism }\end{array}$ & 2 & 4 & 57 & 14 & 7 \\
\hline & & & Mean & 7.5 & 3.8 & 40 & 30 & 9.5 \\
\hline & & & Max & 22 & 8.0 & 100 & 100 & 25 \\
\hline & & & Min & 2 & 1.0 & 20 & 10 & 2 \\
\hline
\end{tabular}

*As part of the de-identification process, all ages are listed as a range.

**For 3 of the 6 notes in case 1, the signature of the documenter was illegible and we could not, with any confidence, tell based on handwriting or signature if it was one, two or three other documenters.

\section{Results}

The medical teaching team (MTT) genre system facilitated collective care of patients by enabling a process that we called "progressive collaborative refinement" (PCR). PCR is an ongoing process rather than a static property; it was made visible through analysis of the intertextuality of the genre set. PCR was most evident in the modifications made to clinical documents over the course of the patient's hospital stay. While modifications were a necessary component of PCR, they were not sufficient; many modifications failed to achieve progressive refinement. These failures were characterized in our analysis by the theme of fragmentation, which captures the main features in the gap between modification 
and PCR. Below, PCR and fragmentation are described and their relationship to one another considered.

\section{Progressive collaborative refinement}

The term PCR refers to the process of the team's collective work addressing the patient's medical issues, and it was understood to be the purpose guiding many communication practices. Over the course of a patient's hospitalization, the MTT defined an initial list of problems to be addressed and modified both the list and their understanding of each item on the list, as well as their plans for addressing each. Modifications were observed to occur both verbally, during review, and textually, in admission, progress and discharge documents. Modifications were considered to be progressive refinements if the list and items on the list became increasingly better defined in terms of the problems and how they were going to be investigated and managed: "So that's one issue. And I think at this point we don't even need to worry too much about making the pulmonary embolus diagnosis because it's been diagnosed basically. The other issue is atrial fibrillation..."(senior resident overnight review 19). Progressive refinement was facilitated by the collective efforts of team members with different levels of experience. "Interesting. I mean myeloma and bowel obstruction don't usually kind of go together in my mind. I suppose you could get a plasmacytoma anywhere but usually it's bony. We have to postulate something else going on here..."(Attending review 17). Refinement was made visible through the integration of new information, such as the results of investigations, a patient's response to therapy, or information gleaned from medical records and family members: "Addendum [to progress note]: CT scan of chest discussed with radiologist, no consolidation, no masses, appears to be right lower lobe atelectasis secondary to parapneumonic effusion with no appearance of empyema. Suggest tap and observe for re-expansion" (Progress notes 18). Refinement was also visible in progress notes during transitions when a new member of the team took over a patient's care and re-characterized the problem list. Progressive refinements were considered to be collaborative as they involved multiple team members interacting.

There were many modifications to the problem list as a whole and to the labeling and plans of individual problems that did not fulfill our definitional criteria for PCR. For example, there were modifications to the way individual problems were labeled and addressed that did not improve the definition of patients' problems in relation to what was previously known. And, there were instances where the modifications undermined the team's ability to collaboratively provide care. Because PCR is both an ongoing process and a goal, and not a singular event, we did not attempt to count instances of PCR. 


\section{Fragmentation}

The theme of "fragmentation" characterizes instances in which a modification did not contribute to PCR, as well as instances in which there was a visible failure to utilize new information for PCR. Three forms of fragmentation were identified: 1 ) fragmented conceptualization; 2) fragmented documentation and; 3) fragmented continuity of care provider (Table 2). In total, there were 160 coded instances of fragmentation, with all but one case having multiple instances of the different forms of fragmentation (Table 3 ). While table 3 presents data on the number of instances coded for each type of fragmentation, the absolute numbers in any given case may be less important than their impact on PCR. At times, a single instance of fragmentation could interfere with PCR while multiple instances in another case did not. During the focus group, participants validated these three forms of fragmentation and offered examples of each from their own experiences. Below we describe each form of fragmentation and provide examples of the features of fragmentation.

Table 2. Definitions of the three types of fragmentation.

Fragmented Conceptualization
Refers to instances where the team's framing of the case, without apparent intent, appeared to
shift or failed to appropriately shift in meaning from one time point to another despite data
supporting a particular level of differentiation in the description of the problem. It could also
involve instances in which the team's framing of a problem failed to capture the underlying issue
that it was intending to addressed.

\section{Fragmented Documentation}

Refers to instances in which information was known by the team but not adequately captured in the patient's chart. Three sub-types were observed:

1) failure to document discussions that took place during the review, leading to changes in how the team conceptualized the problems or how they were to be managed

2) failure to document a problem and how it was handled during responsive care (instances of care that were in response to a new issue or change in status of an existing issue )

3) failure to record all active issues in progress notes and discharge summaries

\section{Fragmented Continuity}

Refers to instances where care provision and documentation were performed by a variety of team members over the course of a patients hospital stay. Contributors included weekends, post-call away time and team changeover. 
Table 3: Frequency of fragmentation instances for the 19 cases analyzed.

\begin{tabular}{|lccccc|}
\hline & Mean/case & Min/case & Max/case & \# of cases & $\begin{array}{c}\text { \# instances } \\
\text { in all cases }\end{array}$ \\
Fragmented Conceptualization & 1.1 & 0 & 3 & 13 & 21 \\
Fragmented Documentation & 6.5 & 0 & 16 & 18 & 123 \\
Fragmented Continuity & 0.8 & 0 & 1 & 16 & 16 \\
Total & 8.4 & $1^{*}$ & 20 & 19 & 160 \\
\hline
\end{tabular}

*While there were cases that had no episodes of a particular fragmentation type, the minimum number of episodes of any type of fragmentation was one and it occurred in patient 1 who was admitted for palliative care.

\section{Fragmented Conceptualization}

The term "fragmented conceptualization" describes problems with the team's framing of a patient's problems. Across the data set, there were 21 instances of fragmented conceptualization occurring in 13 of the 19 cases (Table 3). Two contrasting types of fragmented conceptualization came out of the data. First, there were instances when, without apparent intent or new data, the framing of a problem shifted:

During morning review, the attending indicated the need to rule out an underlying cause for the patient's fall: "So that's the big question, did she have a mechanical fall, or did she have a medicine-related fall?" The team then wrote orders for an echocardiogram to rule out a heart valve related cause and to monitor her heart rhythm with telemetry. In the progress notes, the problem was repeatedly labeled "awaiting echo". While the telemetry revealed a fast and irregular heart beat these results were never documented. In the discharge summary, only the echocardiogram result was reported with no mention as to why it was ordered. Labeling the issue as one of a series of pending tests instead of as the underlying concept "fall, query cardiac etiology" made the underlying question invisible and obscured the significance of an abnormal test result.(Case 2).

Focus group participants postulated several possible causes for this type of fragmented conceptualization: i) inattention during rounds: "they heard blah, blah, blah, order an echo"; ii) a failure to understand: "because people [trainees] don't really understand, they didn't understand the discussion"; iii) a failure to explain clearly: "sometimes the thought [referring to attending's explanation] is anything but clear, and the process gets screwed up continually"; and iv) "just laziness" in documenting. Analysis of the transcripts from the 19 cases revealed that the genre of review did not typically include a verification component to guard against any of these problems. Attendings and senior residents neither asked students to summarize their understanding of what was discussed nor verified what was written in the notes following the discussions. While supervision in this regard was not completely lacking - the on-call seniors typically reviewed or themselves wrote 
the patient care orders - it was unpredictable and did not foster collective understanding across the MTT.

The second type of fragmented conceptualization was the reverse problem, when a framing failed to shift appropriately despite the acquisition of new data supporting a reformulation:

On day 3 of his stay, patient 17 complained of feeling short of breath following a blood transfusion. At that point, despite a normal chest x-ray and other disconfirmatory clinical findings, the junior documented "congestive heart failure" and started treatment. Heart failure continued to be the problem's label for several days despite worsening kidney function as a result of the treatment. For this patient, multiple elements of the data should have led to a further refinement of his new problem. (Case 17)

Focus group participants suggested that this form of fragmentation was common:

"I think the two situations where that happens, in the sense that it has, it potentially has serious consequences, are delirium and dementia... it colours your entire care of the patient and what you think are realistic goals for that admission... The other one is COPD [Chronic Obstructive Pulmonary Disease], where people are happy to tolerate hypoxia and hypocapnia, because the patient got a 'lazy' label of COPD. So they're on 4 litres of oxygen and everybody just shrugs and says, well, you have COPD. When, in fact, they probably don't."

Incorrect labels were felt to potentially lead to inaccurate inferences and to close off further questioning. Moreover, incorrect labels could be applied to both acute and chronic problems. Focus group participants agreed that both types of fragmented conceptualization could lead to clinically significant consequences underscoring the importance of labels in shaping the team's collective perception of a patient's active issues.

\section{Fragmented documentation}

Fragmented documentation became evident through our within-case analysis of the entire genre system for each case. Fragmented documentation refers to instances in which information was known by some team members but not documented, and consequently not adequately shared across the team. Information that was not collected from the patient or existing records was not included in this category as we felt that these reflected a different kind of problem. On average, each case had 6 instances of fragmented documentation, and there were 123 instances across the 19 studied cases (Table 3). Three types were identified: 1) failure to document discussions that took place during review leading to changes in how the team conceptualized the problems or how they were to be managed; 2) failure to document a problem and how it was handled during instances of care in response 
to a new issue or change in status of an existing issue; and 3) failure to record all active issues in progress notes and discharge summaries.

Analyzing instances of fragmented documentation revealed that documenting changes in thinking about a patient's active issues or plans during review was not a regular feature of this genre:

During the on call presentation to the senior, there was a discussion about how to manage patient 18's diabetes while in the hospital. This plan was written in the orders but not captured in the admission note. (Case 18)

In many of the cases, this practice of writing an order but not documenting the problem or plan led to problems being ignored for several days or not being addressed at all. In only one case did we see an explicit strategy that was clearly intended to facilitate the capture of the changes in thinking resulting from review: "take the chart from [presenter] and just document what we talked about as our main addendums to the plan". (Attending physician in Case 9)

The second form was failing to document during responsive care - instances of care that were in response to a new issue or change in status of an existing issue. These typically occurred when a single team member was involved in responding and frequently took place on-call:

Patient 7 was on a diuretic and required several doses of potassium supplement on different days of his hospitalization including the day prior to discharge. While different team members responsively wrote orders for the potassium when needed, neither the need nor the cause (the diuretic) was documented in the progress notes. At discharge, there was no prescription or plan for monitoring the potassium. (Case 7)

Focus group participants confirmed the pervasiveness of this form of fragmentation:

"The biggest one I continually come up against is diuretic and fluid management...I think that's the most dynamic part of the patient's care, and that's the part that gets neglected on discharge the most. We change the diuretic almost daily. None of that is ever described [in the chart]. That's the reality."

Failing to document all active issues was the third form of fragmented documentation, and it regularly interfered with the team's ability to achieve PCR. In nearly all cases, day-to-day documentation contained inconsistencies and omissions of active issues, many of which persisted into the discharge summaries. Moreover, in none of the 19 cases was it apparent where to find a complete and accurate list of the team's current thinking with regards to the patients' full list of problems. Omissions had potentially significant consequences:

During attending review, an echo was ordered on patient 16 . The problem it was ordered for, query aneurysm, was dropped from the progress notes after day 3. Although the echo results became available before discharge, these results were not documented. The test showed the unexpected finding of a very severely reduced ejection fraction of $20 \%$ with segmental wall motion abnormalities. The failure to 
document meant that this finding, suggestive of an undiagnosed severe heart disease, was not part of the explicit discharge follow-up and management plan. (Case 16)

Almost all weekend progress notes had some form of fragmented documentation. Perhaps in recognition of this, a few juniors writing the Monday note wrote a summary of the case to date. While this summarizing strategy could effectively lead to subsequent notes following the issues, there were also instances of notes that appeared to be a summary but which in fact overlooked issues:

The day 4 summary on patient 14 stated: "55-year-old male with a diabetic foot ulcer. Active issues: 1) foot ulcer, 2) diabetes". Following this 'summary', subsequent notes ignored the previously documented problem of heart failure. (Case 14)

Similarly, issues that were only documented mid-chart tended to be omitted in the discharge summary. For example, once the team made the diagnosis and initiated treatment for the bladder infection in patient 4 , the problem was never documented again. While this type of omission appears minor, it may include information that a subsequent care provider requires.

\section{Fragmented continuity among providers}

Fragmented continuity of care among provider arose from the number of different individuals contributing to the patient's chart (Table 3 ) and from turn-over of team members. Fragmented continuity among providers appeared to frequently interfere with PCR in cases reviewed or discharged over the weekend where few of members of the team were present and direct patient care was frequently by someone who did not know their case well. The impact of fragmented continuity on PCR was most evident when it co-occurred with the other forms of fragmentation, a dimension explored further in the next section.

\section{Interactions among forms of fragmentation}

Typically, all three forms of fragmentation were present and interacted to impede the team's ability to progressively refine comprehensive assessments and contextualized plans. Case 2 provides a good example of these interactions:

Patient 2 had several acute medical problems: she suffered from a fall, a bladder infection, dehydration, and a soft tissue injury to the knee limiting her mobility. She also had chronic illnesses: dementia, hypertension, and osteoporosis. During her hospitalization she developed delirium. During attending review, the possibility of a cardiac cause for her fall was raised and orders were written for an echo and telemetry. At this time, no amendment was made to the documentation to capture the reason for ordering these investigations (fragmented documentation). In subsequent progress notes, the problem underwent fragmented 
conceptualization from a clearly articulated clinical question ("cardiac cause for her fall") to that of pending test ("awaiting echo"). Fragmented conceptualization and documentation combined at the time of discharge to produce a threat to PCR: the results of the echo were reported but not the context of why it was ordered thus limiting a subsequent care provider's ability to interpret the results. Both instances of fragmentation were enabled and exacerbated by fragmented continuity of care provider. First, this patient was admitted during the weekend and, the first postweekend progress note was written by a member of the team who had not been present for the initial review. In addition, the attending physician who reviewed the admission rotated off of the team prior to the patient's discharge.

\section{Discussion}

As Miller wrote in her seminal article on rhetorical genre theory, "What we learn when we learn a genre is not just a pattern of forms or even a method of achieving our own ends. We learn, more importantly, what ends we may have". ${ }^{22}$ By using a genre system framework to study MTTs communication practices, we identified what we believe to be one of the fundamental underlying purposes of the MTT genre system: progressive collaborative refinement (PCR). When it occurs, PCR facilitates the collective care of patients by the MTT in the face of the challenges of shifting team membership, varying levels of learners, and patient complexity. PCR helps better understand previous research focused on single MTT genres by demonstrating the connections between genres. ${ }^{23,24,25,26,27}$ It also extends Weed's argument for a problem oriented medical record 36,37 by showing that an accurate and unified problem list is realized or inhibited by the genres in the system that MTTs use to provide collectively competent care. ${ }^{38}$ The concept of PCR has significant implications for how we might improve MTT practices to fulfill the dual goals of effective learning and quality care.

Our study had limitations which necessarily constrain both our insight into the studied phenomena and our ability to infer transferrable knowledge from the results. Part of our approach involved abstracting the chart and making inferences about care. The limits of this approach are evident in prior studies comparing chart documentation to reports by independent recorders or standardized patients, which have suggested that physicians may not document all collected data or care provided. ${ }^{39,40,41}$ While we did not collect data on ongoing team handover, follow-up discussions, or patient encounters, the strength of our methodology was our focus on multiple genres in the system. We acknowledge that, on a day-to-day basis, we may have missed out on elements of care discussed within the team or with patients. However, we had all of the patient care orders and were able to observe the coordinating impact of the chart over time. This represents an advance on most concordance studies, which have involved looking only at single instances of care. 
While we have recommendations to provoke reflection and debate in the medical education community regarding PCR, we would encourage caution in considering the direct transferability of our findings to other settings. Genres of communication are greatly influenced by culture and context; ${ }^{21}$ therefore, other settings may demonstrate different precipitants for fragmentation and support different strategies for achieving PCR. For example, in a centre exclusively using electronic medical records (EMR), we would need to understand the influence of this feature on the genre system's recurrent practices of review and updating documentation. While an EMR might hinder documentation in the moment of review, it may also enhance the ability of the attending to provide oversight. We also chose to focus on the physician team; studies are still needed to explore how PCR can be supported in the broader inter-professional care team that includes the nurses and others healthcare providers on the MTT. Future studies should also consider looking at the phenomena in multiple contexts and broadening the mix of genres studied. Despite these limitations, we believe that the current study findings have implications for clinical practice, clinical teachers and education researchers.

Our four recommendations for refinement and further study of the MTT genre system arise from two key findings. First, review and documentation practices do not consistently take into account the involvement of future care providers. Second, these practices do not take into account the role of the junior trainee in maintaining PCR at all stages of the review, follow-up and discharge processes. Our first recommendation, therefore, is that MTTs need to employ an explicit and consistent system for maintaining, updating, and labeling the patient's list of problems over the course of their stay. We suggest that more attention to documentation and review practices can prevent fragmented conceptualization and documentation, more attention needs to be paid to documentation and review practices. In particular, we concur with Kaplan's assertion that there needs to be a renewed focus on the problem list. ${ }^{42}$ MTTs will need to develop and test different modifications to their genres to ensure that the problem lists and plans are comprehensive, progressive, and use language that appropriately expresses the team's full understanding of the problems as new data emerges and the patient's condition continues to evolve.

PCR was most threatened during the on-call and next morning reviews when important information was discussed but not documented. Our second recommendation, therefore, is to identify and test alternative strategies for ensuring that changes in thinking arising from review lead to a shared understanding that is captured in the documentation. According to the focus group participants, factors contributing to a failure of PCR during reviews included trainee inattention during rounds and unfounded attending assumptions about what trainees comprehend of nuanced review discussions. Another factor contributing to communication errors in the team setting may be ambiguities in the 
hierarchy and roles as described by Sutcliffe. ${ }^{43}$ Because a number of studies have shown that the MTT situated learning environment is particularly prone to these influences, ${ }^{24,44,45}$ we caution that PCR may be undermined by trainees' desire to be perceived - and evaluated - as competent. ${ }^{24,45}$ During review, as the locus of control shifts from the presenter to the attending, we noted that juniors, despite having more to present or clarify, may not seek to do so. ${ }^{44}$ As clinical teachers explore methods of improving review, all of these potential contributors to fragmentation should be taken into account.

Some particularly savvy MTT attendings in our study demonstrated ad hoc strategies to address such recurrent threats to PCR during review. For instance, we identified one communication strategy that appeared to partially address the issue of documenting changes in thinking that arise from review. This involved the attending overtly designating a note taker who was not the presenter to capture all issues discussed during the review. According to studies of team cognition, for this strategy to work it must include a confirmation and cross checking of information component. ${ }^{46}$ In none of our 19 cases was this evident. Another possibility is for attendings to supervise documentation through backstage oversight, which involves returning to the case later on without the trainees present. ${ }^{47}$ While our research design did not allow us to observe backstage activities, our analysis of the follow-up notes in the patient chart suggested some evidence that this occurred in our 19 cases. However, for this strategy to be effective, it would need to be consistent, explicitly indicated to the team and include a format for providing feedback.

Attending and senior resident patient review were not the only aspect of the genre system with recurrent threats to PCR; the progress notes also harboured fragmented conceptualization and documentation. This problem is not merely a matter of poor record-keeping; as our findings demonstrated, these forms of fragmentation actually shape the care MTTs provide to patients. Therefore, our third recommendation is that MTTs treat progress notes not just as an entity that stores patient information, but, following the central premise of genre theory, ${ }^{21,22}$ as an entity that plays an important role in coordinating patient care. The importance of progress notes in the MTT genre system is partially explained by theories of intertextuality, ${ }^{28}$ which posit that the intertextual link between genres within a system depend on the writer's abstract knowledge and their specific knowledge of what has gone on before. ${ }^{28}$ Due to the inherent discontinuity in this situated learning environment, many junior members were asked to care for patients for whom they did not have specific knowledge of prior discussions. Moreover, even if they did, they may not have sufficient expertise (abstract knowledge) to adequately infer the right information. Juniors were also inconsistent in their choice of labels for problems over time and which problems they documented on a day-to-day basis. Other factors also contribute to this problem. At times, likely due to time constraints and attempted efficiencies, team members used sites other than the 
progress notes, such as the patient care orders, to document changes to plans. This particular strategy consistently interfered with PCR and attendings should be aware of this tendency and encourage consistent use of progress notes by all team members including the attendings themselves. Further research on progress notes - which have been largely ignored in both the education and patient safety literature to date - is required to inform strategies for ensuring that PCR continues throughout a patient's hospitalization.

Building on the above three recommendations, our final recommendation is that documentation be treated as an entrustable professional activity (EPA). ${ }^{48}$ Common practice in the MTT setting is to entrust clinical documentation based on roles rather than demonstrated ability or structured evaluation. ${ }^{49}$ Our results suggest that it should be treated as a much higher stakes activity given its role in coordinating the team's ability to provide competent care. According to ten Cate, EPAs are "units of professional practice, defined as tasks or responsibilities to be entrusted to a trainee once sufficient specific competence is reached [and consistently demonstrated] to allow for unsupervised practice". ${ }^{50} \mathrm{~A}$ similar argument has been made for patient handover, recognizing its critical role in ensuring quality patient care in the face of fragmented continuity. ${ }^{50}$

Treating clinical documentation as an EPA would require a major change to how documentation by the MTT is handled. Junior trainees would need to be able to demonstrate that their documentation practices can reliably support PCR prior to documentation being entrusted to them. ${ }^{48}$ While some centres may consider handling this recommendation by not allowing medical students to document, we would argue against this approach. ${ }^{49}$ Although our study was not designed to compare medical students and residents, our data included similar numbers of both and we did not see substantial differences in their ability to document in ways that supported PCR. Moreover, we also saw exemplary notes from both groups suggesting that both are capable of creating high quality notes.

In conclusion, the concept of progressive collaborative refinement has significant implications for how we might improve and further study communication practices on the MTT. It may also have relevance in other health care environments where collaborative care across a patient's hospital trajectory is supported through documentation. In such settings, patient care is a team based task that requires not just competent individuals but competent teams, whose functioning requires genre systems that support PCR.

\section{Acknowledgements}

We wish to express our gratitude to Steven Thomson and Allan McDougall who volunteered countless hours to the initial data collection and organization of the data for this study. Many thanks also to Jeroen van Merriënboer, Georges Bordage 
and Eric Holmboe for their thoughtful commentaries on an earlier draft of the paper; and to Lisa Faden for commentary and editing throughout the revision process. We would also like to acknowledge our funder: The Academic Medical Organization of Southwestern Ontario.

\section{References}

(1) Smith DT, Kohlwes RJ. Teaching strategies used by internal medicine residents on the wards. Med Teach 2011;33(12):e697-e703.

(2) Lave J, Wenger E. Situated learning: legitimate peripheral participation. Cambridge England: Cambridge University Press; 1991.

(3) Bernabeo EC, Holtman MC, Ginsburg S, Rosenbaum JR, Holmboe ES. Lost in transition: the experience and impact of frequent changes in the inpatient learning environment. Acad Med 2011;86(5):591-598.

(4) Amalberti R, Auroy Y, Berwick D, Barach P. Five system barriers to achieving ultrasafe health care. Ann Intern Med 2005;142(9):756-764.

(5) Safford MM, Allison JJ, Kiefe CI. Patient complexity: more than comorbidity. the vector model of complexity. J Gen Intern Med 2007;22 Suppl 3:382-390.

(6) Sutcliffe KM, Lewton E, Rosenthal MM. Communication Failures: An Insidious Contributor to Medical Mishaps. Acad Med 2004;79(2):186-194.

(7) Vogeli C, Shields AE, Lee TA et al. Multiple chronic conditions: prevalence, health consequences, and implications for quality, care management, and costs. J Gen Intern Med 2007;22 Suppl 3:391-395.

(8) Kennedy TJ, Regehr G, Baker GR, Lingard LA. Progressive independence in clinical training: a tradition worth defending? Acad Med 2005;80(10 Suppl):S106-S111.

(9) Egan T, Jaye C. Communities of clinical practice: the social organization of clinical learning. Health (London) 2009;13(1):107-125.

(10) Jaye C, Egan T, Smith-Han K. Communities of clinical practice and normalising technologies of self: learning to fit in on the surgical ward. Anthropol Med 2010;17(1):59-73.

(11) Hoffman KG, Donaldson JF. Contextual tensions of the clinical environment and their influence on teaching and learning. Med Educ 2004;38(4):448-454.

(12) Barnett K, Mercer SW, Norbury M, Watt G, Wyke S, Guthrie B. Epidemiology of multimorbidity and implications for health care, research, and medical education: a cross-sectional study. Lancet 2012;380(9836):37-43.

(13) Partnership for Solutions. Chronic Conditions: Making the Case for Ongoing Care. 2002 Dec.

(14) Hayward RA, Asch SM, Hogan MM, Hofer TP, Kerr EA. Sins of omission: getting too little medical care may be the greatest threat to patient safety. J Gen Intern Med 2005;20(8):686-691. 
(15) Nardi R, Scanelli G, Corrao S, Iori I, Mathieu G, Cataldi AR. Co-morbidity does not reflect complexity in internal medicine patients. Eur J Intern Med 2007;18(5):359-368.

(16) Forster AJ, Murff HJ, Peterson JF, Gandhi TK, Bates DW. The Incidence and Severity of Adverse Events Affecting Patients after Discharge from the Hospital. Ann Intern Med 2003;138(3):161-167.

(17) Juurlink DN, Mamdani M, Kopp A, Laupacis A, Redelmeier DA. Drug-Drug Interactions Among Elderly Patients Hospitalized for Drug Toxicity. JAMA: The Journal of the American Medical Association 2003;289(13):1652-1658.

(18) Baker GR, Norton PG, Flintoft V et al. The Canadian Adverse Events Study: the incidence of adverse events among hospital patients in Canada. CMAJ 2004;170(11):1678-1686.

(19) Boyd CM, Darer J, Boult C, Fried LP, Boult L, Wu AW. Clinical Practice Guidelines and Quality of Care for Older Patients With Multiple Comorbid Diseases: Implications for Pay for Performance. JAMA: The Journal of the American Medical Association 2005;294(6):716-724.

(20) Leape LL. A systems analysis approach to medical error. J Eval Clin Pract 1997;3(3):213-222.

(21) Devitt AJ. Writing genres. Carbondale: Southern Illinois University Press; 2004.

(22) Miller C. Genre as Social Action. Quarterly Journal of Speech 1984;70:151-167.

(23) Irby DM. How attending physicians make instructional decisions when conducting teaching rounds. Acad Med 1992;67(10):630-638.

(24) Lingard L, Schryer C, Garwood K, Spafford M. 'Talking the talk': school and workplace genre tension in clerkship case presentations. Med Educ 2003;37(7):612-620.

(25) Dresselhaus TR, Luck J, Wright BC, Spragg RG, Lee ML, Bozzette SA. Analyzing the time and value of housestaff inpatient work. J Gen Intern Med 1998;13(8):534-540.

(26) Arora V, Johnson J, Lovinger D, Humphrey HJ, Meltzer DO. Communication failures in patient sign-out and suggestions for improvement: a critical incident analysis. Qual Saf Health Care 2005;14(6):401-407.

(27) Foster DS, Paterson C, Fairfield G. Evaluation of immediate discharge documents--room for improvement? Scott Med J 2002;47(4):77-79.

(28) Bazerman C, Prior PA. What writing does and how it does it: an introduction to analyzing texts and textual practices. Mahwah, N.J: Lawrence Erlbaum Associates; 2004.

(29) Yin RK. Case Study Research. Design and Methods. 4th ed. California: Sage Publications, Inc.; 2009.

(30) Eisenhardt KM, Graebner ME. Building Theories from Case Study Research. The Academy of Management Review 2007;50(1):25-32.

(31) Stake R. The Art of Case Study Research. Thousand Oaks: Sage; 1995. 
(32) Fischer CT, Wertz FJ. Empirical phenomenological analyses of being criminally victimized. In: Giorgi A, Knowles R, Smith DL, editors. Duquesne studies in phenomenological psychology.Pittsburgh: Duquesne University Press; 1979. 135-158.

(33) Bringer JD, Halley L, Brackenridge C. Using Computer-Assisted Qualitative Data Analysis Software to Develop a Grounded Theory Project. Field Methods 2006;18(3):245-266.

(34) Denzin NK. The research act: a theoretical introduction to sociological methods. New Brunswick, NJ: Aldine Transaction; 2009.

(35) Thurmond VA. The point of triangulation. J Nurs Scholarsh 2001;33(3):253258.

(36) Weed LL. Medical records that guide and teach. $N$ Engl $J$ Med 1968;278(11):593-600.

(37) Weed LL. Medical records that guide and teach (Concluded). $N$ Engl J Med 1968;278(12):652-657.

(38) Lingard L. What we see and don't see when we look at 'competence': notes on a god term. Adv Health Sci Educ Theory Pract 2009;14(5):625-628.

(39) Luck J, Peabody JW, Dresselhaus TR, Lee M, Glassman P. How well does chart abstraction measure quality? A prospective comparison of standardized patients with the medical record. Am J Med 2000;108(8):642-649.

(40) Tisnado DM, Adams JL, Liu H et al. What is the concordance between the medical record and patient self-report as data sources for ambulatory care? Med Care 2006;44(2):132-140.

(41) Fernando KJ, Siriwardena AK. Standards of documentation of the surgeonpatient consultation in current surgical practice. Br J Surg 2001;88(2):309312.

(42) Kaplan DM. Perspective: Whither the problem list? Organ-based documentation and deficient synthesis by medical trainees. Acad Med 2010;85(10):1578-1582.

(43) Sutcliffe KM, Lewton E, Rosenthal MM. Communication Failures: An Insidious Contributor to Medical Mishaps. Academic Medicine 2004;79(2):186-194.

(44) Goldszmidt M, Aziz N, Lingard L. Taking a Detour: Positive and Negative Effects of Supervisors' Interruptions During Admission Case Review Discussions. Acad Med 2012;87(10):1382-1388.

(45) Kennedy TJ, Regehr G, Baker GR, Lingard L. Preserving professional credibility: grounded theory study of medical trainees' requests for clinical support. BMJ 2009;338:b128.

(46) Salas E, Rosen MA, Burke CS, Nicholson D, Howse WR. Markers for Enhancing Team Cognition in Complex Environments: The Power of Team Performance Diagnosis. Aviation, Space, and Environmental Medicine 78[Supplement 1], B77-B85. 2007. 
(47) Kennedy TJ, Lingard L, Baker GR, Kitchen L, Regehr G. Clinical oversight: conceptualizing the relationship between supervision and safety. J Gen Intern Med 2007;22(8):1080-1085.

(48) Ten Cate 0. Entrustability of professional activities and competency-based training. Med Educ 2005;39(12):1176-1177.

(49) Ratcliffe TA, Hanson JL, Hemmer PA, Hauer KE, Papp KK, Denton GD. The Required Written History and Physical is Alive, but Not Entirely Well, in Internal Medicine Clerkships. Teach Learn Med 2013;25(1):10-14.

(50) Ten Cate 0, Young JQ. The patient handover as an entrustable professional activity: adding meaning in teaching and practice. BMJ Qual Saf 2012;21 Suppl 1:i9-12. 


\section{CHAPTER 4}

A Model of Four Supervisory Styles 


\section{Abstract}

Purpose: While the attending physician roles on medical teaching teams include safeguarding patient care and trainee learning, there is wide variability in how they are enacted. This study sought to better understand this variability by considering how different attendings configured and rationalized their direct patient care, trainee oversight and teaching activities.

Methods: The authors used constructivist grounded theory to guide iterative data collection and analyses. Data included interviews with 24 attending physicians from two academic centres in Ontario, Canada.

Results: Four supervisory styles were identified: Direct Care, Empowerment, Mixed Practice, and Minimalist. Driven by concerns for patient safety, the Direct Care style involves delegating minimal patient care responsibility to trainees. Focused on supporting trainees' progressive independence, the Empowerment style uses teaching and oversight strategies to ensure quality of care. In the Mixed Practice style, patient care is privileged over teaching and the approach is adjusted based on trainee competence and contextual features such as patient volume. The Minimalist style involves a high degree of trust in the senior residents delegating most patient care and teaching to them. Attendings rarely discussed their styles with trainees or colleagues.

Conclusions: The proposed model adds to the literature on variability in supervisory practice by showing that the four supervisory styles reflect different ways of responding to the tensions in the role and the context. This model could be refined through observational research exploring the impact of context on style development and enactment. Making supervisory styles explicit could support efforts to improve team competence.

Published as:

Goldszmidt, M., Faden, L., Dornan, T., Merriënboer, J., Bordage, G., and Lingard, L. Attending Physician Variability: A Model of Four Supervisory Styles. Acad Med 2015 (in press; accepted for publication October 23, 2014)

(C) 2013 the Association of American Medical Colleges 


\section{Introduction}

In the North American academic hospital setting, the attending physician is a staff physician who has overall responsibility for inpatient care and supervises the physicians-in-training (residents and medical students) who help deliver that care in a teaching team setting. The attending role is a challenging one, in part, due to the expectation to safeguard both patient care and trainee learning in an inpatient setting characterized by increasing patient complexity, ${ }^{1-3}$ shortened rotation schedules, and teaching teams with ever-changing membership. ${ }^{4}$ Research has offered important insights into the attending role, with Kennedy et al. theorizing the strategies attendings use to trade-off between supervision and independence, ${ }^{5}$ and Irby articulating attendings' teaching strategies on rounds. 6,7 While these have been important advances in our understanding of attending practice, they do not map the full spectrum of attending activities. In their guide to effective clinical supervision, Kilminster et al. delineate a broader set of supervisory and teaching activities. $^{8}$ However, these are largely derived from survey-based research and their applicability to real-world attending practices remains unexplored. Moreover, while Kilminster et al. addressed underlying principles such as relationshipbuilding and autonomy, they do not address how attendings balance the inherent tensions between such activities. And, while supervisory practices appeared to be highly variable, ${ }^{9}$ it is unclear whether this variability is purposeful or idiosyncratic. In light of this, Kilminster et al. have called for "more structured and methodologically sound programmes of research into supervision in practice settings so that detailed models of effective supervision can be developed and thereby inform practice."8

When medical students enter the clinical environment for the first time, ideally they take on legitimate but peripheral roles ${ }^{10}$ that progress over time to involve increasing levels of responsibility. ${ }^{11}$ This progression is considered to be essential for the development of clinical skills and professional identity. ${ }^{11-13}$ Environments in which there are opportunities for prolonged exposure to working with one or a small group of physicians have been shown to allow for the development of progressive independence. ${ }^{14,15}$ However, continuity of exposure is not the norm for most internal medicine teaching teams where the trend has been to move towards shorter rotations, shorter days, larger teams and frequent changeover of attending physicians. ${ }^{4}$ These organizational constraints arguably increase tension between ensuring patient safety and supporting progressive independence.

According to Kennedy et al., attending physicians vary their levels of oversight to ensure patient safety and encourage progressive independence. 5,16 These range from the routine or planned to more responsive practices that may escalate to the point of taking over the provision of direct patient care, ${ }^{5}$ and involve the use of 
questioning of trainees to assess their competence. ${ }^{16}$ Questioning is used to assess learner needs and adjust teaching practices, as well.6,7 Attendings also engage in a broad array of other supervisory and teaching activities, such as guiding clinical work, drawing connections between practice and theory, participating in joint problem-solving, role modelling and explicitly delineating roles.7, 8 However, perhaps due to the many inherent tensions in the role, attending physician supervisory practices are highly variable. ${ }^{8,9}$

This variability begs the question: Is there a gold standard for the attending role on the medical teaching team (MTT)? We suggested in a previous study an ideal of practice called progressive collaborative refinement (PCR). ${ }^{9}$ PCR argues that for successful patient care to occur, the MTT must work collectively to conceptualize the patient's medical problems and plans, and they must progressively refine their understanding of these in light of new information or changes in the patient's condition. ${ }^{9}$ That study reported recurrent lapses in PCR and wide variability in attendings' case review practices, which seemed associated with the presence or absence of PCR. However, that study did not explore attending physicians' rationales for their case review practices, nor did it consider them within the broader context of the attending role. Addressing these critical gaps in our knowledge, the purpose of the current study was to better understand the variability in supervisory practices.

\section{Method}

\section{Study Design}

We used a constructivist grounded theory methodology, an approach suited to our goal of building a theoretical model of a social phenomenon. ${ }^{17}$ The focus on attending physician supervisory practices was determined based on findings from our previous study of MTT communication. ${ }^{18}$ Using this methodological approach, data were collected and analyzed in iterative cycles to facilitate a theoretical sampling strategy in which the findings from each cycle informed the collection of data in the following cycle. The study was approved by the University of Western Ontario Health Sciences Research Ethics Board.

\section{Setting and sample}

Data were collected from two academic health sciences centres in Ontario, Canada during the periods February-May and November-December 2012. Recruitment began with a letter sent to all MTT attendings ( $n=53$ ) at two teaching hospitals in the first research site (City A) to participate in an interview "to better understand how different forms of communication impact patient care and team functioning." 
Theorizing that a different hospital site might lend itself to different practices, as a preliminary exploration, we sampled a limited number of physicians at a second site (City B). ${ }^{17}$ In both cities, the typical MTT included an attending physician and approximately 6-8 trainee members: one to two senior (second or third year) residents, two to four junior (first year residents) and two to four senior medical students. We will refer to members of this team of residents and medical students as trainees. Twenty-four attendings participated (20 from City A, 4 from City B). While more than 24 attendings volunteered to participate, we terminated data collection when theoretical sufficiency was achieved. ${ }^{19}$ The distribution across specialties of those interviewed was: 10 general internists, 4 nephrologists, 3 geriatricians, 2 respirologists, 2 endocrinologists, 1 hematologist, and 1 rheumatologist. For one participant, this data was not collected. We conducted 18 individual interviews and 3 paired interviews. The participating attendings had from 1 to 36 years of attending experience $(1-5$ years $=7 ; 6-20$ years $=10 ; 21-36$ years=6); one participant did not report years of experience.

\section{Data collection}

The interview protocol was designed to elicit participating attendings' expert strategies for managing the challenges of MTT teaching and patient care. All interviews were performed by the same interviewer. Following informed consent, the interviewer, a trained research assistant, asked the participant(s) to speak in general about their case review setting and practices. She then proceeded to read a senior medical student's presentation of a complex case taken from a prior study. ${ }^{9}$ Participants were asked to listen and take notes as if they were hearing a case presentation with their teams during a typical admission case review. The patient in this case presented with co-morbidities (chronic heart failure, chronic obstructive pulmonary disorder, and diabetes) that complicated the task of treating the presenting illness, a case of an infected diabetic foot ulcer. Next, participants were asked to reflect on their experience of similar and dissimilar situations, supervisory strategies for balancing patient and learner needs, and the reasoning behind their approach. Consistent with grounded theory methodology, the probes evolved as the study progressed to allow for exploration of identified themes. The interview strategy of having experts reflect on their practices while working through an authentic problem is regarded as an effective method for eliciting tacit expert knowledge. ${ }^{20}$ Interviews took place in the participant's office or in a conference room located in the hospital in which they worked and lasted a a median of 50 minutes. Interviews were audio recorded and anonymized during transcription. 


\section{Data analysis}

Analysis of the data proceeded iteratively, using multiple strategies. NVivo 9 (QSR, Doncaster, Australia) qualitative data analysis software was used to create a database and to manage coding of the data. Trustworthiness was addressed using a number of strategies including: investigator and theoretical triangulation; the use of analytical memos throughout to document the development of analytical concepts; the use of individual participant narratives to generate thick descriptions of each participant's practice; and the use of matrix displays to illustrate the variations in belief and practice across participants. ${ }^{21-23}$ The combination of research team members from medicine and medical education (MG), education (LF), rhetoric (LL), medicine and educational psychology (GB), medicine and medical education (TD) and psychology and instructional technology (JvM) afforded the opportunity for investigator and theoretical triangulation. ${ }^{24,25}$ During early data collection and analysis, transcripts were read, re-read, and discussed between the interviewer and lead researcher (MG). This afforded the opportunity for modifying interview probes to explore identified themes. Data collection continued until sufficiency was achieved. ${ }^{19}$ We (LF, MG) used constant comparison by reading the transcripts multiple times to identify and define coding categories for themes relevant to the central questions of the study. Through a series of data analysis meetings that included the other team members, we developed and revised the definition for each theme and identified new ones. Once the coding scheme was finalized, the complete data set was analyzed for relationships between themes and within and across participants. This study contains our analysis of the data related to the theme of supervisory style.

\section{Results}

Analysis of the data revealed that attending physicians differed markedly in their case review and follow-up practices. In order to explore these differences, our research team identified four themes around which to code the full data set: case review and follow-up practices; perceptions about supervision; beliefs regarding the role and capabilities of trainees; and perceptions of the nature of learning and teaching in clinical settings. Following the coding of data into each of these four themes, we considered the relationships among the themes and conceptualized those relationships into a model of four supervisory styles: Direct Care, Empowerment, Mixed Practice, and Minimalist. The different styles were characterized by how attendings prioritized and organized three core, and at times, overlapping activities: 1) Direct patient care (e.g., seeing patients alone or with the team, writing orders and documenting in the patient's chart); 2) Oversight (e.g., reviewing new cases, hearing follow-up on previously admitted cases, going to the bedside, reviewing the electronic record, reading patient charts); and 3) Teaching 
(e.g., didactic teaching sessions, bedside teaching, teaching around admitted cases). Both direct patient care and oversight took place in settings visible or less visible to the team (i.e., behind the scenes). We further characterized the four styles according to how attendings regarded trainee capabilities and the constraints of the MTT setting.

While participating attendings acknowledged that they likely differed from their colleagues, they attributed this variability to "different personalities...the way we all think about things is different [as well as] what we view as our priorities" (Attending 15). Moreover, when probed, they indicated that they rarely explicitly discussed these differences with their teams or their colleagues. With the exception of three interviews which provided insufficient detail to allow us to identify a style, the remaining 21 interviews fit within one of the four styles. While there was no apparent relationship between years in practice or specialty of attending and supervisory styles, this study was not designed to explore such relationships. In the following sections, we will describe each style focusing first on its defining characteristics.

In the Direct Care style (4 interviews), attendings described owning the role of care provider. Trainees were seen to play a secondary role in patient care, learning from doing but not ultimately responsible for getting the work done. As one attending asserted, "The first purpose [of case review] is to make sure that the patient is looked after and I as attending know about the patient" (Attending 4).This stance appeared to arise from concerns about trainees' abilities to handle the complexity of the patients:

The ultimate responsibility for patient care is the attending, whether they like that or not...and the quality of that care is really dependent upon how responsible they are making sure that issues are dealt with in a continuous fashion. I think it's inappropriate, unfair to expect a medical student or a junior resident to be able to grasp the whole picture and run with it (Attending 11).

In the Direct Care interviews, attendings described being sensitive to time constraints and therefore typically reviewed new cases in a conference room rather than at the bedside. They also portrayed teaching and patient care as competing for the team's time: “I don't rely on residents very much. I think they're there to learn. They do as much as they can. But my job is to teach and also my job is for these patients. And sometimes, if we're very understaffed, I just do everything on my own" (Attending 9). In three of the four Direct Care interviews, this philosophy seemed to drive the practice of providing parallel patient care alongside trainees' efforts. For the fourth, rather than having the team do independent parallel work, they would spend hours rounding together while the attending directed the care.

In the Empowerment style (6 interviews), attendings described focusing their oversight activities on empowering the trainees to deliver the direct patient care and they used strategies for ensuring that the trainees could safely take over care in each other's absence: 
From a patient care standpoint, the purpose [of case review] is to get us all on the same page about what's going on and what our plan is for all the problems. So my emphasis on somebody writing a note at the time of our review and me double checking it and comparing it to my list is to make sure that when we leave this we have the right labels that I think are the right labels, the right plans for each problem. And then I know the team should, should I hope be able to take that and provide follow-up care on this patient over time while they're hospitalized (Attending 2).

This style was also characterized by a high degree of integration between teaching and patient care activities, with attendings describing case review as an opportunity to develop trainees' skills in clinical reasoning and communication:

They get direct feedback and also learn about approaches. So, if they're not sure and come with a problem and didn't know what to do, now we have talked about it and it is open discussion and everyone's present so you can learn from the other people as opposed to doing it not as a group... I think it's an opportunity for the whole team to learn and it's good for the staff too because you can get an update on all of your patients without having to necessarily go see all of them (Attending 13).

In the Empowerment style interviews, attendings also described periodically engaging in providing direct patient care. However, in order to avoid undermining the trainees, they had strategies for ensuring that this was explicitly communicated to the team: "Sometimes I go back during the day and see the patient and it's an opportunity for me to talk to them [the patients]. As well, I say [to the team]: I went to see the patient and this is what I found. Do you want to go back together?" (Attending 13).

In the Mixed Practice style (9 interviews), attendings described engaging in various activities including reviewing patient records, editing notes in the patient chart, and providing direct patient care. Many reported that their balance of direct care with oversight was dictated by their assessment of the trainees' competence:

The autonomy I give the resident is directly proportional to how much I trust them... It's all to do with the presentations... They may not have the experience and knowledge base that I have, but that's ok... The other thing is that by talking to the residents you kind of get a sense of character and personality. I try and really assess if the resident, especially the resident who does know a lot, if they know their own limitations....You can kind of get that just from talking to them (Attending 8).

In those interviews identified as Mixed Practice style, attendings explained that they might determine the plan for patients with the team, but they also felt that "it's important for the consultant to go back and make sure that that's done as well" (Attending 12). They also reported tension around the context of case review. A common "preference would be to have the chart at the bedside and going over everything and the patient also getting involved in the discussion" (Attending 5), but participants consistently felt constrained in doing so and many acknowledged 
that "running the list [in the conference room] has replaced the bedside round" (Attending 14). While these attendings' descriptions of their practices suggested that they privileged patient care, they also emphasized their efforts to make time for teaching. However, descriptions of these efforts were imbued with tension: "You have to pick your battles; there is only so much time" (Attending 8). Teaching topics in this style were described as being triggered by cases and the trainees' knowledge but, unlike the Empowerment style, effort was less overtly made to integrate and contextualize them to the case:

I try and base [the teaching] on need. So when I ask the clerks a question, I move on and ask the residents a question, and if it seems to be an area that nobody seems to know too much about, then I spend more time on teaching it (Attending 16).

The Minimalist style (2 interviews) was defined by two main characteristics. First, they reported minimal direct or indirect participation in either patient care or teaching: "There is very little direct communication, to be perfectly honest. Again, it depends on the senior. Sometimes, I will make a point of being at the morning meeting of the senior resident with the junior house staff" (Attending 22). Second, they relied heavily on the senior medical resident's capability to run the team and provide teaching, even while recognizing the limits of this approach: "And it's probably bad, I often assume that it's been taken care of. I have been burned before because you shouldn't really assume that, I suppose" (Attending 19).

As part of our theoretical sampling approach, we sampled four physicians at a second site with different admission practices. In this sample of interviews, we identified one each of Minimalist, Mixed Practice, and Empowerment. The fourth interview transcript did not contain sufficient information for us to determine supervisory style.

\section{Discussion}

Variability of supervisory practices has been documented in the literature, both in observational studies ${ }^{9}$ and in surveys. ${ }^{8}$ Our model of supervisory styles contributes to Kennedy's recent effort to understand such variability as more than random or idiosyncratic behavior. ${ }^{5}$ Our model explains MTT attendings' supervisory practices as a product of the relative prioritization of three competing activities - patient care, trainee supervision, and teaching. In this section, we discuss the model, compare it to other proposed explanations of supervisor variability, and consider its implications for the field.

Our model is unique in its integration of all three primary attending practices: patient care, trainee supervision, and teaching. Kennedy et al.'s model focused exclusively on the relationship between supervision and patient care ${ }^{5}$ and Irby's considerations of supervisory teaching ${ }^{6,7}$ largely treated this practice in isolation. 
Similar to Kennedy et al., we found that attendings engage in a spectrum of oversight behaviors, ranging from the routine to the responsive. ${ }^{5}$ However, our model of supervisory styles contributes two novel dimensions to our understanding of supervisory practices. First, it broadens our understanding of the factors that influence oversight practices. Second, it places patient care and oversight in relation to the supervisory practice of teaching.

Kennedy et al. posit that supervisors' decisions to provide close supervision or allow trainee independence occur in response to contextual triggers, the most important of which are trainee competence and patient acuity: "When clinical supervisors encounter a situation that is perceived to exceed the boundaries of a trainee's competence, they move beyond clinical oversight to the third and most intensive level of clinical activity, which was termed 'direct patient care'" (p. 1083). ${ }^{5}$ However, participating attendings' interview discussions of various supervisory situations suggest that supervisory style may be an approach to contextual triggers, not only a response to them. For example, when asked about how their supervisory practices might be affected by contextual triggers such as a weak senior resident or a high number of overnight admissions, the interviewed attendings responded in a manner consistent with a single style - Empowerment or Direct Care styles indicated that such contextual triggers would increase their efforts to empower or take over care, respectively. The Mixed Practice interviews appeared to resemble more closely Kennedy et al.'s model, indicating that a weak resident might cause attendings to increase direct care, and a high patient census would cause them to decrease teaching. Importantly however, such contextual triggers did not produce a wholesale shift to Direct Care in Mixed Practice style descriptions of their activities; rather, attendings continued to describe teaching as important but achievable in a more limited way: "I will try and hopefully pick something out of the case that may be at least a useful learning point like when you admit a type 1 diabetic to hospital you don't stop their insulin. Something like that, as opposed to focusing on every detail if we don't have time for it" (Attending 4).

While participants' responses to interview probes suggested that they largely maintained their style-affinity regardless of trainee ability and patient load, we do not intend to imply that the styles were impervious to contextual pressures or that an attending was necessarily limited to a single style. Attendings describing all four styles reported that their morning case review practices were consistently driven away from the bedside due to the large sizes of teaching teams and the inefficient distribution of patients around the hospital. Supervisory style was also variably vulnerable to rotation schedules: for instance, resident changeover at the end of the first week of an attendings' two-week stint on the MTT could have more impact on those attendings describing an Empowerment style, who reported a preferred strategy of increasing trainee independence in the second week, than on those describing a Direct Care style. 
Another critical feature of supervisory styles is their tacit nature: our participants consistently indicated that they did not discuss differences in styles or practices with their trainees or colleagues. It is unclear from our data why this was the case. Possibilities include a lack of awareness of a style preference, of the existence of a variety of styles, or of the impact of style and differing practices on team function. Given the striking differences in expectations around trainee and supervisor roles in the four styles, we feel that the failure to explicitly discuss these expectations may help to explain our previous finding that not all MTT teams functioned competently. ${ }^{9}$ Rather than progressively and collaboratively refining the MTT's diagnostic and management thinking, we found that clinical documents and discharge summaries often failed to address all aspects of a patient's problems and to reflect accurately the team's understanding of them. Our current results suggest that future research could explore the relationship between team competency and the transition between attending styles within a rotation and as they rotate on and off the MTT. For instance, when a team transitions from an attending with a Direct Care style to one using a Mixed Practice or Minimalist style, do trainees recognize the difference and its implications for teamwork? Do trainees perceive the differences as strategic or idiosyncratic? How do trainees, particularly senior residents who have their own oversight role on the MTT, adapt their own practices to supervisory styles?

Understanding the four supervisory styles provides additional insight into the challenges of providing progressive independence for trainees amidst contemporary concerns about patient safety. It has been argued that the support of progressive independence may be the single most important feature of a highquality clinical experience, necessary for the development of competence ${ }^{12,14,26}$ and professional identity. ${ }^{12,13}$ However, the supervisory styles may have very different impacts on progressive independence. While the Minimalist style granted trainees the greatest degree of independence, it appeared to do so in a somewhat indiscriminate fashion rather than being based in entrustment decisions. This approach raises questions of the adequacy of competency assessments, skill development and patient care. ${ }^{14,} 26$ By contrast, both the Empowerment and Mixed Practice styles involve spending time trying to determine and progressively grant independence and subsequent entrustment, and the premise of the Direct Care style is that this is not achievable.

\section{Limitations}

Grounded theory seeks to map out the range of possible practices embedded in the studied phenomenon. While we have presented the number of participants in each style, these should not be considered to reflect the proportions in practice, because sampling in grounded theory is theoretical rather than representative. ${ }^{17}$ Further, while we interviewed to a point of sufficiency, it is quite possible that more than 
four styles exist. In particular, the style identified as mixed practice may in fact represent more than one style. Our interview probes explored participants' perceptions of how they adapted their practices to contextual factors, but we sampled a single point in time and relied on self-reported data. Observational data will be required to explore the ways in which supervisory practice reflects the perceptions we've described in this study, and to refine our understanding of the impact of context on supervisory styles and the variability of style in a given attending over time. Furthermore, a purposive sampling of attendings from different clinical specialties, institutional cultures, and healthcare systems might provide insight into the (in)stability of style in the face of fundamental contextual changes such as fee structures, ${ }^{27}$ patient volume, ${ }^{28}$ and duty hour restrictions, ${ }^{29}$ which may mandate attendings towards another supervisory style.

\section{Conclusions}

Our work responds to the call for research exploring supervision in clinical settings. In doing so, we were able to gain insights into the relationships among patient care, oversight and clinical teaching. Focused on variability in supervisory practice, our model adds to the literature by showing that supervisory practice is not idiosyncratic. Rather, we describe four styles which reflect different ways of responding to the tensions in the roles of the attending physician and the context that they work in. While our results do not suggest a gold standard among these styles, they inform both future research into the impact of supervisory practice on team competence, and professional development for both trainees and faculty working in these settings. Given that attendings expressed limited awareness of the variations in supervisory practices, explicit dialogue about supervisory styles could support efforts aimed at improving team competence.

\section{Acknowledgements}

The authors wish to thank Dr. Meredith Vanstone, Dr. Parveen Wasi, and the internal medicine attendings who participated in the study, all of whom were invaluable to the completion of this project.

\section{Funding/Support}

This study was funded in part by Academic Medical Organization of Southwestern Ontario (AMOSO) Innovations Grant Project R3381A06 and Program of Experimental Medicine (POEM), Department of Medicine, Schulich School of Medicine \& Dentistry, University of Western Ontario Project R3381A03. 


\section{Ethical approval}

This project was approved by The University of Western Ontario Health Sciences Ethics Review Board.

\section{References}

(1) Barnett K, Mercer SW, Norbury M, Watt G, Wyke S, Guthrie B. Epidemiology of multimorbidity and implications for health care, research, and medical education: a cross-sectional study. Lancet 2012;380(9836):37-43.

(2) Vogeli C, Shields AE, Lee TA et al. Multiple chronic conditions: prevalence, health consequences, and implications for quality, care management, and costs. J Gen Intern Med 2007;22 Suppl 3:391-395.

(3) Safford MM, Allison JJ, Kiefe CI. Patient complexity: more than comorbidity. the vector model of complexity. J Gen Intern Med 2007;22 Suppl 3:382-390.

(4) Bernabeo EC, Holtman MC, Ginsburg S, Rosenbaum JR, Holmboe ES. Lost in transition: the experience and impact of frequent changes in the inpatient learning environment. Acad Med 2011;86(5):591-598.

(5) Kennedy TJ, Lingard L, Baker GR, Kitchen L, Regehr G. Clinical oversight: conceptualizing the relationship between supervision and safety. J Gen Intern Med 2007;22(8):1080-1085.

(6) Irby DM. How attending physicians make instructional decisions when conducting teaching rounds. Acad Med 1992;67(10):630-638.

(7) Irby DM. What clinical teachers in medicine need to know. Acad Med 1994;69(5):333-342.

(8) Kilminster S, Cottrell D, Grant J, Jolly B. AMEE Guide No. 27: Effective educational and clinical supervision. Med Teach 2007;29(1):2-19.

(9) Goldszmidt M, Dornan T, Lingard L. Progressive collaborative refinement on teams: implications for communication practices. Med Educ 2014;48(3):301314.

(10) Lave J, Wenger E. Situated learning: legitimate peripheral participation. Cambridge England: Cambridge University Press; 1991.

(11) Egan T, Jaye C. Communities of clinical practice: the social organization of clinical learning. Health (London) 2009;13(1):107-125.

(12) Kennedy TJ, Regehr G, Baker GR, Lingard LA. Progressive independence in clinical training: a tradition worth defending? Acad Med 2005;80(10 Suppl):S106-S111.

(13) Monrouxe LV. Identity, identification and medical education: why should we care? Med Educ 2010;44(1):40-49. 
(14) Hirsh DA, Holmboe ES, ten Cate O. Time to Trust: Longitudinal Integrated Clerkships and Entrustable Professional Activities. Acad Med 2014;89(2):201204.

(15) Teherani A, Irby DM, Loeser H. Outcomes of different clerkship models: longitudinal integrated, hybrid, and block. Acad Med 2013;88(1):35-43.

(16) Kennedy TJ, Lingard LA. Questioning competence: a discourse analysis of attending physicians' use of questions to assess trainee competence. Acad Med 2007;82(10 Suppl):S12-S15.

(17) Watling CJ, Lingard L. Grounded theory in medical education research: AMEE Guide No. 70. Med Teach 2012;34(10):850-861.

(18) Charmaz K. Constructing grounded theory: a practical guide through qualitative analysis. London: SAGE; 2006.

(19) Dey I. Grounding grounded theory: Guidelines for qualitative inquiry. San Diego, CA: Academic Press; 1999.

(20) Ericsson KA. Protocol analysis and expert thought: Concurrent verbalizations of thinking during experts' performance on representative tasks. In: Ericsson KA, Charness N, Feltovich PJ, Hoffman RR, editors. The Cambridge handbook of expertise and expert performance.Cambridge: Cambridge University Press; 2006. 223-241.

(21) Lincoln YS, Guba EG. Naturalistic inquiry. Beverly Hills, CA: Sage Publications; 1985.

(22) Miles MB, Huberman AM. Qualitative data analysis: An expanded sourcebook. 2nd ed. Thousand Oaks: Sage Publications; 1994.

(23) Maxwell JA. Understanding and validity in qualitative research. Harvard Educational Review 1992;62(3):279-300.

(24) Mitchell ES. Multiple triangulation: a methodology for nursing science. Advances in Nursing Science 1986;8(3):18-26.

(25) Thurmond VA. The point of triangulation. J Nurs Scholarsh 2001;33(3):253258.

(26) Hauer K, ten Cate O, Boscardin C, Irby D, Iobst W, Sullivan P. Understanding trust as an essential element of trainee supervision and learning in the workplace. Adv in Health Sci Educ 2014;19(3):435-456.

(27) McConville JF, Rubin DT, Humphrey H, Carson SS. Effects of billing and documentation requirements on the quantity and quality of teaching by attending physicians. Acad Med 2001;76(11):1144-1147.

(28) Aldeen AZ, Gisondi MA. Bedside teaching in the emergency department. Acad Emerg Med 2006;13(8):860-866.

(29) Roshetsky LM, Coltri A, Flores A et al. No time for teaching? Inpatient attending physicians' workload and teaching before and after the implementation of the 2003 duty hours regulations. Acad Med 2013;88(9):1293-1298. 


\section{CHAPTER 5}

Taking a Detour: Positive and Negative Effects of Supervisors' Interruptions During Admission Case Review Discussions 


\section{Abstract}

Purpose: During admission case review, teams work to develop a shared understanding of the problems they need to address during the patient's hospitalization. However, research on the effects of the case review on patient care is limited. Informed by rhetorical genre theory, the authors explored the impact of team's communication practices on the comprehensiveness of the case review.

Method: Using a multiple case study approach, the authors in 2010 observed in person, audio-recorded, and transcribed data from overnight and morning case review discussions for 19 patient cases in the internal medicine department of an academic medical center. They also extracted data from the corresponding admission notes. They used a constant comparison approach to identify emerging themes within and across cases.

Results: The authors identified detours, which typically arose from supervisors' interruptions, in all 19 cases. They identified five detour types: pausing the presentation, referring to a section later in the presentation, presenting sections out of sequence, skipping a section, and truncating the presentation. While supervisors' interruptions during case review discussions allowed for teaching and patient care, they also created detours from the usual case presentation, which then could lead to the omission of relevant case details.

Conclusions: Supervisors' interruptions during case review discussions can lead to detours, which simultaneously afford valuable opportunities for teaching and threaten comprehensive information sharing. Future research should explore detours in other teaching settings to better understand their positive, negative, and unintended consequences for patient care.

Published as:

Goldszmidt, M., Aziz, N., Lingard, L. Taking a Detour: Positive and Negative Effects of Supervisors' Interruptions During Admission Case Review Discussions. Acad Med 87(10), 1382-1388. 8-21-2012

(C) 2013 the Association of American Medical Colleges 


\section{Introduction}

Admission case review occurs daily at teaching hospitals around the world. During these reviews, the medical team gathers, and the attending physician listens to a case presentation by a junior team member (a first-year resident or senior medical student), asks questions, then provides guidance and teaching to the team.

Admission case review serves two, at times, competing functions--teaching and patient care. ${ }^{1}$ According to Irby, during case review, attending physicians iteratively diagnose the patient, diagnose the learner, and teach. ${ }^{2}$ As this process occurs in real time regarding a patient who is usually unfamiliar to the attending physician, the teaching and patient care discussions require a significant amount of improvisation. ${ }^{2}$ Attendings must strike a balance between teaching their teams and addressing the necessary patient issues. From a patient care standpoint, case review provides the team with an opportunity to receive guidance on how to further assess and manage their patients, who often suffer from a number of problems other than the main reason for their hospitalization. ${ }^{3,4}$ Failing to address a patient's full set of problems can lead to medical errors and hospital readmission. ${ }^{4-6}$

Many previous studies of case reviews have focused on the teaching and learning aspects of the team's morning presentation to the attending. This research established general principles of good teaching and the characteristics of good clinical teachers. ${ }^{7,8}$ These characteristics include actively involving learners, modelling clinical thinking, focusing teaching around the case, and providing explicit direction and feedback. ${ }^{7,8}$ Researchers also have characterized patterns of dialogue during case reviews and identified variables that can alter the division of talk time. They found that the presenter (junior team member) does most of the speaking during the first half of the case review while the supervisor (attending physician) dominates the final quarter. ${ }^{1}$ From the attending's perspective, variables that can alter the ratio of talk time and the discussion topics include the quality of the presentation, the complexity of the case, and the number and type of issues that trigger particular teaching scripts. ${ }^{1,2}$ From the junior team member's perspective, other variables include hierarchical differences, conflicting roles, role ambiguity, and interpersonal conflict. ${ }^{9}$

The morning case review is only one in a complex series of oral and written episodes that also includes the junior team member's admission note and overnight review with the senior resident. The patient care assessment and plan that the teams develops through these conversations and documents in the clinical notes serves as the organizing framework around which all subsequent care takes place during the patient's hospital stay. ${ }^{10}$ Many previous studies of case reviews have focused on the teaching and learning aspects of single episodes of communication 
and have not reflected the complex, intersecting nature of communication in a hospital setting, limiting our understanding of how case review interacts with the whole set of communication practices to shape patient care plans.

Rhetorical genre theory provides a useful lens for understanding how recurring communication practices, or genres, produce social action. Case review discussions and clinical documentation are genres because they recur predictably, involve distinct participant roles and common expectations with regards to structure and purpose(s), and serve to shape both current and future actions.11,12 These genres influence the work the team does together; they make possible certain actions and constrain others. ${ }^{12}$ Additionally, the concept of genre sets, which are combinations of interrelated genres, ${ }^{11}$ such as admission notes, case review discussions, etc., affords a way to analyze how what happens in one genre influences and informs other genres in the set.

As part of a larger study on the impact of case review and documentation practices on patient care, the purpose of this study was to explore case review discussions and examine their influence on the comprehensiveness of case review.

\section{Method}

This study is part of a multiple instrumental case study. The methodology facilitated our exploration of complex, real world phenomena. ${ }^{13}$ The study was conducted with approval from the University of Western Ontario Research Ethics Board for Health Sciences Research Involving Human Subjects.

\section{Setting and participants}

We conducted our study through the internal medicine teaching unit at London Health Sciences Centre, University Hospital in Ontario, Canada. Here, the majority of patients are admitted overnight by the on-call team. This team consists of a senior resident and one junior team member (senior medical student or first-year resident) from each of the three teams at the site. The on-call senior resident performs the overnight case reviews. The attending physician supervises case reviews during morning rounds. The majority of presentations are given by the post-call junior team member (senior medical student or first-year resident).

We recruited participants for our study from the team members on service at the time of our data collection and included 10 attending physicians, 13 senior residents, 19 junior residents, and 14 medical students. To minimize observer effect, we did not disclose the specifics of the study to the participants. ${ }^{14}$ 


\section{Data collection}

We collected data throughout the admission process through direct observation, audio-recording, and chart extraction. We audio-recorded, transcribed, and anonymized both the overnight and morning case review discussions. We also observed the morning case review discussions in person and collected field notes. For each case review discussion, we copied the admission notes from the patient's record and de-identified all data.

We collected data over two eight-week periods (winter and summer of 2010). Our data sampling was purposeful to include factors that may influence case review practices, such as the team to which the patient was admitted, the attending physician, weekday versus weekend admission, level of training of the admitting junior team member (senior medical student versus first-year resident), and team pairings between the senior resident and the admitting junior team member (same versus different teams). The patient cases themselves were a convenience sample-we included all cases admitted during periods when we had consent from the oncall junior and senior residents as well as the team attending.

Our data collection yielded 19 patient cases each consisting of three sources: (1) the note written by the admitting junior team member at the time of admission and subsequent follow-up notes; (2) the overnight oral case review discussion with the senior resident on-call; and (3) the morning case review discussion with the attending physician and team.

\section{Data analysis}

We coded the case review discussion transcripts using a constant comparative analytic method informed by sensitizing concepts including theories of supervisory practice and genre sets. ${ }^{15,16}$ Our analysis explored: (1) the characterization of the interactions between team members, and (2) an assessment of how these interactions impacted the details of the case discussed and the sequence of the case discussion. We next analyzed interactions between team members for recurring patterns. Two of us (MG, LL) reviewed a subset of the transcripts and developed preliminary codes. The other of us (NA) then applied those codes to a portion of the transcripts and consulted with the others to further develop, revise, and refine the codes. We repeated this iterative process of coding and re-coding four times until we had accounted for all key interaction patterns. We then applied the final codes to our full data set using NVivo version 9 (Sydney, Australia) qualitative data analysis software. ${ }^{17}$ Lastly, one of us (MG) reviewed a portion of the final coding to ensure consistency. We resolved discrepancies by returning to excerpt instances in the transcripts and clarifying code language.

We analyzed the impact of team interaction on the comprehensiveness of the case review discussions using both within- and across-case analyses. ${ }^{15} \mathrm{We}$ 
examined case details such as medical history, physical exam findings, and details of the assessment and plan. Our across-case analysis explored commonalities and variations in the case review discussion genre. Our within-case analysis described interaction types and explored their consequences as seen through differences in source content (admission note and on-call case review transcripts versus next morning case review transcripts).

To ensure rigor and increase authenticity in our methodology, we used two kinds of triangulation--investigator triangulation and data triangulation. ${ }^{18,19} \mathrm{We}$ sought analytical rigor using an audit trail and multiple coders; our coding team included an experienced clinician (MG) as well as a non-clinician with expertise in medical communication and team dynamics (LL).

\section{Results}

Our analysis of the case review discussion genre demonstrated that junior team members were expected to present in a standard sequence that largely followed a textbook documentation format (see List 1). ${ }^{20}$ Still, deviations from this sequence were common; sometimes presenters spontaneously introduced these deviations themselves, but often supervisors prompted them by interrupting the presentation. When a presenter introduced the deviation, the supervisor typically redirected the presenter back to the standard sequence.

\section{List 1}

Standard Patient Case Review Presentation Format

1. Patient identification

2. Reason for referral

3. Past medical history

4. Medications and allergies

5. Social history

6. History of presenting illness

7. Review of systems

8. Physical exam findings

9. Results of investigations

10. Assessment and plan 


\section{Interruptions}

In all 19 cases that we analyzed, supervisors created opportunities for teaching and patient care via their "interruptions." We identified five interruption types: (1) probing for further data; (2) prompting for expected sequence; (3) teaching around the case; (4) thinking out loud; and (5) providing direction (see Table 1). Several interruption types served both goals of the case review discussions--teaching and patient care. For example, when thinking out loud, supervisors reasoned through problems and taught the team: "So that's the big question, did she have a mechanical fall, or did she have a medicine-related fall?" (Case 2). Supervisors prompted for expected sequence, preventing presenters from skipping over information, while simultaneously allowing the supervisor to instruct the team on presentation style: "So now you can tell me what the rest of his test results are because I haven't heard those" (Case 16).

While interruptions were an important form of supervisor-presenter interaction, we can best see the effect of these interruptions on the comprehensiveness of the case review discussion by examining their ability to cause "detours." We conceptualized detours to include both purposeful and unintentional deviations from the usual case review discussion presentation sequence. We focus the remainder of our report on these detours.

\section{Detours}

We found detours in all 19 cases (average: 18.3/case). We identified five detour types: (1) pausing the presentation; (2) referring to a section later in the presentation; (3) presenting sections out of sequence; (4) skipping a section or section element; and (5) truncating the presentation (see Table 2). As shown in Table 2, pausing the presentation was the most common detour type (311 instances; average: 16/case) and the only type that appeared always to be intentional.

We found detours to be triggered by all interruption types, as well as a number of other causes (see Tables 1-2). Supervisors' interruptions played a major role in initiating pausing (261 of 311 instances) and truncating the presentation (7 of 7 instances). As presenters used their admission note to guide their presentation, disorganization of this note, as identified by our within-case analysis of the admission note, was another detour trigger. At times, presenters also signalled this in their case review presentation: "I think I missed my investigations because I wrote my note funny" (Case 7).

We found alternative focus to be another contributor to detours. For example, a supervisor's viewing of the electronic patient record while listening to the case review presentation contributed to detours. In Case 13, field notes indicated that when the supervisor interrupted the presentation of the physical to ask about 
ordering a particular test, she was reviewing lab values. Her interruption led to the team skipping the remainder of the physical findings and moving the discussion to the results of other investigations. Other sources of alternative focus, such as the junior or senior resident writing orders during the presentation or being paged, appeared less likely to cause detours.

The main differences between pausing the presentation and the other detour types were detour length and subsequent communication. Following longer pausing type detours, supervisors often used prompting or summarizing to bring the presenter back to the right place in the presentation: "Okay, what are you doing about her diabetes?" (Case 11). Similarly, presenters would use transitional or regrouping statements to get back on track: "Okay, just let me make sure, what else did I have to say about him?" (Case 13). We also found that a well-organized admission note with a clear assessment and plan seemed to help the presenter get back on track.

The following representative case summary provides an example of how detours can arise and their consequences:

The patient, a female in her 80s, is admitted overnight for foot cellulitis. She is seen by a junior resident on the team who identifies five issues: (1) cellulitis, (2) edema, (3) diarrhea, (4) diabetes, and (5) hyponatremia. The junior resident documents a plan for each issue in the admission note. During the overnight case presentation, the team discusses each of these issues.

During the morning case review discussion, the attending interrupts when the presenter mentions diabetes to teach the team about diabetes management. This discussion continues for some time and engages many of the team members. The attending then gives instructions for the team to investigate the patient's newly identified atrial fibrillation before concluding the discussion. The team does not discuss the patient's hyponatremia. (Case 10)

This example illustrates two kinds of detours--pausing and truncating the presentation. The initial pause, triggered by teaching around the case, allowed the attending to teach the team about diabetes management and address the issue of atrial fibrillation. However, as a result of the pause, the presentation is truncated and patient's hyponatremia is not presented or discussed. This instance is representative in that most detours have both potential positive and negative consequences with regards to the team completing a comprehensive review. This example also demonstrates the insight afforded by our collection and analysis of multiple, inter-related, communication episodes--only through analyses across the genre set do potential omissions become visible. 
Table 1

Types of Supervisors' Interruptions during Patient Case Review Presentations*

\begin{tabular}{|c|c|c|}
\hline Type & Description & Example \\
\hline Probing for further data & $\begin{array}{l}\text { Supervisors ask questions about } \\
\text { patient facts, management } \\
\text { details, or clarification }\end{array}$ & $\begin{array}{l}\text { Case } 17 \text {; AM } \\
\text { CC-5: Her hemoglobin was } 94 . \\
\text { A-9: Do we have a previous? } \\
\text { CC-5: Yeah, she had one done at the } \\
\text { cancer clinic. }\end{array}$ \\
\hline $\begin{array}{l}\text { Prompting for expected } \\
\text { sequence }\end{array}$ & $\begin{array}{l}\text { Supervisors indicate what is } \\
\text { expected to come next in the } \\
\text { presentation, either proactively } \\
\text { or as a correction }\end{array}$ & $\begin{array}{l}\text { Case 10; AM } \\
\text { A-3: Cardiovascular exam? } \\
\text { IM1-7: Her cardiovascular exam was } \\
\text { completely normal. }\end{array}$ \\
\hline Teaching around the case & $\begin{array}{l}\text { Supervisors teach the team } \\
\text { using a variety of teaching styles }\end{array}$ & $\begin{array}{l}\text { Case 2; PM } \\
\text { SR-6: So what's the best route to } \\
\text { replace potassium? } \\
\text { CC-4: Orally. } \\
\text { SR-6: Yeah, orally. Do you know why? }\end{array}$ \\
\hline Thinking out loud & $\begin{array}{l}\text { Supervisors convey their } \\
\text { thoughts or provide their inter- } \\
\text { pretation of the case }\end{array}$ & $\begin{array}{l}\text { Case 19; AM } \\
\text { A-10: And common things being } \\
\text { common, I mean, that probably was } \\
\text { the trigger. It'd be highly unlikely that } \\
\text { she's got two independent things. }\end{array}$ \\
\hline Providing direction & $\begin{array}{l}\text { Supervisors give instructions for } \\
\text { managing the case. }\end{array}$ & $\begin{array}{l}\text { Case 14; AM } \\
\text { A-4: He's going to need prolonged IV } \\
\text { antibiotics, probably } 6 \text { weeks if he's } \\
\text { true osteo and someone's going to } \\
\text { need to follow that. }\end{array}$ \\
\hline
\end{tabular}



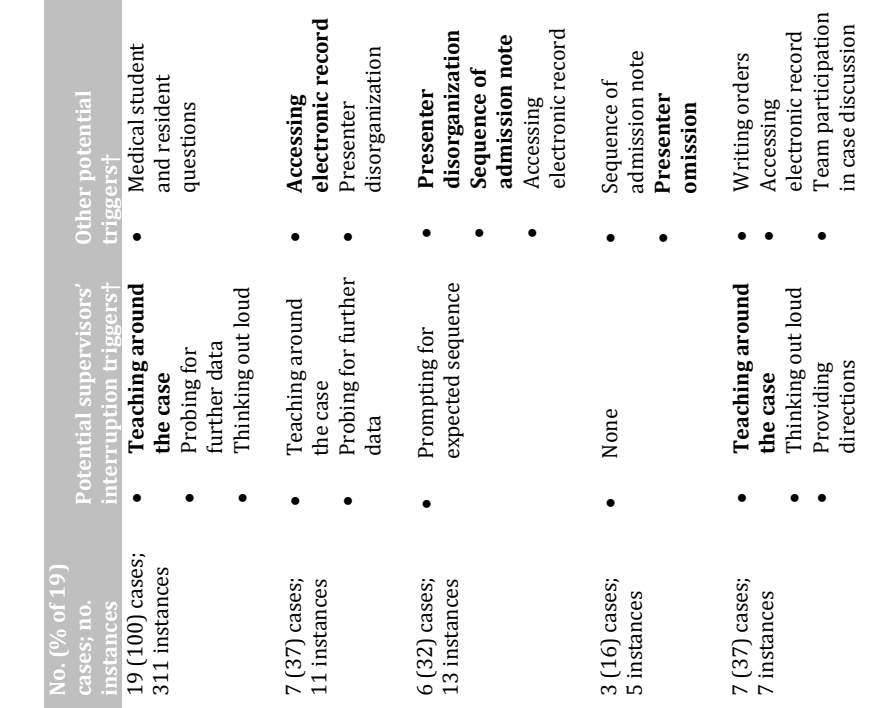

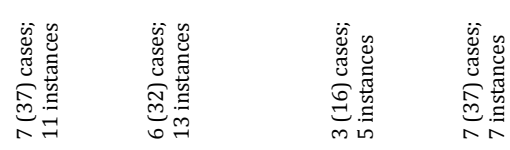

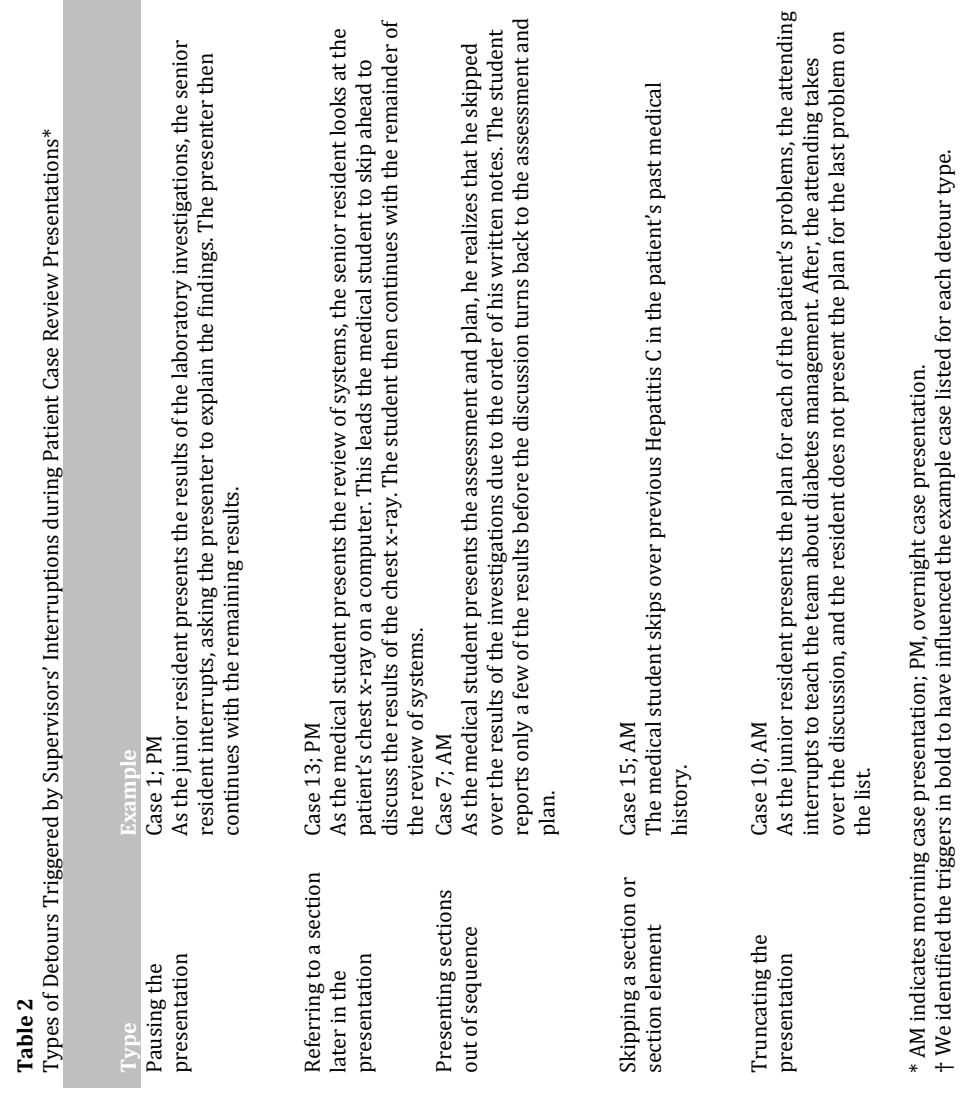




\section{Omissions}

We defined "omissions" as instances in which relevant information from the admission note and/or the overnight case review discussion was not included in the morning case review discussion. Omissions included skipping medical problems, not reporting patient data (e.g. results of laboratory investigations), and not discussing plans for some of the patient's medical problems. Detour types varied in their likelihood to cause omissions. Pausing the presentation did not result in any omissions in our dataset. Referring to a section later in the presentation resulted only in a few omissions, as the team generally repeated these details in the appropriate section. While both presenting sections out of sequence and skipping a section or section element did cause omissions, their impact on information sharing was difficult to gauge since they involved omissions of unknown significance, such as omitting the social history. In comparison, truncating the presentation could lead to the team omitting from the discussion one or more of the patient's active medical problems. These detours typically occurred at the impression and plan stage of the case review presentation if the supervisor took control of the discussion. We found truncating the presentation to be the result of an interruption by an attending rather than a senior resident in 6 of 7 instances. Some instances of truncating the presentation evolved from other detour types. For example, pausing the presentation for teaching could lead to truncating the presentation when the supervisor remained in control of the discussion.

\section{Discussion}

Our study builds on prior research, including explorations of attendings' teaching scripts during case review discussions, studies of supervisor interruptions and questioning-strategies, and analyses of the oral case presentation genre. 1,2,7,8,21-23 $^{-1}$ The innovation in our study arises from the theoretical lens of genre sets that we used, which afforded us the opportunity to analyze how communication episodes intersect and the impact of particular patterns of supervisors' practices on the comprehensiveness of case review discussions. The five interruption types that we identified are consistent with prior research describing features of supervisors' interruptions, such as frequency, ${ }^{21}$ types of utterances, ${ }^{22}$ and the role of supervisors' questions in assessing competence. ${ }^{23}$ Additionally, many of the supervisors' interruptions in our study exhibited a "dual focus on the patient and the learner."2 However, we also found that interruptions can lead to detours, which can have both positive and negative effects on the comprehensiveness of the case review.

We found detours to be a pervasive and essential element of case review discussions--they provided the supervisor an opportunity to interrupt the case 
review presentation to teach, gather more information on the patient, and guide the team. However, detours also caused the presenter to omit details. Even those detours that included established features of good teaching, such as being anchored in the case and actively involving learners, ${ }^{7,8}$ could result in omissions.

Questions critical to interpreting our results include: Are supervisors in control of the case review genre? Are they aware that detours can lead to omissions? Are omissions purposeful and deliberate? During case review discussions, supervisors must balance being detail-oriented, working efficiently, and finding time for teaching. ${ }^{24}$ With the exception of pausing the presentation, we found no explicit evidence that supervisors recognized or intended to omit details as the result of a detour. We expect that some of the omissions that we observed were likely remedied by the supervisors outside the case review discussion. According to Kennedy and colleagues, not all work done by attending physicians is front-stage; they also employ "back stage" oversight strategies to ensure patient safety while giving trainees an experience of independence. ${ }^{25}$ We did not capture these backstage strategies in our study because we did not observe supervisors outside of case review discussions. The supervisors in our study may indeed have attended to the details omitted in case review discussions by reviewing the patient's chart in advance or addressing them at a later time.

However, recent attention in the literature to the issue of "team competence" led us to question teams' reliance on the "attending-with-a-master-plan" approach to comprehensive patient care. ${ }^{26,27}$ Case review is an important time for the whole team to develop and document a shared understanding of the patient's problems. ${ }^{10}$ The well-documented problems with handoff, continuity of care, and clinical documentation further highlight the importance of case review as a time for building this shared understanding. ${ }^{9,28-30}$ While supervisors might choose to focus a particular case review on teaching rather than on a comprehensive discussion of the complete patient problem list, we did not observe any supervisors explicitly indicating this strategy, nor did we observe a team discussion of their expectations regarding omitted items. Therefore, we concluded that junior team members were left to interpret omissions, should they notice them at all, in a variety of ways--as essentially unimportant patient details, as unimportant right now in the care trajectory, or as low priority for discussing in the case review but high priority for capturing at another time, such as in the progress note. Past research suggests that these novice interpretations of such tacit issues may have unintended consequences. ${ }^{31}$

\section{Limitations}

Our study has several limitations. It was conducted at a single institution and focused on the two admission case review discussions (overnight and morning); other departments and institutions may have different review practices, triggers, 
and strategies for handling detours, so our results may not apply outside our institution. Broadening the observational scope of our study to include shadowing attendings throughout the day and various handoff conversations would allow us to expand the genre set included in our study, providing more insight into how team members strategically use the whole genre set to balance effective teaching and appropriate patient care planning.

\section{Recommendations for improving future case review discussions}

We cannot establish the full impact of omitting patient details from case review discussion on actual patient care from our findings alone. However, in a larger study, of which this study is a part, we identified that the details not discussed during case review can lead to medical error and decreased quality of care, especially if those details are also not accurately documented. ${ }^{10}$ Because patients with multiple medical problems appear to be at a higher risk for omissions and subsequent errors in their care, ${ }^{4}$ supervisors should pay special attention to these cases. To mitigate the risk of omissions arising from detours, supervisors should avoid interruptions in the middle of the presentation of the assessment and plan or develop strategies for returning to the presentation when such interruptions are deemed necessary. While prior research has noted that clinical supervisors tend to dominate this later stage of the case presentation, ${ }^{1}$ we found that this shift of control is accompanied by the potential omission of salient patient problems during case review. Reflecting on this finding, we propose adding a fourth step to the iterative set outlined by Irby $^{2}$ for supervising physicians--diagnose the patient, diagnose the learner, teach, and monitor the case review presentation genre to ensure that relevant details and problems are not omitted. As part of this step, supervisors should use strategies such as prompting and summarizing to reorient the presenter following an interruption. While we observed some junior team members also playing a role in this monitoring, prior research has shown that hierarchical differences, conflicting roles, and role ambiguity influence who will take charge of such strategies within the team. ${ }^{9}$ We therefore advocate that the supervisor should take responsibility for this extra step. We hope that this monitoring will support supervisors in ensuring that their case reviews provide comprehensive guidance to the team and avoid unintentional omissions.

\section{Acknowledgments:}

The authors thank Dr. David Irby for his useful commentaries on an earlier draft of this research report. 


\section{Support/Funding:}

Summer Research Training Program, University of Western Ontario, Schulich School of Medicine \& Dentistry, and The Academic Medical Organization of Southwestern Ontario

\section{Ethical Approval:}

Granted by the University of Western Ontario Research Ethics Board for Health Sciences Research Involving Human Subjects.

Previous Presentations: The abstract of an earlier version of this research report was presented at the Centre for Education Research \& Innovation 2011 Annual Research Symposium, October 2011, London, Ontario, Canada, and at the Canadian Conference on Medical Education, April 2012, Banff, Alberta, Canada.

\section{References}

(1) Spafford MM, Schryer CF, Mian M, Lingard L. Look who's talking: teaching and learning using the genre of medical case presentations. Journal of Business and Technical Communication. 2006;20:121-158.

(2) Irby DM. How attending physicians make instructional decisions when conducting teaching rounds. Acad Med. 1992;67:630-638.

(3) Vogeli C, Shields AE, Lee TA et al. Multiple chronic conditions: prevalence, health consequences, and implications for quality, care management, and costs. J Gen Intern Med. 2007;22 Suppl 3:391-395.

(4) Hayward RA, Asch SM, Hogan MM, Hofer TP, Kerr EA. Sins of omission: getting too little medical care may be the greatest threat to patient safety. J Gen Intern Med. 2005;20:686-691.

(5) Singh H, Thomas EJ, Petersen LA, Studdert DM. Medical errors involving trainees: a study of closed malpractice claims from 5 insurers. Arch Intern Med. 2007;167:2030-2036.

(6) Dunlay SM, Redfield MM, Weston SA. Hospitalizations after heart failure diagnosis a community perspective. J Am Coll Cardiol. 2009;54:1695-1702.

(7) Irby DM, Ramsey PG, Gillmore GM, Schaad D. Characteristics of effective clinical teachers of ambulatory care medicine. Acad Med. 1991;66:54-55.

(8) Irby DM. Three exemplary models of case-based teaching. Acad Med. 1994;69:947-953.

(9) Sutcliffe KM, Lewton E, Rosenthal MM. Communication failures: an insidious contributor to medical mishaps. Acad Med. 2004;79:186-194. 
(10) Goldszmidt M, Dornan T, Lingard L. Fragmented communication: understanding a common threat to quality patient care on medical teaching units. Manuscript currently in preparation.

(11) Devitt AJ. Writing Genres. Carbondale, IL: Southern Illinois University Press; 2004.

(12) Miller CR. Genre as social action. Quarterly Journal of Speech. 1984;70:151167.

(13) Stake RE. The Art of Case Study Research. Thousand Oaks, CA: Sage Publications; 1995.

(14) Hammersley M, Atkinson P. Ethnography: Principles in Practice. 3rd ed. Milton Park, Abingdon, Oxon: Routledge; 2007.

(15) Eisenhardt KM. Building theories from case study reasearch. Academy of Management Review. 1989;14:532-550.

(16) Bowen G. Grounded theory and sensitizing concepts. International Journal of Qualitative Methods. 2006;5:12-22.

(17) Bringer JD, Johnston LH, Brackenridge CH. Using computer-assisted qualitative data analysis software to develop a grounded theory project. Field Methods. 2006;18:245-266.

(18) Thurmond VA. The point of triangulation. J Nurs Scholarsh. 2001;33:253-258.

(19) Denzin NK. The Research Act: A Theoretical Introduction to Sociological Methods. New Brunswick, NJ: Aldine Transaction; 2009.

(20) Bickley LS, Szilagyi PG, Bates B. Bates' Guide to Physical Examination and History-Taking. 9th ed. Philidelphia, PA: Lippincott Williams \& Wilkins; 2007.

(21) Yang G, Chin R. Assessment of teacher interruptions on learners during oral case presentations. Acad Emerg Med. 2007;14:521-525.

(22) Jackson JL, O'Malley PG, Salerno SM, Kroenke K. The teacher and learner interactive assessment system (TeLIAS): a new tool to assess teaching behaviors in the ambulatory setting. Teach Learn Med. 2002;14:249-256.

(23) Kennedy TJ, Lingard LA. Questioning competence: a discourse analysis of attending physicians' use of questions to assess trainee competence. Acad Med. 2007;82:S12-S15.

(24) Lingard L, Schryer C, Garwood K, Spafford M. 'Talking the talk': school and workplace genre tension in clerkship case presentations. Med Educ. 2003;37:612-620.

(25) Kennedy TJ, Lingard L, Baker GR, Kitchen L, Regehr G. Clinical oversight: conceptualizing the relationship between supervision and safety. J Gen Intern Med. 2007;22:1080-1085.

(26) Lingard L. What we see and don't see when we look at 'competence': notes on a god term. Adv Health Sci Educ Theory Pract. 2009;14:625-628.

(27) Lingard L. Rethinking Competence in the Context of Teamwork. In: Hodges B, Lingard L, eds. The Question of Competence. Ithaca, NY: Cornell; 2012. 
(28) Arora V, Johnson J, Lovinger D, Humphrey HJ, Meltzer DO. Communication failures in patient sign-out and suggestions for improvement: a critical incident analysis. Qual Saf Health Care. 2005;14:401-407.

(29) Petersen LA, Brennan TA, O'Neil AC, Cook EF, Lee TH. Does housestaff discontinuity of care increase the risk for preventable adverse events? Ann Intern Med. 1994;121:866-872.

(30) Kaplan DM. Perspective: Whither the problem list? Organ-based documentation and deficient synthesis by medical trainees. Acad Med. 2010;85:1578-1582.

(31) Lingard LA, Haber RJ. What do we mean by "relevance"? A clinical and rhetorical definition with implications for teaching and learning the casepresentation format. Acad Med. 1999;74:S124-S127. 


\section{CHAPTER 6}

\section{Developing a Unified List of Physicians' Reasoning Tasks During Clinical Encounters}




\section{Abstract}

Purpose: The clinical reasoning literature focuses on how physicians reason while making decisions, rather than on what they reason about while performing their clinical tasks. In an attempt to provide a common language for discussing, teaching, and researching clinical reasoning, the authors undertook the task of developing a unified list of physicians' reasoning tasks, or what they reason about, during clinical encounters.

Method: The authors compiled an initial list of 20 reasoning tasks based on the literature from four content areas--clinical reasoning, communications, medical errors, and clinical guidelines. In the summer and fall of 2010, they surveyed a purposive sample of 46 international experts in clinical reasoning and communications. From the results of the first survey, the authors refined their list of reasoning tasks, then resurveyed 22 of the original participants. From the results of the second survey, they further refined their list and validated the inclusion of the reasoning tasks.

Results: Twenty-four of $46(52 \%)$ and 15 of 22 (65\%) participants completed the first and second round surveys respectively. Following the second round survey, the authors' list included 24 reasoning tasks, and a clinical example corresponding to each, that fell into four broad categories: framing the encounter (3); diagnosis (8); management (11); and self-reflection (2).

Conclusions: The development of this unified list represents a first step in offering a vocabulary for discussing, reflecting on, teaching, and studying physicians' reasoning tasks during clinical encounters.

Published as:

Goldszmidt, Mark, Minda, John Paul, and Bordage, Georges. Developing a Unified List of Physicians' Reasoning Tasks During Clinical Encounters. Acad Med 88(3), 390-397. 2013.

(C) 2013 the Association of American Medical Colleges 


\section{Introduction}

During clinical encounters, physicians engage in numerous clinical tasks, including: listening to the patient's story; reviewing his or her past records; performing a physical examination; choosing the appropriate investigations; providing advice or prescribing medications; and/or ordering a consultation. These behaviors are driven, or at least influenced, by "what" physicians think about and "how" they think. Since Elstein, Shulman, and Sprafka's 1978 seminal book on medical problem solving, numerous studies on clinical reasoning and expertise in medicine have been published.1,2 This line of research has led to important insights on how novice and expert physicians reason during clinical encounters. Eva categorized these various reasoning processes under two broad umbrellas: non-analytical and analytical processes. ${ }^{3}$ Non-analytical processes are automatic and unconscious, such as pattern recognition. Conversely, analytical processes are deliberate and detailed, such as hypothetico-deductive reasoning that involves the generation and testing of a set of hypotheses around a set of clinical data. Still, no one has published a comprehensive list of what physicians reason about during a clinical encounter, such as the precipitants or triggers to the current clinical problem or the impact of the available resources on the treatment options.

In an attempt to provide a common language for discussing, teaching, and researching clinical reasoning, we undertook the task of developing a unified list of physicians' reasoning tasks during clinical encounters. We purposefully distinguished between clinical tasks, reasoning tasks (the what), and the process of reasoning (the how). A clinical task is something that a physician does, such as eliciting a history, performing a physical examination, or ordering a consultation. A reasoning task is what a physician reasons about while performing a clinical task. The process of reasoning is the cognitive process in which a physician engages for the purpose of completing a clinical task. For example, in reviewing the results of numerous investigations and the report from a consultation (i.e., clinical tasks), a physician may consider the possible impact of the patient's co-morbid conditions while at the same time also considering the resources available for his or her treatment (i.e., reasoning tasks), using pattern recognition or decision analysis (i.e., processes of reasoning). While a physician's knowledge base, skills, and values each exert an influence on how well he or she performs clinical and reasoning tasks, we considered those attributes to be separate but related issues and did not address them in the present study.

Having a unified list of physicians' reasoning tasks for practice, teaching, and research in medicine is important for a number of reasons. For example, a large number of patients suffer from multiple co-morbidities, ${ }^{4-6}$ and research suggests that medical teams do not adequately address these patients' co-morbid medical 
problems when admitting them to the hospital, thus many of these patients are readmitted at a later date. ${ }^{7,8}$ While many factors contribute to such diagnostic and management errors, a physician's failure to consider his or her patient's chronic active diseases--a reasoning task--may play an important role. During clinical patient safety audits or teaching rounds, explicitly considering this particular reasoning task could help physicians improve their practice. The literature supports that physicians frequently learn reasoning tasks tacitly through the case presentation and clinical documentation genres.9-11 However, research also suggests that, at some institutions, the apparent purpose of the case presentation may be too focused on defending a diagnosis, which may hinder the learning of other reasoning tasks. ${ }^{11}$ While most physicians likely recognize that reasoning tasks completed during clinical encounters extend beyond diagnosis, the lack of a shared language for describing and labeling these tasks may perpetuate this misconception and hinder efforts to teach trainees the broader spectrum of reasoning tasks. As a first step in addressing this problem, the purpose of this study was to develop a unified list of what physicians reason about during clinical encounters.

\section{Method}

In the summer and early fall of 2010, we conducted a two-stage validation study by surveying a group of 46 international experts in clinical reasoning or communications in health care. Using a thematic summary of the existing literature, we created an initial list of reasoning tasks, then, using our two surveys, we modified it and validated the final list. We obtained ethics approval from the Psychology Research Ethics Board at the University of Western Ontario and the Research Ethics Board at the University of Illinois at Chicago. We conducted this study with local departmental funds and guaranteed confidentiality to participants.

\section{Initial list of reasoning tasks}

While no one publication comprehensively identifies the reasoning tasks completed during clinical encounters, many discrete sources include fragmented lists. We compiled our initial list by searching four relevant content areas from the literature. We include here only those exemplary and/or key references from these topic areas: communications, ${ }^{12,13}$ medical errors, ${ }^{7,14,15}$ clinical reasoning, ${ }^{1,16,17}$ and clinical guidelines. We chose these references because they most shaped our thinking on the topic and conveyed best our rationale for including one or more of the reasoning tasks that we identified on our list. We further modified this list and thematically organized the reasoning tasks through a formal iterative discussion process among the coauthors. We then piloted the list with four experienced physician colleagues familiar with the clinical reasoning and communications 
literature, and further edited the list based on their feedback (see Column 1, Appendix 1 for our initial list).

\section{Participants}

During the first round of our study, we contacted 46 international experts. We chose these experts because each had published scholarly work in either clinical reasoning or communications in health care. We also included a purposeful mix of physician and non-physician researchers in this group. In the second round of our study, we invited only half the original participants because of the high degree of consensus that they reached during the first round and to minimize the burden on them. This second group was again purposively selected based on our knowledge of their areas of scholarship and to ensure that we included a mix of physician and non-physician researchers.

\section{Procedure}

During the first round of our study, we contacted each participant via email and sent a reminder two weeks later. In the email, we directed participants to a webbased survey that included instructions to complete the first survey. This first page of the survey also contained an explanation of the purpose of our study and the full list of reasoning tasks, organized into three thematic sections (i.e., framing the encounter, diagnosis, and management) (see Column 1, Appendix 1). We also asked participants to review and consider printing the list of reasoning tasks to ensure that they answered each question in the context of the complete list. On the second page of the survey, we asked participants to list their professional qualifications.

For each reasoning task, we gave participants the following statement: "The reasoning task $\mathrm{X}$ should appear on the final list of reasoning tasks in which physicians may engage during the course of a clinical encounter." The answer options were: (a) yes as written; (b) yes with alternative wording; (c) no; or (d) unable to judge. We also provided participants with a comment box to suggest alternative wording. At the end of the survey, we asked participants to suggest additional tasks that we had not included.

During the second round of our study, we considered the suggestions made during the first round and modified our list of reasoning tasks accordingly. To improve the clarity of each survey item, we also added a relevant clinical example for each reasoning task then sent a new email to half the original participants. This second survey included the same set of questions regarding each reasoning task as the first survey.

All survey responses were anonymous. 


\section{Results}

Of the original 46 participants invited to complete our first survey, 30 replied. Of those 30 participants, three indicated that they were unable to participate (insufficient expertise, maternity leave, and sabbatical leave), 27 began the survey, and 24 completed it, for an overall response rate of 52\% (24/46). The respondents represented a variety of backgrounds with just over one third (9/24) having a doctoral degree and two thirds (16/24) having a medical degree; six participants $(25 \%)$ had more than one degree. The majority of physician respondents $(13 / 16)$ had trained in either internal medicine or family medicine, and just over half of the doctoral respondents (5/9) came from cognitive psychology. The percentage of respondents with doctoral and/or medical degrees closely matched that in the original group of invited participants (i.e., $38 \%$ vs. $28 \%$ with doctoral degrees and $67 \%$ vs.72\% with medical degrees).

The main findings from our study are included in Appendix 1, which contains the original list of 20 proposed reasoning tasks (Column 1), the final list of 24 reasoning tasks (Column 2), and a set of illustrative case examples (Column 3) intended to help readers better understand our intent behind each reasoning task as well as the distinctions between tasks. For the purpose of clarity, we listed each task under only the one category (framing the encounter, diagnosis, management, or self-reflection) that we felt best captured the overall intent of the reasoning task.

Our original list included 20 proposed reasoning tasks, organized into three categories (framing the encounter, diagnosis, and management) (see Column 1, Appendix 1). On average, $83 \%$ of respondents (20/24) agreed with the inclusion of all 20 original tasks (standard deviation (SD) $=12$; range $=50-100$; see Column 5 , Appendix 1 for details). On average, 25\% (6/24) made suggestions regarding the wording used to describe each task ( $\mathrm{SD}=14$; range $=8-54$ ). We made changes to the wording of all 20 reasoning tasks based on this feedback following the first round survey. We followed respondents' suggestions based on their ability to add clarity to the task (see Appendix 1 for the changes to wording between the original list and the final list). We followed additional suggestions from the respondents and added two new reasoning tasks to the list for the second round survey.

of the 22 participants who we invited to complete the second round survey, 19 began the survey and 15 completed it (68\% response rate). Respondents again came from a variety of backgrounds: $6(40 \%)$ had a doctoral or master's degree, 12 $(80 \%)$ had a medical degree, and $6(40 \%)$ had dual degrees. Again, the percentages of respondents with doctoral and medical degrees were similar for respondents and invited participants. Several of the participants contacted $(3 / 22)$ who did not have a medical background felt that they could not complete the second round survey.

During the second round survey, 97\% of respondents (14/15) agreed with the list of proposed reasoning tasks $(S D=4$; range $=93-100$; see Column 7, Appendix 1 
for details). Twelve of the 22 tasks (55\%) had unanimous approval. Compared to the first round survey, respondents made approximately half as many suggestions regarding wording $(2 / 15,13 \%, \mathrm{SD}=11$, range $=0-33)$. Moreover, of the changes suggested, many were related to the examples rather than to the reasoning tasks themselves. Based on this feedback, we made wording changes to 17 of the 22 reasoning tasks. The majority of these changes were more minor than the substantive changes we made as a result of the first round survey. For example, we changed Task 6 from "identifying or determining potential alternatives for diagnostic workup (investigation)" to "determine diagnostic investigations" following the first round survey, and to "select diagnostic investigations" following the second round survey. The respondents' comments and suggestions also resulted in the addition of two new tasks. While the group of expert reviewers did not validate these new items, we felt that they were well supported by the literature and had appropriate implications for shaping and studying clinical practice. Because the two additional items did not fit under the three original categories (i.e., framing the encounter, diagnosis, and management), we added a fourth category--selfreflection. Our final list thus included 24 reasoning tasks.

\section{Discussion}

The purpose of our study was to begin to develop a unified list of physicians' reasoning tasks during clinical encounters. Our two-round validation study resulted in the identification and initial validation of 24 reasoning tasks. What is unique about this list is not the items themselves but rather that we compiled them into a unified list and separated reasoning tasks from reasoning processes, instead of considering them as a single construct, as others often do. For example, many studies have focused on diagnostic reasoning as if it were a single entity1,3,18; our list however contains eight related but distinct diagnostic reasoning tasks. Past research has shown the importance of case specificity with regards to diagnosis and management. ${ }^{19}$ Case specificity may also extend to the reasoning task level (i.e. a student knowing how to determine that the most likely diagnosis is heart failure does not predict his or her ability to consider the implications of managing heart failure in the context of the patient's chronic kidney disease). While further validation is needed, we hope that the development of this list of reasoning tasks will allow physicians, teachers, and researchers to begin to expand their thinking about clinical reasoning. The proposed list has the potential to impact clinical practice and teaching as well as future education and clinical research. 


\section{Clinical practice}

In many jurisdictions, regulatory bodies require physicians to reflect on their practice or conduct practice audits to ensure that they maintain their competence. Whether or not it is required, many physicians still regularly spend time reflecting on their practice and identifying personal learning needs. To this end, we envision that a motivated practitioner might use our list of reasoning tasks to reflect on the extent to which she regularly addresses the various items, when warranted, during clinical encounters. For example, as we indicated earlier, reflecting on the reasoning tasks involved in caring for patients with multiple co-morbidities would be beneficial to physicians.6,7 Several reasoning tasks directly relate to this issue and may prompt physicians to question their tacit assumptions about what and how they reason when seeing this particular group of patients. ${ }^{20,21}$ For those who work in interprofessional teams, the list may also be useful in clarifying role expectations. For example, in caring for a patient with new onset diabetes who needs to learn about managing a diabetic diet, Task 19 ("select education and counseling approach for patient and family") could prompt the physician to involve the team's dietician. While some physicians might be tempted to turn our list of reasoning tasks into a checklist to follow during clinical encounters, at this stage in its development, we do not support this use.

\section{Teaching}

We envision several uses for this list in teaching, including supporting teachers while thinking aloud during case review to foster student learning. Many physician teachers have only a tacit understanding of the reasoning tasks of a clinical encounter. ${ }^{20}$ By providing them with a standardized vocabulary and a list of the possible tasks that are part of their case-based teaching, they may be better able to reflect on and think aloud about their own reasoning18; this reflection is an essential step in practicum-based professional education. ${ }^{21}$ In addition, the list may help students both to develop a deeper understanding of the multiple purposes of the clinical encounter and to connect the process skills of communication with the purpose of communication in the context of the clinical encounter. For example, the first communication step that a student must take is to initiate the encounter. ${ }^{13,22}$ As part of framing the encounter during this initial phase, we identified three related reasoning tasks--identify active issues, assess priorities, and re-prioritize based on assessment. A teacher could use these reasoning tasks to explore specific issues, such as how and when a physician should introduce health maintenance, screening, or smoking cessation into a clinical encounter, or how many issues a physician can and should address during an encounter and how he or she should prioritize them. Finally, the list also can be used to help students categorize the information that they learned in the classroom or from textbooks in such a way as to enhance their ability to use that information in the clinical setting. ${ }^{23}$ For example, 
students could connect the content of a didactic lesson on the pharmacological principles of drug interactions with their consideration of "the consequences of management on co-morbid illnesses" (Task 15).

\section{Education research}

Each of the teaching suggestions above also should be studied in terms of their impact on learning and practice. In addition, other important related research questions include: "Do particular history taking and case presentation practices support or deflect attention from certain reasoning tasks?" and "Does teaching students to approach patient care with these tasks in mind lead them to provide more comprehensive care than their current level of education would otherwise do?"

\section{Clinical research}

Those researchers who are interested in quality assurance and reducing medical errors may use the list in their root cause analyses to explore the extent to which certain error types are related either to framing errors or to the failure of physicians or clinical teams to address particular issues, such as those related to Tasks 14 and 15 (consider the impact of co-morbid illnesses on management and consider the consequences of management on co-morbid illnesses). In addition, in a recent article, Ely and colleagues proposed using a checklist to enhance physicians' cognitive approaches to clinical encounters to reduce medical errors. ${ }^{24}$ Our list of reasoning tasks could help identify or refine items for such a checklist.

\section{Further research and limitations}

While our results have implications for current practice, they also represent the first step in building a unified list of reasoning tasks in medicine. Our list can, and should, be expanded in a number of ways. In developing the list itself, we made no attempt to identify or define the number of times that any task, or set of tasks, might be performed during a typical encounter or the sequence and relative hierarchy of each task in a given encounter. An appropriate next step in expanding our list would therefore be to study physicians in practice both to further validate our list and to begin to identify the relative influence of particular reasoning tasks on physicians' actions. Next, physicians may experience negative consequences when they engage in clinical encounters that require them to address specific reasoning tasks or multiple tasks at once. For example, Durning and colleagues recently examined the influence of context on clinical reasoning and cognitive load. 25,26 By linking how physicians think with what they reason about, we can expand Durning and colleagues' work and ask research questions like: (1) How do physicians handle the cognitive load of multiple reasoning tasks during a clinical 
encounter?; (2) Do physicians more frequently ignore certain tasks as a strategy for handling cognitive load?; and (3) How do physicians handle the inherent multitasking and task-switching--going from one task to another--during a clinical encounter?

While we know that physicians assume a variety of roles outside their one-onone interactions with patients, the focus of our study was the reasoning tasks associated with those types of clinical encounters. As such, one of the limitations of our study is that our list of reasoning tasks does not represent all clinical reasoning tasks in all clinical contexts. For example, different reasoning tasks are associated with performing a surgery or running a busy emergency room than with caring for patients one on one. Therefore, we recommend that future research focus on broadening our list to include the reasoning tasks involved in these situations as well. Similarly, our list is not intended to provide a language for communicating with patients. While we consider many of the reasoning tasks to be patientcentered, the language that we used represents what physicians reason about, not what they say. Next, while we developed clinical examples associated with each reasoning task to provide clarity, users should not be constrained by these examples, as each reasoning task can lead a physician down many different paths of inquiry. For example, a patient being seen for health prevention or maintenance would yield a set of different clinical examples than would a patient presenting with a new problem in the context of prior active ones.

In conclusion, the development of this unified list represents a first step in offering a language for discussing, reflecting on, and studying what physicians reason about during clinical encounters. While our list has many potential uses in current clinical practice and teaching, it also provides avenues for future research in clinical reasoning.

\section{Acknowledgments:}

The authors wish to express their gratitude to the survey participants for their thoughtful comments and suggestions; and to Drs. Judy Bowen, Peter McLeod, and Jeroen Merrienboer for their useful commentaries on an earlier draft of this report.

\section{Ethical approval:}

The authors obtained ethics approval from the Psychology Research Ethics Board at the University of Western Ontario and the Research Ethics Board at the University of Illinois at Chicago. 


\section{References}

(1) Elstein AS, Shulman LS, Sprafka SA. Medical problem solving: an analysis of clinical reasoning. Cambridge, MA: Harvard University Press; 1978.

(2) Norman G. Research in clinical reasoning: past history and current trends. Med Educ. 2005;39:418-427.

(3) Eva KW. What every teacher needs to know about clinical reasoning. Med Educ. 2005;39:98-106.

(4) Fried LP. Establishing benchmarks for quality care for an aging population: caring for vulnerable older adults. Ann Intern Med. 2003;139:784-786.

(5) Safford MM, Allison JJ, Kiefe CI. Patient complexity: more than comorbidity. the vector model of complexity. J Gen Intern Med. 2007;22 Suppl 3:382-390.

(6) Marengoni A, Rizzuto D, Wang HX, Winblad B, Fratiglioni L. Patterns of chronic multimorbidity in the elderly population. J Am Geriatr Soc. 2009;57:225-230.

(7) Hayward RA, Asch SM, Hogan MM, Hofer TP, Kerr EA. Sins of omission: getting too little medical care may be the greatest threat to patient safety. J Gen Intern Med. 2005;20:686-691.

(8) Pitt B. Male gender, diabetes, COPD, anemia, and creatinine clearance $<30$ $\mathrm{mL} / \mathrm{min}$ predicted hospitalization after heart failure diagnosis. Ann Intern Med. 2010;152:JC4-2, JC4-3.

(9) Lingard L, Haber RJ. Teaching and learning communication in medicine: a rhetorical approach. Acad Med. 1999;74:507-510.

(10) Miller C. Genre as social action. Quarterly Journal of Speech. 1984;70:151-167.

(11) Montgomery K. Doctors' stories: the narrative structure of medical knowledge. Princeton, NJ: Princeton University Press; 1991.

(12) Lipkin M, Putnam SM, Lazare A. The medical interview: clinical care, education, and research. New York, NY: Springer-Verlag; 1995.

(13) Kurtz SM, Silverman J, Draper J. Teaching and learning communication skills in medicine. 2nd ed. Oxford: Radcliffe Publishing; 2005.

(14) Bordage G. Why did I miss the diagnosis? Some cognitive explanations and educational implications. Acad Med. 1999;74(10 Suppl):S138-S143.

(15) Graber ML, Franklin N, Gordon R. Diagnostic error in internal medicine. Arch Intern Med. 2005;165:1493-1499.

(16) Higgs J, Jones M. Clinical reasoning in the health professions. 2nd ed. Oxford: Butterworth-Heinemann; 2000.

(17) Montgomery K. How doctors think: clinical judgement and the practice of medicine. Oxford: Oxford University Press; 2006.

(18) Bowen JL. Educational strategies to promote clinical diagnostic reasoning. $\mathrm{N}$ Engl J Med. 2006;355:2217-2225.

(19) Norman G, Bordage G, Page G, Keane D. How specific is case specificity? Med Educ. 2006;40:618-623. 
(20) Schön DA. The reflective practitioner: how professionals think in action. New York, NY: Basic Books; 1983.

(21) Schön DA. Educating the reflective practitioner: towards a new design for teaching and learning in the professions. San Francisco, CA: Jossey-Bass; 1987.

(22) Kurtz S, Silverman J, Benson J, Draper J. Marrying content and process in clinical method teaching: enhancing the Calgary-Cambridge guides. Acad Med. 2003;78:802-809.

(23) Schwartz DL, Bransford JD, Sears D. Efficiency and innovation in transfer. In: JP Mestre, ED. Transfer of learning from a modern multidisciplinary perspective. Greenwich, CT: IAP; 2005.

(24) Ely JW, Graber ML, Croskerry P. Checklists to reduce diagnostic errors. Acad Med. 2011;86:307-313.

(25) Durning S, Artino AR Jr, Pangaro L, van der Vleuten CP, Schuwirth L. Context and clinical reasoning: understanding the perspective of the expert's voice. Med Educ. 2011;45:927-938.

(26) Durning SJ, Artino AR, Boulet JR, Dorrance K, van der Vleuten C, Schuwirth L. The impact of selected contextual factors on experts' clinical reasoning performance (does context impact clinical reasoning performance in experts?). Adv Health Sci Educ Theory Pract. 2012;17;65-79. 


\section{Appendix}

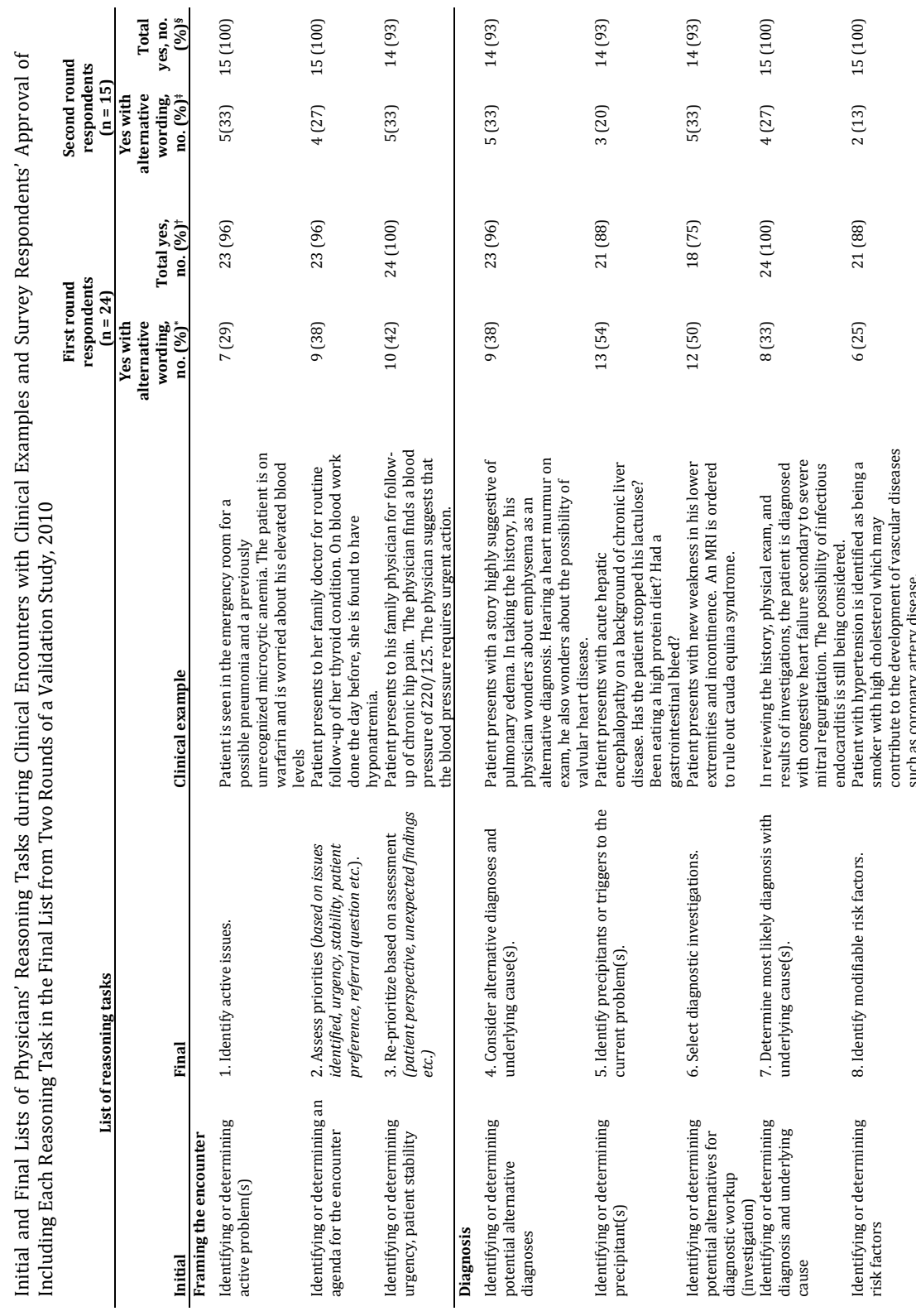


CHAPTER 6

\begin{tabular}{|c|c|c|c|c|c|}
\hline 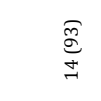 & 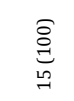 & 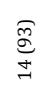 & 淧 & 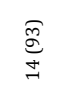 & 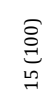 \\
\hline$\stackrel{\widetilde{g}}{\mathrm{v}}$ & $\frac{\bar{g}}{N}$ & $\underset{\mathrm{O}}{\mathrm{N}}$ & $\underset{-}{E}$ & $\underset{-}{E}$ & $\underset{J}{E}$ \\
\hline$\stackrel{\mathbb{D}}{\vec{\sigma}}$ & $\frac{\sqrt{\mathbf{m}}}{\vec{N}}$ & 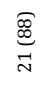 & 㩊 & $\stackrel{g}{z}$ & $\stackrel{g}{\sharp}$ \\
\hline 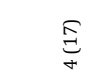 & 爵 & 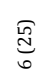 & $\frac{\sqrt{3}}{0}$ & $\stackrel{\Xi}{\Xi}$ & $\cong$ \\
\hline
\end{tabular}

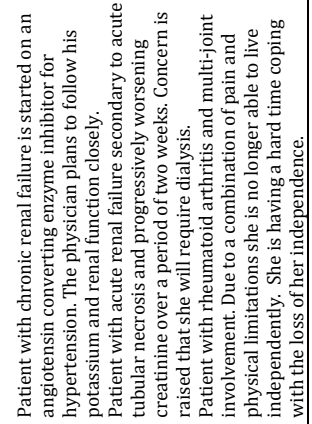

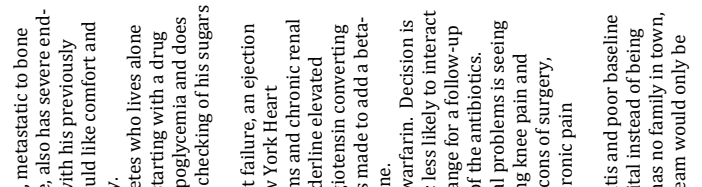

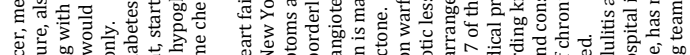

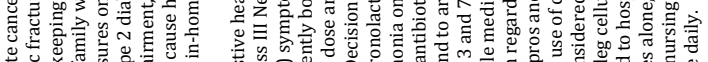

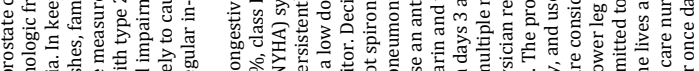

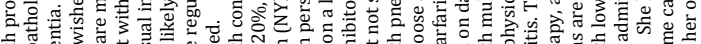

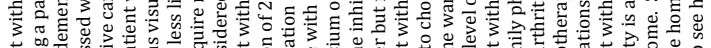

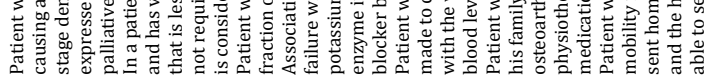

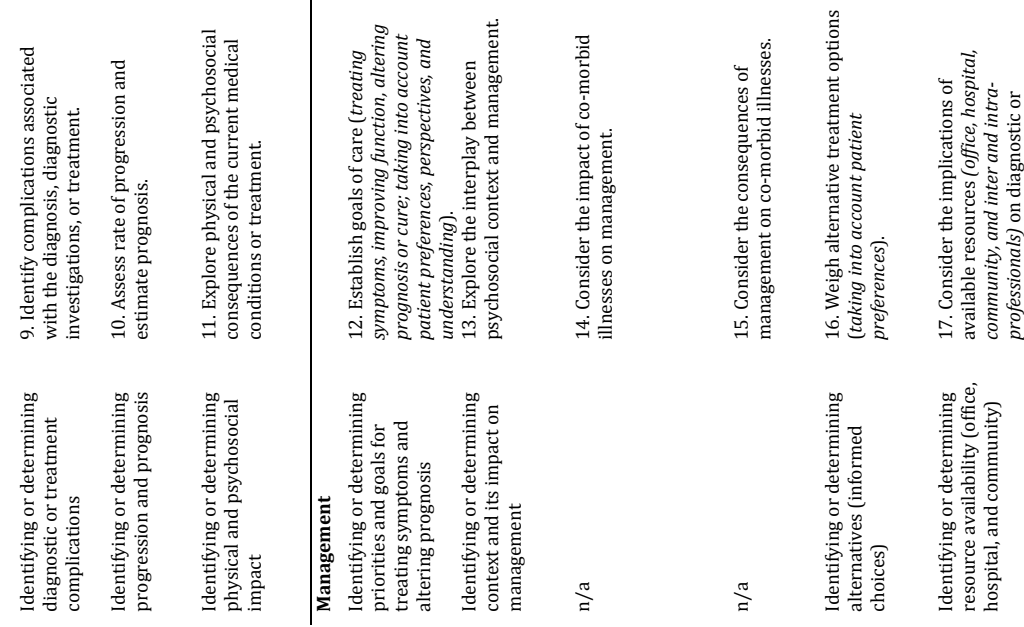




\begin{tabular}{|c|c|c|c|c|c|}
\hline 离 & & & $\underset{\substack{\mathrm{d} \\
\text { d్ }}}{\widehat{a}}$ & 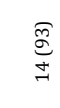 & $\stackrel{\pi}{\Xi}$ \\
\hline$\stackrel{\Omega}{N}_{N}$ & $\stackrel{\bar{o}}{0}$ & $\stackrel{\varrho}{\circ}$ & $\underset{-}{E}$ & $\underset{t}{E}$ & $\stackrel{\pi}{\Xi}$ \\
\hline 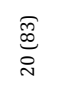 & 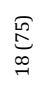 & 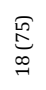 & 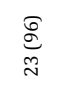 & 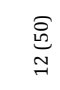 & $\stackrel{\pi}{\Xi}$ \\
\hline & $\underbrace{\infty}_{\sim}$ & న్ర & $\widehat{\Xi}$ & 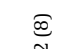 & $\stackrel{\pi}{\Xi}$ \\
\hline
\end{tabular}
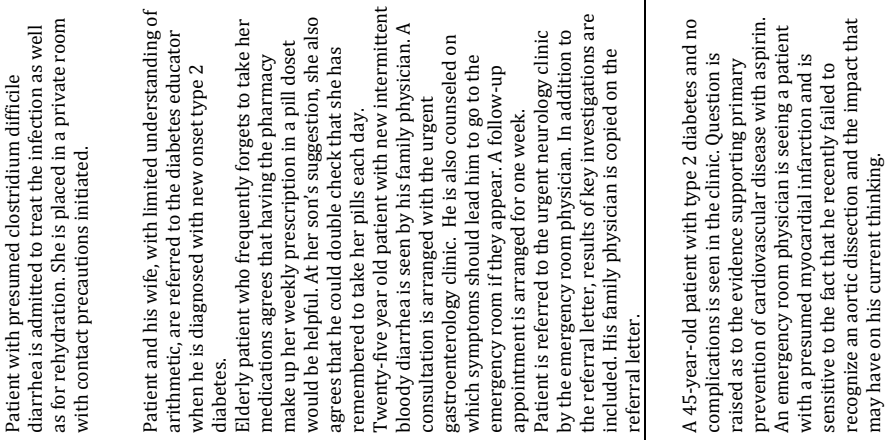

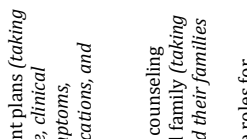

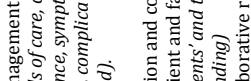

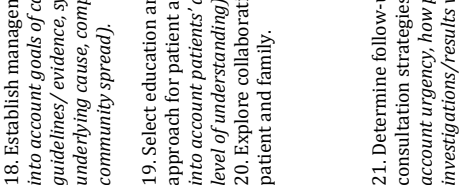

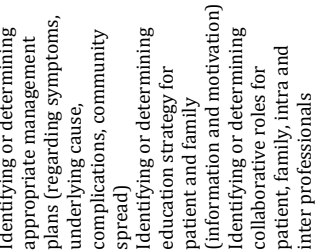
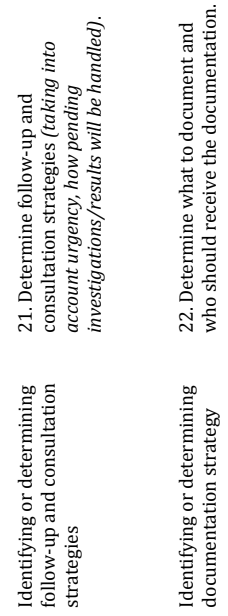
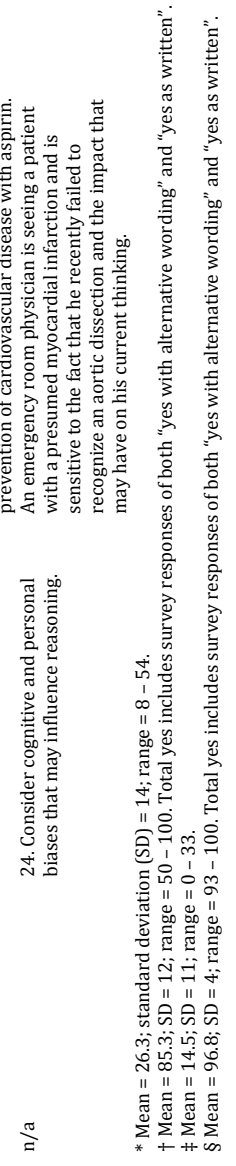


\section{CHAPTER 7 \\ Discussion \\ The Genres of Collaboration}


The goal of my program of research reported in this dissertation was to explore the CTU genre system and the ways in which its current practices support and constrain the team's ability to provide safe patient care and trainee education. The four studies in this dissertation share a focus on providing clinician-educators with some knowledge that can help them fulfill their roles of supervisor and teacher in the clinical setting. The studies also provide insights for students and likely for faculty developers. From a medical education research perspective, the studies provide insights into new questions and new ways of studying issues concerning the delivery of clinical care in the context of teaching teams. In particular, they challenge clinician-educators and researchers to reconsider the facets of clinical reasoning and the communication required to provide high quality patient care within this context. In this chapter, consistent with my constructivist approach, I will begin with a section on reflexivity. I will then use the lens of RGT to discuss the findings from all four studies together and to explore what further insights arise regarding supervision and teaching on CTUs, implications for clinical practice and implications for future research.

\section{Reflexivity}

An important convention for those who approach research from a constructivist approach is researcher reflexivity. ${ }^{1,2}$ According to Charmaz (2006), reflexivity is:

The researcher's scrutiny of his or her research experience, decisions, and interpretations in ways that bring the researcher into the process and allow the reader to assess how and to what extent the researcher's interests, positions, and assumptions influenced inquiry. A reflexive stance informs how the researcher conducts his or her research, relates to the research participants, and represents them in written reports. ${ }^{1(\mathrm{p} 188-189)}$

Given the relationship between the researcher and the interpretations, it is important for me to provide a reflexive statement prior to discussing my findings. This will enable you, the reader, to take into consideration how my perceptions and possible assumptions may have shaped my questions and interpretations. Because of the publication constraints imposed on the journals in which I published my work, there were only limited opportunities for this type of reflexivity prior to this point. Moreover, with all of the studies completed, it is now possible to be reflexive in relation to the entire body of the work.

I am a practicing clinician, specialized in general internal medicine, and nearly all of my clinical work takes place in the inpatient CTU setting. I also have a special interest in medical education and clinical supervision. Moreover, over the years, I have studied the existing research in this area and played an active role in faculty development efforts to improve supervisory and teaching practice. Like other clinician qualitative researchers, I'm often concerned with "what is missing and 
how the story is framed" in research 3(p.608). That is, I am concerned with research that focuses on studying and describing universal truths rather than individual experiences and their interactions with particular contexts. This has led me to conduct research focused on describing the complexities of practice. That being said, my goal is to not just study practice but to also change practice based on the results of my research. More specifically, to try to improve the quality of supervision and care provided by learning teams to the complex patients that they serve. Without question, we can do a better job of providing patient care and educating those that provide the care. While many speak of learners as 'future providers of care,' in my experience, they are actually active members of the careproviding team. Thus, it is imperative that we treat them as both learners and care providers.

Both my desire to change practice and my status as a clinician have impacted my research. The biggest impact is on my framing of research questions and interpreting the results. In terms of research questions, for the most part, they have originated from my experiences. For example, the study reported in chapter 6 on clinical reasoning tasks arose from my frustration with the content of the literature on clinical reasoning and my experiences indicating that clinical reasoning in practice involved a much broader mix of tasks than what was being reported in the literature. Similarly, the studies on progressive collaborative refinement (Chapter 3) and styles of supervision (Chapter 4) arose from experiences in practice that were not represented in the literature.

Being a clinician and a researcher offers both affordances and constraints. One of the affordances of my clinical role in the research setting that I studied was my ability to serve as an informed insider. As Devitt (2004) writes: "a genre commonly reveals its social functions with characteristic discourse features, but interpreting those features may require active participation with the genre and can never be complete" 4(p.54). Given the extent to which in-depth knowledge of the clinical world and clinical knowledge was required for the analyses, it was essential to have an insider as a member of the research team. This was especially true for the first study that required an analysis of the relationship between communication practices and patient care. Having access to the clinical world is another area in which being an insider was helpful.

Being an insider can also give rise to constraints such as failing to collect or recognize meaningful data due to shared assumptions with the study participants or my own personal perspectives and pre-conceived ideas, over interpreting data to match my own pre-formed assumptions, getting caught between loyalties - loyalty to the CTU research subjects and loyalty to the research community ${ }^{5}$. In the context of my research, I was blessed with a strong supervisory team who collaborated extensively in my research, helping me to benefit from the affordances and to tread carefully regarding the constraints of my insider-researcher position. 
To maximize the affordances of my role while minimizing potential constraints, I was supported by my supervisory team to take several important steps. First and foremost, I engaged in ongoing reflections on my personal perceptions and assumptions and on the research questions and data collection and analysis methods I was using. I did this through a process of memoing and having recurring dialogue with my research collaborators and dissertation supervisors. I then used the insights gained from this process to inform my data collection and interpretations. Second, I used a combination of volunteer and paid research assistants to assist with gathering the data. Given my role as an attending physician on the CTU, this was important to insure the anonymity of participants who took part in the research and to dispel any fear of impacting their evaluations or relationship with me. For my colleagues, this also allowed them to participate in the research while minimizing the potential for feeling personally judged. My research team, that included some (but usually not all) of my research supervisors, was also selected for its diversity thus facilitating researcher triangulation ${ }^{6}$. Depending on the study focus, I would typically have one or two supervisors collaborating closely on the work while the others were solicited at critical junctures in the planning, data collection, and analysis phases. In the writing of all four manuscripts, I was deliberate in trying to present a balanced perspective on the study findings, one grounded in the data, and less influenced by my personal beliefs about what was best. At times, this balance was harder to achieve by myself. Having the expertise and collaboration from the members of my supervisory team was extremely helpful in pointing out areas where I may have taken too strong a stance in favour of a particular perspective. For example, in the second study, I personally hold a strong opinion favouring the empowerment style of supervision. However, in the manuscript, I offer a balanced presentation of the results and discussion that reflected the affordances and constraints of each of the four styles.

While I approach research as a social constructivist, I have done so from the perspective of RGT. RGT focuses on how genres shape social action and therefore draws particular attention to communication practices. In the CTU context, communication practices undoubtedly play an important role. However, there are also many other perspectives that may be equally important that I did not focus on. A few salient examples include power and hierarchical differences, individual agency and identify formation. All of these could represent important areas of focus in the CTU and were evident in my data. For example, case review is clearly dominated by senior members of the team who enforce particular ways of practicing that, over time, shape the development of junior team members.

This research program and the RGT lens have also had an impact on my clinical and teaching practice. For me, RGT was an opportunity to see the world in a different way - to make the invisible, visible. As Kenneth Burke (1966) writes:

Any given terminology is a reflection of reality, by its very nature as a terminology it must be a selection of reality; and to this extent it must 
function also as a deflection of reality...much that we take as observations about "reality" may be but the spinning out of possibilities implicit in our particular choice of terms 7 (p. 45-46).

For those readers who are not familiar with the practice of internal medicine, it is important to note that it is renowned for being a strong proponent of the evidence-based medicine movement and it is highly associated with positivist ways of thinking. Combining constructivist grounded theory with RGT therefore represented a dramatic change in my thinking about research and clinical practice and provided me with a whole new vocabulary and possibilities to consider. Having previously completed a master's degree in health professions education, helped tremendously. Nonetheless, my learning curve was steep at first. Now, however, I cannot participate in any form of clinical encounter, with and without learners, without also seeing its location in the genre system and trying to take into account issues related to intertextuality, recontextualization, and uptake. Rather than thinking about a clinical document as a mere storage device, I now see every document in relation to how it might shape future social actions, be they patient care or trainee education. This of course poses some added difficulties in relating with my clinical colleagues. While I am becoming increasingly adept at translating these specialized research terms into ones that are readily accessible to a clinical audience, there are still times when the issue is less about translation and more about fundamental, epistemological ways of seeing the world. The task of translating findings from this dissertation and my ongoing research to clinical audiences is one that I continue to work on.

In terms of my own clinical practice, the findings from my research have changed it substantially. I spend more time than I used to teaching the team how to use case review and documentation to support progressive collaborative refinement (PCR). I teach them to use and share informal genres for keeping track; I have the trainees repeat back their understanding with regards to the issues and plans; I focus on the labels used to document each issue; and I strive to consistently use an "empowerment style" of supervision and explicitly discuss this with the trainees. During the times when I feel that circumstances prevent me from acting in this supervisory style, I am also overt about this. I also explicitly discuss the purpose of a hospital admission and how we can work as a team to ensure that we consistently high quality admissions. Given my personal relationship to the studies and my individual uptakes of the findings, in the remainder of this chapter I will, when possible, identify areas of interpretation that I am aware are particularly influenced by strongly held personal beliefs. 


\section{Supervision and Teaching on CTUs: What We Have Learned From a Genre Perspective}

Because of the intended journal audiences for each study - clinical educators and medical education researchers - none were written using genre terminology. Instead, I translated this terminology into plain language in the published papers in order to facilitate practitioner uptakes of study findings 3 (p.616). However, in order to enable a more sophisticated theorizing from a RGT perspective, I will discuss my findings in this section using genre terminology. I will organize the insights gained according to two key areas, that is, exigence and intertextuality. While I reviewed several other genre concepts in Chapter 2, most of these were definitional and necessary for understanding these two pivotal areas. Prior to delving deeply into these two areas, I will first review the key learnings from this work.

\section{Review of Key Learnings}

The goal of this dissertation was to explore the CTU genre system and the ways in which its current communication practices support and constrain the team's ability to provide safe patient care and trainee education. Figure 1.1 (reproduced here for convenience) is a depiction of the CTU genre system (centre), and the relationships of the four dissertation studies to the genre system. As can be seen in the figure, the primary contribution of my dissertation findings was defining the genre system and describing its purpose and some of the forces that shape it.

In brief, the primary purpose of the genre system was addressed in my first study (Chapter 3). In that study, I identified one of the key characteristics of what an effective CTU admission genre system should achieve from a patient care perspective: "progressive collaborative refinement" (PCR). That is, from the start of a patient's admission through to their discharge from hospital, all of the team's oral and written communications about patients should capture the full progression of thinking that the team went through regarding all of the patient's active problems. While prior research ${ }^{8-23}$ had focused on the types of care gaps that arise due to patient complexity, fragmented learner teams, poor handovers and ultimately, a lack of PCR, the notion of PCR itself represented a novel way of understanding the problem. Moreover, by studying the communication practices in the context of RGT and genre systems, I was able to describe key ways in which the system could, at times, constrain PCR. The study described in Chapter 5 is an example of one way in which PCR can become constrained if attending physicians and senior medical residents are not sufficiently attentive to how they structure their interruptions during case review. The study in Chapter 4 described a broader set of influences on PCR; that is, attending physician styles. Finally, in Chapter 6, I explored the vocabulary of reasoning tasks to facilitate future research on what CTU teams consistently reason or fail to reason about. 


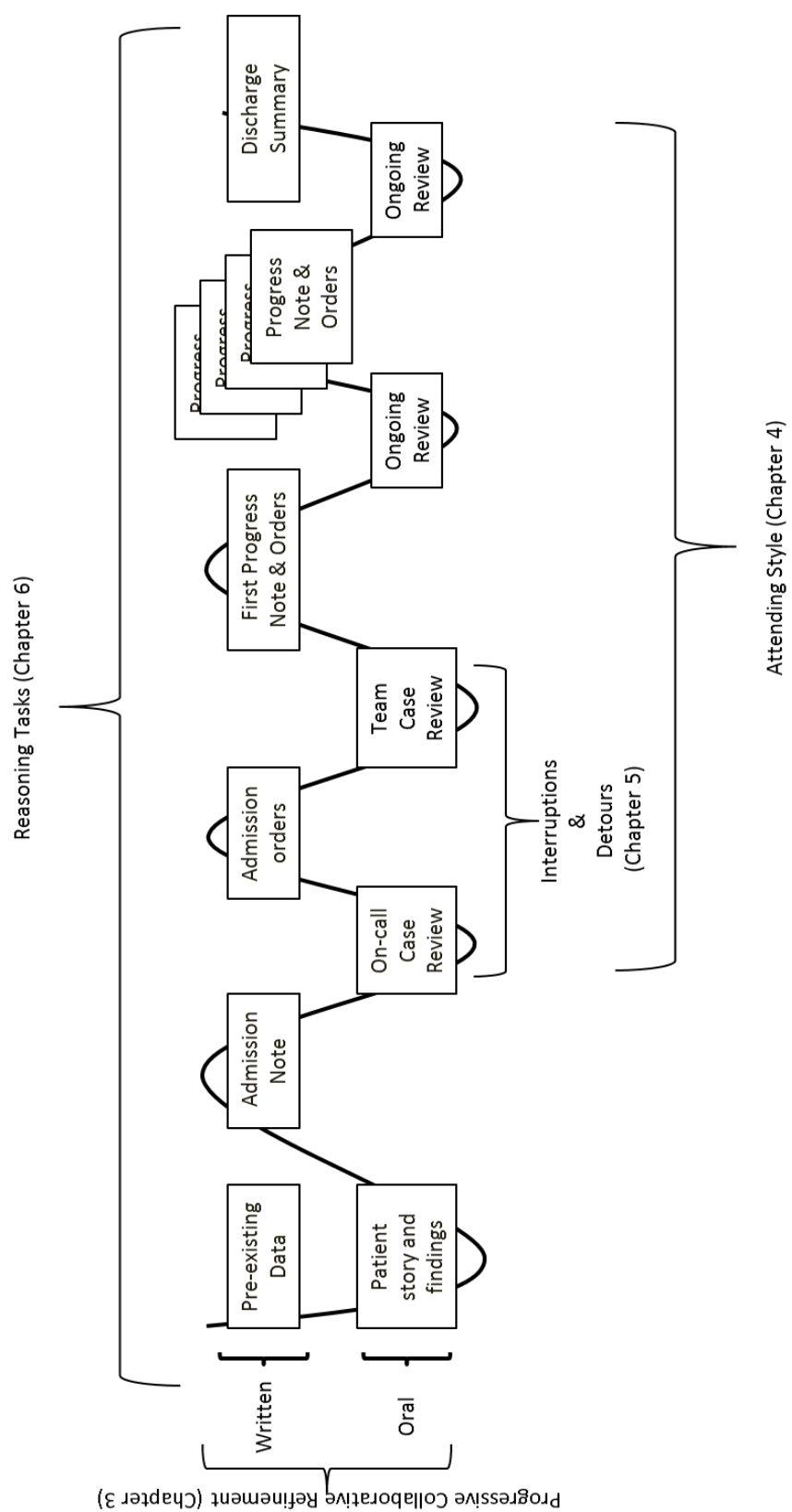

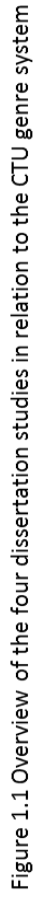

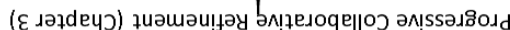


The dissertation studies also contributed to the dissertation goals by expanding our understanding of how culture and context contribute to trainee education. While prior research had identified some best practices in clinical teaching24-28 and a generic model of supervision ${ }^{14,18-21,24-26,29,30}$, in the study reported in Chapter 4, I described the variability of supervisory practice in relation to all three components of the role - supervision, teaching and direct patient care. I also identified how different attending styles can shape the learning and practice culture of a CTU team. The findings from this study gave rise to as many questions as it answered. I further address these in the section below on implications for future research.

With the above overview in mind, I will now turn my attention to the nuances of supervision and teaching on CTUs and what we have learned from a RGT perspective. Following this, I will discuss the implications of the research in relation to practice and future research.

\section{Exigence and the CTU Genre System}

The first set of insights relates to the exigencies of the CTU admission genre system. In chapter 2, I reviewed Miller's definition of exigence as social motive ${ }^{31}$ and Bawarshi and Reiff's explanation that "how we define and act within a situation depends on how we recognize the exigence it offers"32(p. 70). Building on these key points, the studies in this dissertation all provide insights into a variety of social motives - exigencies - that drive the genre system and enable and constrain its ability to support safe patient care and quality trainee education. In total, three categories of exigence were identified: task-based, trainee education, and patient care. Below I provide a description of each exigency and explore possible tensions that arise between and within each.

Task-based exigencies are based on doing what one is supposed to do (i.e., following the rules) without necessarily understanding the underlying social function(s) it serves. These exigencies were mostly identified from the PCR (Chapter 3) and detours (Chapter 5) studies. Because these studies relied primarily on observations and chart analyses, this category is mostly inferred. In a training setting such as the CTU, many of these rule-based exigencies are achieved through the genres themselves. A typical example is the standard case presentation format identified in Chapter 5. In that study, presenter deviations from the standard case presentation format typically resulted in an interruption and redirection back to the expected sequence. Given that trainees participate in case reviews on a daily basis, it is not surprising that, regardless of their understanding of the social functions served by this genre format, they would learn to document and present in a specified sequence.

Another key example of a task-based exigence is the need to write a progress note daily about each patient. According to Markel (2009), texts that are written over a period of time can be referred to as temporal genres ${ }^{33}$. In the study reported in Chapter 3, it was observed that each patient had a clinical note written daily. On 
days where there was little or no change in the patient's status, the content of those notes often did not appear to differ from the prior day's note. Moreover, when they did differ, the differences did not appear to be purposeful. Rather, many of these notes appeared to use the prior note as a template and simply reproduce the same note, making minor updates like the current day's blood work and vitals. Such strategies allow writers to produce a note as efficiently as possible. However, at times, as will be discussed in the section on intertextuality below, this shortcut also led the note writers to exclude one or more of the patient's active problems. Over time, this led the team to ignore some of the active problems. While there are likely medical-legal as well as other exigencies that drive this practice of daily note writing, these were not overtly discussed by participants or evident to observers. Temporal exigence was of course only one of several exigencies driving note writing practices.

The second category of exigence, education, was identified in the detours (Chapter 5) and attending styles studies (Chapter 4). In the detours study, I analysed the case review genre from the standpoint of interruptions and detours and found that one of the key reasons for interruptions was teaching. In fact, it was through interruptions that teaching took place. Moreover, I identified two distinct exigencies that led to teaching interruptions. The first was genre lapses: if a trainee did not know the correct sequence of presentation or the type of information required at a particular point in time, they would be interrupted and corrected. The second was patient care-related knowledge gaps: if the presenter or team demonstrated a particular knowledge gap or if the attending felt like particular knowledge was important to teach, they would respond to this exigence by interrupting. Interruptions could take on the form of interactive or didactic teaching or thinking aloud with the team.

In the attending styles study, all styles of attending identified trainee education as an exigence driving the genre system. However, the nature of their education-related exigencies and how they used the genre system to enact them were quite different. In common, most shared the sense that learning-by-doing was an important part of trainee education. In the empowerment attending style, this led to genre practices that supported empowering trainees to safely provide patient care. By contrast, attendings describing a minimalist style felt that senior residents were already capable of supporting the team's educational needs and that providing that support independently was important for their educational development. In response to the exigence of supporting independence, they stayed away. In the mixed practice and empowerment styles, attendings also spoke about assessing trainee learning needs through questioning and using the exigence that arose from that as a basis to guide teaching.

The third category, patient-care based exigence, was identified in the detours (Chapter 5), PCR (Chapter 3) and attending styles (Chapter 4) studies. Without question, the provision of patient care was a powerful social motive driving both 
trainee and attending genre use. In the detours study, the need to probe for further data to enable decision making was a common exigence leading to interruptions during case review. Similarly, documentation in the form of progress notes, patient care orders, and discharge summaries all appeared to serve the purpose of supporting patient care; they were not purely temporal genres. However, there was a dearth of strategies for consistently supporting collective patient care. I referred to this collective care-related exigence as progressive collaborative refinement (PCR). This was described in the study reported in Chapter 3 and was a representation of how the CTU admission genre system should work if its exigence was supporting continuity of care in a team setting. In particular, recognizing that continuity of care is not the norm and that handover is almost always incomplete, a heavy responsibility is placed on the medical record and, therefore, those who document in the record. In this study, I described this form of exigence as an ideal of practice that was identified because of its frequent absence rather that because of its consistent presence. While I clearly found instances of PCR, it was inconsistent across the genre system and was not explicitly part of the trainees' socialization into CTU practice. An excellent example of how trainees did try to support PCR was through the summary notes. While the exigence of time, as described above, clearly played a role in clinical documentation, there were also numerous instances of trainees trying to recapture patient issues that had been dropped by summarizing their current thinking about the patient; the main problem however was the inconsistency of this approach across documentation over time.

According to Devitt (2004), "genres function for groups, though those functions are typically multiple and ideological as well as situational" 4(p64). While multiple exigencies can co-exist harmoniously, in the PCR (Chapter 3), detours (Chapter 5) and attendings' styles (Chapter 4) studies, I identified many instances where ideological differences led to variability in the genre system and where there was clearly tension or competition among exigencies. The four attending styles represent an excellent set of examples for how variability in practices can lead to different configurations of tensions. At one extreme was the direct care style that was driven by concerns for patient safety where attendings responding to this exigence could spend a considerable amount of time directing or directly providing patient care. At times, this direct provision of care led to tensions with the exigence of trainee learning. In particular, the need for trainees to experience progressive independence ${ }^{34}$ and the opportunity for using trainee-led patient care as a way of assessing learners and directing teaching towards their knowledge and skill needs. The identification of this set of tensions is not new. Trainees often use the term "micromanager" when they perceive this tension. According to Ranji (2014), attendings are increasingly being forced into this position because of situational factors, including duty hour restrictions, discontinuity of trainee provided care, and increasing numbers of externally imposed quality metrics ${ }^{35}$. 
At the other extreme was the minimalist style. Driving exigencies included being able to attend to work external to the CTU as well as a supporting trainee independence. In tension with both of these was patient safety. The empowerment style arose in response to combining exigencies related to progressive independence, collective care, and patient safety. In this style, attendings described strategies to minimize tensions between the three. Of all the attendings, those describing this style seemed most aware that they could not and should not be everywhere at once and that others could play meaningful roles in supporting care if they were empowered by both the attending and the system to do so. Enacting this style required a considerable amount of time. As such, the greatest tension described in this style related to being unable to attend to any work outside of the CTU context.

Regardless of style, tensions also existed between genres when attendings were trying to fulfill multiple exigencies. This was clearly demonstrated in the detours study (Chapter 5). While interruptions were essential for supporting trainee education, they were not without cost. With a limited amount of time for achieving all of their clinical tasks, the exigence for teaching appeared at times to come at the cost of time spent on patient care-related issues and this lost time could hinder PCR. Detours were an example of how PCR could be inadvertently constrained because of a teaching interruption.

\section{Exigence in RGT}

To my knowledge, the identification of an ideal exigence in genre system research is somewhat unique in RGT studies. In their chapter "Genre Research in Workplace and Professional Contexts", Bawarshi and Reiff (2010) provide a detailed overview of both genre and genre systems research focused on workplace based settings ${ }^{32}$. Studies in the professions have included many healthcare-related professions including physicians, veterinarians, and social workers as well as other professions including engineering, law and accounting. While none of the studies reviewed were focused on the identification of an ideal of practice, they were also not restricted to mere description. Many move beyond describing 'what is' happening in a genre towards a more critical stance regarding what 'should be' happening in a genre. For instance, according to Bawarshi and Reiff, RGT research has considered the disconnect between academic and workplace genres and the difficulty in transitioning to practice 36,37 ; the ways in which existing genres serve to enforce hierarchical differences and political ideologies even when they purport to equalize hierarchy and challenge ideology38; and the tensions that differing social purposes between groups of users can cause in their genre variation choices 39,32 . However, in their analyses, most of these studies appear to have upheld one of Devitt's (2004) six principles of the social nature of genres: "A genre reflects, constructs, and reinforces the values, epistemology and power relationships of the group from which it developed and for which it functions" $4(\mathrm{p} 64)$. Implicit here is the notion that 
the genre system functions; that is, it does the work that those using it need to get done.

Reconciling my findings with the above, implicit notion, that a genre system must function to exist requires close scrutiny of the principle. According to Devitt (2004), genres must function for groups. However, in reference to the genre system she states another principle:

A group usually operates through a set of genres to achieve the groups' purposes, but the nature of that genre set varies in different types of groups. Genres interact with one another in the context of genres and genre repertoires, genre sets, genre systems, overlapping genres, call and response genres, super genres, and other possible relationships that further research will uncover. ${ }^{4(\mathrm{p} 64)}$

She does not say that the genre system always functions. For a genre to be used by a group, it must function. However, I would suggest that it is possible for individual genres in a genre system to all function well enough in the moment of their use leading to appropriate and effective actions while still undermining, in subtle but influential ways, the long-term collective competence of a group. Thus, a genre can be functional at the individual level while being dysfunctional at the collective level. An excellent example is what I referred to as "responsive care" in the PCR study (Chapter 3). During responsive care, responding to the exigence of an abnormal laboratory value, an on-call resident can prescribe the correct treatment at that moment to correct that abnormality while at the same time creating a situation that prevents the team from recognizing the recurrent nature of the problem and planning more effective long-term solutions. Thus, responsive care upholds the key genre principles while simultaneously undermining the genre system in its ability to support collective competence.

\section{The Genre System of a CTU Admission - Intertextuality, Recontextualization and Uptake}

The second set of insights comes from my exploration of the relationship between case review and documentation practices, and the nature and impact of their intertextuality. In Chapter 2, I described intertextuality and the related concepts of recontextualization and uptake. As a reminder, intertextuality represents the relationship that exists between texts as mediated through individual interpretation. Because no two individuals hold exactly the same knowledge and understanding of a situation, as a new person draws on their own intertextual relationships, they may come to different interpretation of the same data and thereby represent that data in ways that change their meaning, thereby recontextualizing them. From a genre as social action standpoint, genres lead to actions through uptake. Knowledge of uptake is knowledge of the options that exist for responding within and to a genre. Like most other aspects of genre, knowledge of possible uptakes is socially learned: 
What we choose to take up and how we do so is the result of learned recognitions of significance that over time and in particular contexts become habitual. Knowledge of uptake is knowledge of what to take, how, and when, including how to execute uptakes strategically and when to resist expected uptakes. ${ }^{32(p .219)}$

The centre square in Figure 7.1 represents the majority of formal genres used by the CTU teams in what I have referred to as the genre system of a CTU admission. In the figure, the boxes are used to represent genres that were included in my data collection from the PCR study (Chapter 3) and arrows to represent some of the intertextual relationships that exist between and among genres in the system. The solid-line arrows represent situations in which there were consistent intertextual relationships; The dashed-line arrows are ones where intertextual relationships existed to support PCR but in an inconsistent manner. In contrast to an ideal PCR, the enacted genre system was fraught with problems relating to intertextualities, recontextualizations, and uptakes. In the next paragraphs I will describe my study findings in relation to these three concepts. My focus will be on applying theories of intertextuality to explain why the current genre system fails to consistently support PCR. The terms used in Chapter 3 to represent intertextuality were" fragmented documentation" and "conceptualization". The third form of fragmentation discussed in that chapter was fragmented continuity. While I will not be discussing fragmented continuity in the section below, it is worth reviewing briefly as it is the context in which the genre system exists.

As discussed in Chapters 1 and 3, the CTU team composition is constantly changing. Typically, each CTU has approximately 8-10 members: one faculty member (attending physician), one or two senior residents in their second and third years of postgraduate training, two to four first-year residents and two to four senior medical students. Attendings rotate every two weeks, residents every 4-8 weeks, and medical students every 6 weeks. Moreover, different members of the team may be absent on a day to day basis due to a combination of post-call leave, academic half days and vacation requests. Because junior trainees all take on the main responsibility of caring for individual patients and performing the requisite documentation, it is not uncommon that a junior trainee is asked to care for a patient they have never cared for before. This constantly shifting team membership therefore places an added burden on the genre system. 


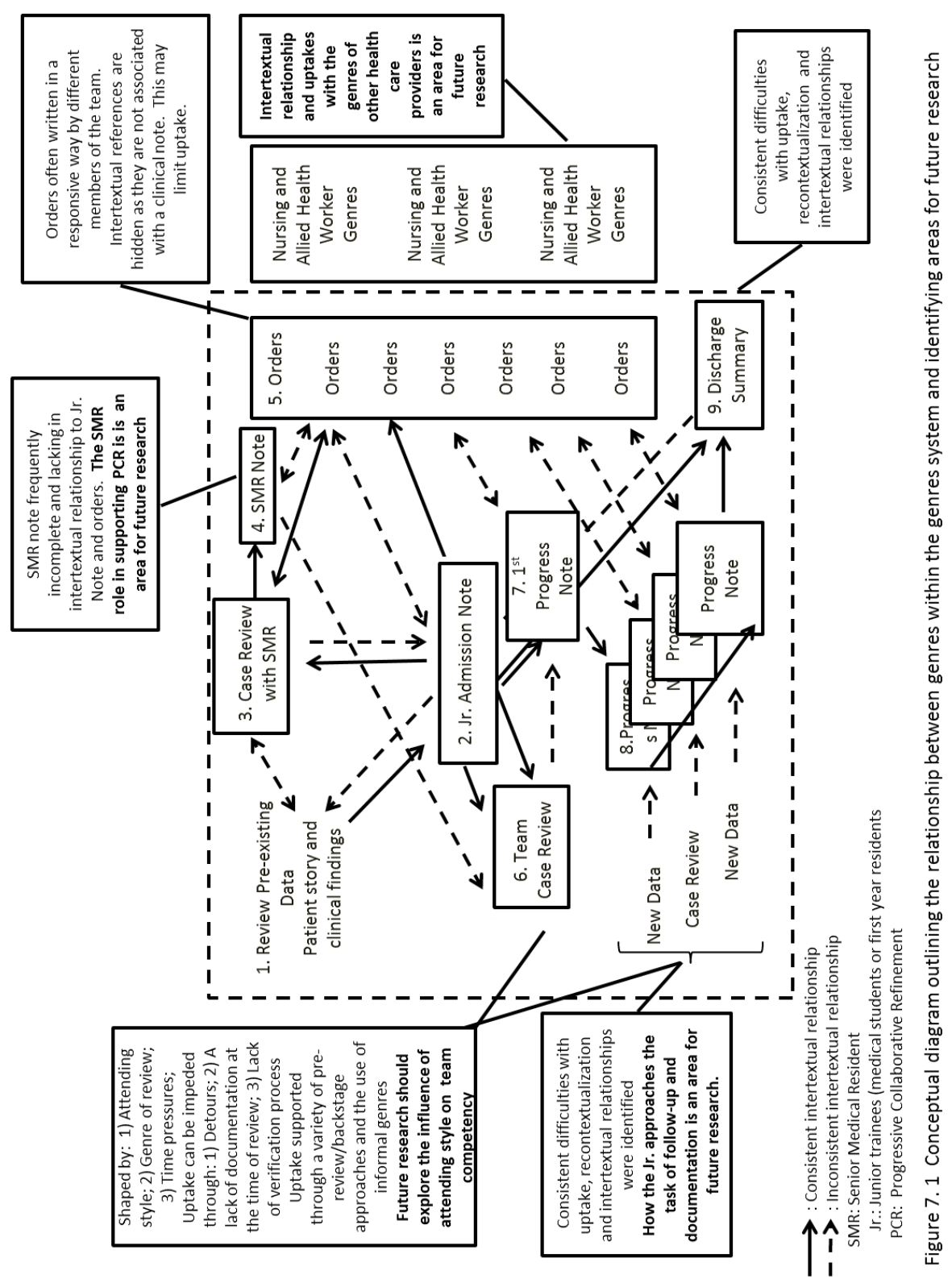




\section{Fragmented Documentation}

In Chapter 3, fragmented documentation was the term used to describe "instances in which information was known by the team but not fully captured in the patient's chart". Three subtypes were observed: (1) failure to document discussions that took place during the case review, leading to changes in how the team conceptualised or managed the problems; (2) failure to document a problem and how it was handled during responsive care (instances of care that were in response to a new issue or change in status of an existing issue), and (3) failure to record all active issues in the progress notes and discharge summaries." Each admission to the CTU begins with a case review between the senior medical resident and a junior trainee. In the study reported in Chapter 3, there were frequent episodes of fragmented documentation stemming from the Senior medical resident's note and the case review. There were numerous instances of issues discussed with the senior medical resident that were not documented in the junior's clinical note. The next morning, when the junior trainee presented to the attending physician and the team, the junior trainee also failed to include these issues in their presentations. Similarly, the team case review also led to fragmented documentation in that issues discussed were not noted in the subsequent progress note. In both cases, I would describe the issue as one where the genre system created a situation that allowed for a weakening of the intertextual relationship between the two genres - the genre of review and the genres of documentation. On further analysis, there were two salient features that allowed for this to occur. The first relates to the 'how' and the second to the 'when' components of uptake in the genre system.

The genre of review is predominantly an oral genre. Accordingly, the 'how' of the uptake - or generic response - is to listen and remember and not create and confirm. In other words, as observed in the study reported in Chapter 3, trainees rarely document at the actual time of the case review as this is not part of the uptake in that genre. The exception to this was patient care orders. There was a strong intertextual relationship between the oral components of the review and the clinical orders as these were typically immediately written at the time of review. As discussed in the preceding exigence section, this likely persists in the genre system because both teaching and patient care exigencies in the moment are being achieved through the orders being written at the time of the case review.

The second related issue is the 'when' component of the uptake. Following the case review, the trainee doing the admission typically goes home and does not return to see the patient until the next day. Moreover, the same trainee is frequently not responsible for that patient upon his/her return the next day. This further weakens the intertextual relationship between case review and clinical documentation. My interpretation of these events is also supported by the strong intertextual relationship observed between the admission note and first progress note as well as the first progress note with subsequent progress notes and the 
discharge summary. In the hospital admission genre system, written text more consistently supports uptake.

A similar situation was identified with regards to patient care orders and clinical documents. As discussed in the section on exigence, the second type of fragmented documentation was responsive care. During responsive care, orders were written without an accompanying note. While the orders often held a strong intertextual relationship with a laboratory abnormality or new patient symptom, failing to document during responsive care interfered with the ability of other members of the team caring for that patient to adequately uptake the problem that was responded to. Were PCR a strong exigence in the system, this should not have happened as the norm of practice.

The third form of fragmented documentation related to the 'what' component of uptake and was referred to as failing to consistently document on active problems in ongoing progress notes. This was identified as a problem in our analysis because failing to do so led to instances where issues addressed on one day were subsequently not followed up. For some of these, an active issue was not resolved and important information for the next care provider was not included in the discharge summary. Review of the clinical documents showed that the discharge summary held a strong intertextual relationship with both the admission note and the last progress note. Issues identified at other points in time during the patient stay, but not documented in the last or near last progress note, held a weaker intertextual relationship to the discharge summary. In other words, trainees did not seem to realize that, in the context of progress notes, the 'what' of uptake had to include all active problems and not just a selection of problems for that day. One form of uptake that helped to prevent this form of fragmentation was the summary note where all active issues were written about. At times, this also involved recontextualizing them from a list of problems into labels that reflected a deeper understanding of the underlying issue. Instances of this type of note were identified as being written by attending physicians as well as medical students and junior residents. The attending's informal genres were also described as an uptake that helped prevent this form of fragmentation. In response to daily case reviews, some attendings in the study reported in Chapter 4 described writing on a personal patient summary card that they carried around with them. The list of active issues written on that card could then be used by the attending (only) to remind the trainees of issues that they may have forgotten or dropped from their progress notes.

In summary, one of the key genre system problems interfering with PCR is fragmented documentation. From a genre system perspective, important insights are gained by looking at fragmented documentation through the lens of intertextuality and uptake. The dominance of oral genres during case reviews with the attending and a lack of recognition of the importance of consistently uptaking 
the full problem list into clinical notes are important areas contributing to this form of fragmentation and indicate areas to target improvement efforts.

\section{Fragmented Conceptualisation}

Next I will explore the second type of fragmentation. Fragmented conceptualisation refers to instances where the team's framing of the case, without apparent intent, appeared to shift or failed to appropriately shift in meaning from one time point to another despite data supporting a particular level of differentiation in the description of the problem. It could also involve instances in which the team's framing of a problem failed to capture the underlying issue that it was intending to address. Fragmented conceptualisation is a form of recontextualization. While recontextualization can be either deliberate or unintentional, in the study reported in Chapter 3 and because of study methodology, I could not distinguish between these two - most instances were identified by comparing texts within the genre system and not by reviewing them with participants. Moreover, at the time, I was focusing on identifying recontextualizations that constrained PCR. Therefore, for the most part, recontextualization appeared to be related to junior trainees' level of knowledge and attending physicians' and senior residents' assumptions thereof. Intertextuality exists not only between genres within genre systems but also with genres outside of them ${ }^{40}$. In the context of medical care on the CTU, the large body of knowledge that constitutes the practice of medicine frequently held an intertextual relationship with what the attending would discuss with the team during oral case reviews. However, in these instances, trainee level of knowledge played a necessary mediating role between the two. In the study reported in Chapter 3, there were numerous instances where a trainee's inability to make the intertextual connection could have explained the findings.

One particular type of recontextualization that deserves special attention was the recontextualization of a patient's problem list to a task list in clinical documents. The example of this used in Chapter 3 was the trainee who used the label "awaiting echo" to describe the active issue of query cardiogenic syncope (passing out as a result of a cardiac abnormality). While I could not say with certainty that the junior trainee did not understand the underlying rationale, given the way he/she documented the problem, it prevented the next trainee and attending who took over the team from recognizing the problem as one of syncope. This limited their ability to interpret the results as well as consider alternative explanations for the fall. The main principle is that in the genre system of the CTU, even if the person writing the note understands the intertextual significance, careful attention needs to be paid to document in ways that support the next reader to draw the same intertextual inferences. As seen in the PCR study, failing to do so can and did consistently interfere with PCR.

One area where my findings deviated from other research on recontextualization relates to Kristeva's (2002) hypothesis that even novices can 
recognize a lapse in their ability to uptake an intertextual relationship and seek further support ${ }^{41}$. There are many reasons why the Chapter 3 findings did not support this. From a methodology standpoint, recontextualization was only coded, and therefore counted, when it occurred and interfered with PCR. This means that while there may have been instances of trainees seeking clarification and avoiding recontextualization, these were not necessarily observed or coded. From a training setting perspective, other research has suggested that individual and relational factors such as gender and cultural differences, fatigue and stress, and hierarchical differences may all play a role in stopping trainees from seeking appropriate clarification, even when they recognize the lapse ${ }^{22,}{ }^{42}$. As discussed in Chapter 4, attending style may also play a role. For example, direct care attendings - those who view case reviews as an opportunity for them to acquire data about the patient - may not take the time to ensure that the trainees fully understand the case.

\section{Implications for Practice}

While the issue of PCR is in many ways not a new one, it is one that continues to plague the medical community. As I hope I have shown, the lens of genres systems provides some unique insights into why the CTU context continues to struggle with the issue of PCR. In this section, I will briefly review how my research contributes to insights into how to improve current practices so as to better support PCR. I will structure these insights into three sections: the genre system, supervisory practices and junior trainee practices.

\section{Implications for the Genre System}

If we accept the exigence of PCR as the ideal of CTU collective competence, we also need to accept that it is not currently an exigence that drives the genre system. As Devitt (2004) points out, "A genre reflects, constructs, and reinforces the values, epistemology and power relationships of the group from which it developed and for which it functions" 4 (p64) Therefore, the first implication is that, in order to make PCR an exigence, we need to ensure that relevant stakeholders value PCR. While it might be tempting to ascribe frontline attending physicians with the power to change the genre system, we cannot make that assumption. Moreover, we cannot assume that the system was developed by or for them and their patients' needs. According to Siegler (2010), rather than patient care related exigencies, changes to the medical record have often been driven by external forces such as regulatory requirements or data base management ${ }^{43}$. As we move to more electronic systems, cost, administrative needs, and developer constraints increasingly play a role in shaping the future record and therefore the future genre system ${ }^{43}$. Given that the CTU is also a learning context, other stakeholders include academic leaders who 
play a role in defining the numbers of trainees on rotations, their call schedules and rotation schedules. Therefore, addressing the issue of PCR as exigence will likely require a broad-based approach involving meaningful engagement with hospital and academic leaders as along with frontline practitioners. The collection of meaningful quality measures related to PCR would also likely be of benefit in supporting these discussions. In particular, these measures should relate to the labelling and appropriate level of engagement around a patient's problem list during their hospital stay.

The second implication relates to the power of genres themselves to shape practice. The findings from my program of research suggest several areas where genre variations could influence PCR in a positive way. First, there is a need within the genre system for a single stable location to house a cumulative patient profile. This was proposed by Weed over 40 years ago and, at least in my study settings, has still not been implemented 44,45. Ideally, it would be housed in the electronic medical record. This would allow attendings using backstage supervision to ensure that it was accurate and up to date. For at least three of the four attending styles, this would support them in their approach. For the fourth style, minimalist, it would be available even if they do not always take advantage of it. From a trainee perspective, if integrated well, it would allow them to write focused, updated progress notes without compromising the overall problem list and plans. This modification could also shape both on-call and morning case reviews. One of the main goals would become the confirmation and elaboration of the problem list and plans. Moreover, if updated and reviewed with the attending prior to discharge, the cumulative patient profile and associated problem list would serve to support a greater degree of continuity from admission to admission than does the current discharge summary that is frequently incomplete.

If created, I would also suggest that the cumulative patient profile should be multidisciplinary in nature. The current admission genre system does not appear to integrate non-physician genres well. In the study reported in Chapter 3, there were numerous instances of issues identified by the social workers, nurses, physiotherapists and other allied health care workers that went ignored. Finally, it will be important that the labelling format be flexible. Using standardized terminology does not appear to consistently work for physicians ${ }^{46}$. In our data set, many of the problem labels would not fit under existing coding system like ICD-10 (the $10^{\text {th }}$ revision of the International Statistical Classification of Diseases and Related Health Problems). If the labels themselves are to support and guide the teams' practice, they need flexibility. If hospital administrative leaders need additional standardized codes for administrative and research purposes, data abstractors can add these in post-discharge or they can be used as a secondary field; they should not be required or used as the primary labels as this would hinder the team in achieving PCR. 
Although it is on a much smaller scale, another genre system change would require that responsive care be associated with a mandatory clinical note, as brief as it might be. Again, an electronic solution could support this. For example, when entering new orders, an associated pop-up screen can offer a section for physicians to enter a brief note. Another enhancement would be for the pop-up screen to offer or automatically add the note to a handover list. This would address a related issue reported by Devlin et al. (2014) who found that as many as $40 \%$ of important oncall issues (responsive care issues) are not handed over to the team, and that 85\% of these have no accompanying documentation in the patient's chart ${ }^{47}$. These and other similar genre system changes could go a long way in better supporting PCR on CTUs.

\section{Implications for Supervisory Practice}

From a supervisory practice standpoint, there are several implications that warrant further discussion. These include treating documentation as an entrustable professional activity (EPA) ${ }^{48}$, handling interruptions during case reviews, explicitly discussing attending style variations, and supporting progressive independence.

As discussed in the study described in Chapter 3, junior trainees should not be entrusted with the role of maintaining the clinical record by virtue of status alone. In this study, irrespective of level of training - senior medical students, off-service first-year residents or core internal medicine first-year residents - junior trainees did not consistently use clinical documentation to support PCR. Instead, I would recommend that clinical documentation be treated as an EPA 48 that needs to be assessed by the senior medical resident and/or attending physician prior to allowing junior trainees to document independently.

EPAs are increasingly becoming a norm in medical training environments and have been developed in relation to numerous clinical tasks and responsibilities, including patient handovers ${ }^{49}$, 50. According to Ratcliffe et al. (2013), very few internal medicine programs currently include structured evaluations forms for assessing the documentation skills of medical students ${ }^{51}$. For programs that are moving in the direction of including clinical documentation in their EPAs ${ }^{52}$, I would suggest that PCR be overtly included as one of the key criteria for assessing the quality of the clinical documentation, rather than simply focusing on the accuracy or thoroughness of the data documented, not that these are not important but that in of themselves don't guarantee PCR. Given the multiple levels of entrustment, this would require the senior medical resident or attending to actively review the daily clinical notes of trainees until full independence (competence) is achieved. At discharge, similar to admission case reviews, there also needs to be a re-review of what the junior trainee will indicate in their discharge summary with regards to active problems and the ongoing plans for addressing them post-hospitalization. In order to implement such an EPA, given how busy the senior medical resident and 
attending are, strategies for facilitating this ongoing document review will be required. The use of electronic documentation systems and the introduction of an electronic cumulative patient profile would greatly enhance the senior resident and attending's ability to do participate in this type of documentation review.

The second implication relates to interruptions and detours during case reviews. As described in Chapter 5, interruptions are essential for teaching and patient care. However, attendings and senior medical residents need to be aware of the potential for interruptions to cause detours and the need to ensure that any detours arising from an interruption need to go back to the place where they left off. Failing to do so puts the review at risk of missing important details. Moreover, awaiting trainees to speak up and ask clarifying questions or redirect the discussion back to the place in the review where the detour began is not sufficient because of the well-established prohibition on revealing ignorance and interrupting senior team members in the clinical setting 22,42 .

The third set of implications relates to the variations in practices seen across the four attending styles. One of the implications of the identification of these styles is knowledge of the practice variations themselves. As discussed in Chapter 4, the model is unique in that it integrates all of the attending practice functions - patient care, trainee supervision, and teaching. Prior models only addressed components of these such as Kennedy's exploration of patient care and supervision 30 and Irby's consideration of clinical teaching 27,53. The spectrum of how attending physicians configure these activities (styles) can be used by attendings for both individual reflection as well as group development. Further discussion between colleagues may lead attendings to better recognize their own styles and possibly to develop consensus around shared expectations of the attending role. Because attending style could arise as a response to particular contextual triggers, discussing these and ways in which the context could also be modified would be a valuable way in which attendings can use the study findings.

Attendings indicated that they rarely, if ever, discussed these differences with their teams or colleagues. While future research is needed to better explore the affordances and constraints of each style, in the interim, it is essential that attending style be overtly discussed with the CTU team along with how the different styles modulate PCR. I am particularly concerned with the mixed messages that trainees receive when transitioning from one attending to another, especially when styles change from one attending to another. Overt labelling of style by the attending may help the whole team engage in meaningful dialogue regarding how their roles may need to change as a result.

The final implication from the attending physician perspective relates to supporting progressive independence. This issue is increasingly present in the literature $34,35,49,54$. In the context of shorter rotations, shorter work days, and more teaching that pulls trainees away from the rotation, it is becoming increasingly difficult for attendings to provide trainees with the degree of independence 


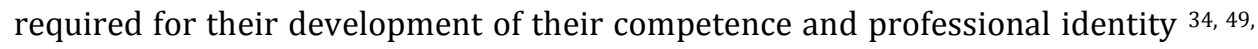
54,55 . While the results from the studies in this dissertation do not immediately translate to solutions, they can be used to support the necessary dialogues among attendings, their teams, and the educational leaders and managers, all in the interest of being more supportive of progressive independence.

\section{Implications for Junior Trainee Practices}

The implications for junior trainees on the CTU team are concrete and processoriented. First, clinical documentation should be made into an entrustable professional activity ${ }^{48}$. While the overarching goal is for documentation to support PCR, there are several key steps that all trainees can and should include in their practice. The first relates to case presentations and admission notes. As shown in List 1 , Chapter 5, the admission note should include all of the main headings and be written in the expected sequence. Failing to do so leads to interruptions and may give rise to omissions. Careful attention also needs to be made to update all notes such that they reflect what was discussed during case review. Proper labelling of the problem list items is also essential. As Weed identified over 40 years ago, the labels in the problem list should be at the highest level of differentiation possible based on what is currently known about the patient 44, 45. During case reviews, when an interruption occurs, trainees should mark the spot they were at and use re-orienting statements when the detour is completed. This strategy was identified in the study reported in Chapter 5 as being particularly effective in preventing omissions.

Trainees also need to become comfortable with timing and using clarification questions. According to Kristeva (2002), trainees should recognize times when they do not own the requisite intertextual knowledge for realizing an uptake ${ }^{41}$. It is then essential for them to speak up and use an appropriate clarifying or summarizing question. A good example of how this could be done is summarizing - "If I understand it correctly, our problem list should include the following five items... ." Similarly, in progress notes, it is essential that the notes reflect an updated account of what is currently known about the patient. The creation of "false" summary notes appeared to be particularly dangerous in contributing to omissions. If a trainee is writing a summary note, the full, complete problem list is essential, including items that were resolved or for which results are still pending, even when they are not active that day. If the trainee is having difficulty labelling or identifying the problems or the accompanying plans, they should take the time to double check with the senior medical resident or attending. This is especially true when dictating the discharge summary. Finally, when performing responsive care, trainees need to be sure that they note, write the problem in their handover list as well as document the problem in the chart. 


\section{Implications for Future Research}

From a medical education research perspective, each study in this dissertation had implications regarding ongoing and future research. For some of these, studies in the dissertation were developed to address them. For others, subsequent studies provided the opportunity for a further and deeper elaboration of the questions. Rather than create a summary of questions arising from each study, in this section I will review what I consider to be the most important future studies in my program of research. Thematically, these do however map onto three of the dissertation studies areas: PCR, attending styles, and reasoning tasks. In addition, the proposed future research often builds on the main PCR theme in relation to the others.

\section{Progressive Collaboration on Teams}

As depicted in Figure 7.1 and from a PCR perspective, there are at least four further studies that are warranted. First, one of the limitations of the studies described in Chapters 3 and 5 was that we did not include direct observation of junior trainees as they performed their daily patient follow-up and documentation tasks. From a genre system perspective, Paré and Smart suggest focusing on four dimensions: the texts (written or spoken), the composing practices, the reading practices, and the social roles of those who compose and use them ${ }^{56}$. Regarding the progress notes and discharge summaries, we largely focused on the texts themselves in the study reported in Chapter 3. In order to fully understand how to improve the genre system and the training of junior trainees, we also need to study their composing practices (e.g., how trainees collect the data for and compose their notes), reading practices (e.g., how trainees using existing documentation), and social roles (e.g., the variety of roles that trainees play on the team in relation to clinical documentation). Such a study should involve a combination of direct observation, field interviews, and textual analysis. It should also include purposeful sampling regarding time of year and level of training. This study would likely provide further insights into the extent to which the current progress note genre is a temporal genre ${ }^{33}$. It would also help to identify strategies for effective composing and the extent to which uptakes in progress notes are shaped by preceding notes compared with other factors.

A proposed second study should involve an exploration of the role of attending styles in supporting or constraining PCR and thereby the collective competence of the team. Given the large variations in practice inherent in the different styles, it is likely that they impact the team's ability to function differently. While there are many ways to conduct research regarding this topic, I would suggest focusing on two key areas. First, I would focus on the impact on the genre system of different styles: what genres variations arise; what is their intertextual relationship to other genres in the system; and what uptakes do they lead or fail to lead to? The second 
area of focus should be on transitions. This would require purposeful sampling around transitions from one style to another. In theory, some of the important transitions go from direct care style to minimalist and empowerment or minimalist to direct care style. In the first instance, how do teams adapt when the expectation changes from a situation where they may feel marginalized to one requiring them to take on a greater degree of responsibility. In the second instance, it would involve studying the reverse. In order to conduct such a study, it is first necessary to identify ways in which attending style could be measured. In the CTU, the senior medical resident also plays a major role in supervising and providing direct patient care. Similar to the attending physician, senior medical resident's likely do not all approach their role in exactly the same way. Future research should therefore explore senior medical resident styles of practice and how these influence PCR.

To date, the issue of how PCR functions across the entire health care team has not been studied. Moreover, it needs to be studied with regards to how it supports patients and their families as they re-integrate back into the community and participate in ongoing healthcare with other providers. Alvarez and Coiera (2006) suggested that weak interprofessional communication may be a source of medical errors ${ }^{57}$, but this question has not been examined empirically in the inpatient internal medicine context. Research on interprofessional communication in this context has focused on describing the nature of interprofessional communication 58,59, attitudes towards interprofessional communication 60,61 , and interventions to improve interprofessional communication ${ }^{62}{ }^{63}$. While studies have examined the impact of interprofessional communication on patient care ${ }^{64}$, it has not explored the extent to which the required formats and the number, types, and location of written documents enables or hinder collaboration and continuity of care and education across the series of communication events that make up a patient's hospital stay. Such a study would focus on the extent to which the different members of the interdisciplinary team effectively communicate their knowledge about patients in ways that support PCR. Moreover, data is also needed from patients to understand the extent to which documentation in the chart reflects the patient's own understanding of their medical issues and goals of care.

\section{Attending styles}

There are two other areas regarding attending styles that are worth exploring further. As previously stated, there will be a need to develop methods to study attending physicians based on their style, especially in light of the fact that it is not clear whether attending style is a stable trait or one that changes depending on the context or over time. Several possible study designs exist for exploring these ideas further. One approach could involve having trainees assess their attendings based on the four styles while also having the attendings perform a self-reflection exercise in relation to the styles. Given the possibility that style is not a fixed trait, it would 
we be enlightening to have attendings participate in some form of diary exercise to reflect on their style over time. As well, trainees could be asked to provide an estimate of the percentage of time, and under what circumstances, that attendings acted within a style. For example, they may rate an attending as spending $80 \%$ of their time in one style and $20 \%$ in another. The development of the styles descriptions could also be used for formative purposes. Assuming that no style is inherently bad, what are the key characteristics or circumstances that make each style more or less effective?

Different styles likely arise in response to key contextual features and exigencies. Exploring how attendings using different styles respond to the tensions between patient care and education would also be important. In particular, studying how the different styles impact trainees' development of progressive independence and professional identity. This type of research could be conducted in conjunction with the PCR related research outlined above as well as by using other less labour intensive methodologies such as interview or focus group based studies.

\section{Reasoning Tasks}

Given the paucity and shortcomings of current vocabularies related to clinical reasoning, I undertook the clinical reasoning tasks study (Chapter 6) to enable further exploration of the terms used to describe and study clinical reasoning. While I was able to list multiple reasoning tasks used during clinical encounters, these have not yet been verified in relation to the exigencies of real world practice. Accordingly, I would propose several studies to further explore and validate the reasoning tasks in real world settings. In Chapter 6, I outlined several possible future studies. Here I would like to focus on a couple of these that directly relate to collective competency and CTU teams.

In line with my program of research on genre systems, I would like to study the relationship between reasoning tasks and the different genres of the system. For example, what tasks are addressed during admission case reviews and how do these tasks differ from what the junior trainees originally addressed? Similarly, how do the reasoning tasks discussed with the senior medical resident differ from those discussed during attending case reviews? Are there patterns that could be identified and used to support trainee education? In a prior study, Lingard and Haber (1999b) identified that during case reviews, trainees learned that certain types of information, such as the social history, were not considered relevant 65 . Consequently, this may lead to them no longer collecting this type of information. By studying the reasoning tasks in the context of the genre system, it may be possible to identify where and when such types of data re-emerge and become relevant. 
Also germane are studies to explore the relationship between context and reasoning tasks. As discussed in the reasoning tasks study, it is assumed that not all tasks need to be addressed during each encounter with a patient. By purposefully selecting cases in relation to different contextual features, it should be possible to explore the relationship between tasks and context. One obvious example identified in the study reported in Chapter 3 relates to the reasoning task of "establishing goals of care" and the context of severe end-stage disease states, such as was the situation in one of the cases where the patient had advanced dementia. I would hypothesize that this task might become quite prominent in this context whereas in others it may play a lesser role.

The other specific area that should be explored are omissions related to failing to consider a patient's chronic active issues when managing their acute illness 10 . Again, this could be studied by focusing on the reasoning tasks addressed within the different genres of the system. Focusing on the omissions related to chronic active issues would allow us to develop a better understanding of how such omissions occur and why they persist.

While there are many other possible future studies, what I have chosen to present are some of the viable and relevant studies that would extend my own program of research. My goal has been to use this dissertation as a vehicle for offering insight into new questions and new ways of studying issues around the provision of clinical care in the context of teaching teams. By providing a new perspective and vocabulary for looking at old problems, it is my hope to spark the creativity of researchers who follow up on this work.

\section{References}

(1) Charmaz K. Constructing grounded theory: a practical guide through qualitative analysis. London: SAGE; 2006.

(2) The Sage Handbook of Grounded Theory. Thousand Oaks, CA: Sage Publications Ltd; 2007.

(3) Miller WL, Crabtree BF. Clinical Research. In: Denzin NK, Lincoln YS, editors. Handbook of qualitative research. 2nd ed ed. Thousand Oaks, Calif: Sage Publications; 2000. 607-643.

(4) Devitt AJ. Writing genres. Carbondale: Southern Illinois University Press; 2004.

(5) Corbin Dwyer S, Buckle JL. The space between: On being an insider-outsider in qualitative research. International Journal of Qualitative Methods 2009;8(1):54-63.

(6) Thurmond VA. The point of triangulation. J Nurs Scholarsh 2001;33(3):253-258.

(7) Burke K. Language as symbolic action : essays on life, literature, and method. California: Berkeley: University of California Press; 1966. 
(8) Vogeli C, Shields AE, Lee TA et al. Multiple chronic conditions: prevalence, health consequences, and implications for quality, care management, and costs. J Gen Intern Med 2007;22 Suppl 3:391-395.

(9) Partnership for Solutions. Chronic Conditions: Making the Case for Ongoing Care. 2002 Dec.

(10) Hayward RA, Asch SM, Hogan MM, Hofer TP, Kerr EA. Sins of omission: getting too little medical care may be the greatest threat to patient safety. J Gen Intern Med 2005;20(8):686-691.

(11) Pitt B. Male gender, diabetes, COPD, anemia, and creatinine clearance $<30$ $\mathrm{mL} / \mathrm{min}$ predicted hospitalization after heart failure diagnosis. Ann Intern Med 2010;152(8):JC4-3.

(12) Dunlay SM, Redfield MM, Weston SA et al. Hospitalizations after heart failure diagnosis a community perspective. J Am Coll Cardiol 2009;54(18):1695-1702.

(13) Bernabeo EC, Holtman MC, Ginsburg S, Rosenbaum JR, Holmboe ES. Lost in transition: the experience and impact of frequent changes in the inpatient learning environment. Acad Med 2011;86(5):591-598.

(14) Moore C, Wisnivesky J, Williams S, McGinn T. Medical errors related to discontinuity of care from an inpatient to an outpatient setting. J Gen Intern Med 2003;646-651.

(15) Coleman EA, Berenson RA. Lost in transition: challenges and opportunities for improving the quality of transitional care. Ann Intern Med 2004;141(7):533536.

(16) Amalberti R, Auroy Y, Berwick D, Barach P. Five system barriers to achieving ultrasafe health care. Ann Intern Med 2005;142(9):756-764.

(17) Safford MM, Allison JJ, Kiefe CI. Patient complexity: more than comorbidity. the vector model of complexity. J Gen Intern Med 2007;22 Suppl 3:382-390.

(18) Arora V, Johnson J, Lovinger D, Humphrey HJ, Meltzer DO. Communication failures in patient sign-out and suggestions for improvement: a critical incident analysis. Qual Saf Health Care 2005;14(6):401-407.

(19) van Walraven C, Seth R, Austin PC, Laupacis A. Effect of discharge summary availability during post-discharge visits on hospital readmission. J Gen Intern Med 2002;17(3):186-192.

(20) van Walraven C, Seth R, Laupacis A. Dissemination of discharge summaries. Not reaching follow-up physicians. Can Fam Physician 2002;48:737-742.

(21) Epstein RM. Communication between primary care physicians and consultants. Arch Fam Med 1995;4(5):403-409.

(22) Sutcliffe KM, Lewton E, Rosenthal MM. Communication Failures: An Insidious Contributor to Medical Mishaps. Acad Med 2004;79(2):186-194.

(23) Singh H, Thomas EJ, Petersen LA, Studdert DM. Medical Errors Involving Trainees: A Study of Closed Malpractice Claims From 5 Insurers. Arch Intern Med 2007;167(19):2030-2036.

(24) Kennedy TJ, Lingard LA. Questioning competence: a discourse analysis of attending physicians' use of questions to assess trainee competence. Acad Med 2007;82(10 Suppl):S12-S15. 
(25) Haber RJ, Lingard L. Learning oral presentation skills: a rhetorical analysis with pedagogical and professional implications. $J$ Gen Intern Med 2001;16(5):308-314.

(26) Lingard L, Haber RJ. Teaching and learning communication in medicine: a rhetorical approach. Acad Med 1999;74(5):507-510.

(27) Irby DM. How attending physicians make instructional decisions when conducting teaching rounds. Acad Med 1992;67(10):630-638.

(28) Irby D, Bowen JL. Time-efficient strategies for learning and performance. The Clinical Teacher 2004;1(1):23-28.

(29) Hoff TJ, Pohl H, Bartfield J. Teaching but not learning: how medical residency programs handle errors. J Organiz Behav 2006;27(7):869-896.

(30) Kennedy TJ, Lingard L, Baker GR, Kitchen L, Regehr G. Clinical oversight: conceptualizing the relationship between supervision and safety. J Gen Intern Med 2007;22(8):1080-1085.

(31) Miller C. Genre as Social Action. Quarterly Journal of Speech 1984;70:151-167.

(32) Bawarshi AS, Reiff MJ. Genre: An introduction to history, theory, research, and pedagogy. West Lafayette, Ind: Parlor Press; 2010.

(33) Markel M. Time and Exigence in Temporal Genres. Journal of Business and Technical Communication 2009;23(1):3-27.

(34) Kennedy TJ, Regehr G, Baker GR, Lingard LA. Progressive independence in clinical training: a tradition worth defending? Acad Med 2005;80(10 Suppl):S106-S111.

(35) Ranji SR. A piece of my mind. What gets measured gets (micro)managed. JAMA 2014;312(16):1637-1638.

(36) Dias P. Worlds apart: acting and writing in academic and workplace contexts. Mahwah, N.J: Lawrence Erlbaum Associates; 1999.

(37) Dias P, Paré A. Transitions: writing in academic and workplace settings. Cresskill, N.J: Hampton Press; 2000.

(38) Winsor D. Genre and Activity Systems: The Role of Documentation in Maintaining and Changing Engineering Activity Systems. Written Communication 1999;16(2):200-224.

(39) Schryer CF. The Lab vs. the Clinic: Sites of Competing Genres. In: Freedman A, Medway P, editors. Genre and the new rhetoric.London: Taylor \& Francis; 1994. 105-124.

(40) Bazerman C, Prior P. Intertextuality: How texts rely on other texts. In: Bazerman C, editor. What writing does and how it does it: An introduction to analyzing texts and textual practices.Mahway, NJ: Lawrence Erlbaum Associates; 2004. 82-96.

(41) Kristeva J. "Nous Deux" or a (Hi)Story of Intertextuality. Romantic Review 2002;93(1/2):7-13.

(42) McCue JD, Beach KJ. Communication barriers between attending physicians and residents. J Gen Intern Med 1994;9(3):158-161.

(43) Siegler EL. The evolving medical record. Ann Intern Med 2010;153(10):671677.

(44) Weed LL. Medical records that guide and teach. $N$ Engl $J$ Med 1968;278(11):593-600. 
(45) Weed LL. Medical records that guide and teach (Concluded). $N$ Engl J Med 1968;278(12):652-657.

(46) Holmes C. The problem list beyond meaningful use. Part 2: fixing the problem list. J AHIMA 2011;82(3):32-35.

(47) Devlin MK, Kozij NK, Kiss A, Richardson L, Wong BM. Morning handover of oncall issues: opportunities for improvement. JAMA Intern Med 2014;174(9):1479-1485.

(48) Ten Cate 0. Entrustability of professional activities and competency-based training. Med Educ 2005;39(12):1176-1177.

(49) Hauer K, ten Cate O, Boscardin C, Irby D, Iobst W, Sullivan P. Understanding trust as an essential element of trainee supervision and learning in the workplace. Adv in Health Sci Educ 2014;19(3):435-456.

(50) Aylward M, Nixon J, Gladding S. An entrustsable professional activity (EPA) for handoffs as a model for EPA assessment development. Acad Med 2014.

(51) Ratcliffe TA, Hanson JL, Hemmer PA, Hauer KE, Papp KK, Denton GD. The Required Written History and Physical is Alive, but Not Entirely Well, in Internal Medicine Clerkships. Teach Learn Med 2013;25(1):10-14.

(52) Chang A, Bowen JL, Buranosky RA et al. Transforming primary care training-patient-centered medical home entrustable professional activities for internal medicine residents. J Gen Intern Med 2013;28(6):801-809.

(53) Irby DM. What clinical teachers in medicine need to know. Acad Med 1994;69(5):333-342.

(54) Hirsh DA, Holmboe ES, ten Cate O. Time to Trust: Longitudinal Integrated Clerkships and Entrustable Professional Activities. Acad Med 2014;89(2):201204.

(55) Monrouxe LV. Identity, identification and medical education: why should we care? Med Educ 2010;44(1):40-49.

(56) Paré A, Smart G. Observing Genres in Action: Towards a Research Methodology. In: Freedman A, Medway P, editors. Genre and the new rhetoric.London: Taylor \& Francis; 1994. 146-154.

(57) Alvarez G, Coiera E. Interdisciplinary communication: An uncharted source of medical error? Journal of Critical Care 2006;21:236-242.

(58) Gotlib Conn L, Lingard L, Reeves S, Miller K-L, Russell A, Zwarenstein M. Communication channels in general internal medicine: A description of baseline patterns for improved interprofessional collaboration. Qualitative Health Research 2009;19(7):943-953.

(59) Manias E, Street A. Nurse-doctor interactions during critical care ward rounds. Journal of Clinical Nursing 2001;10:442-450.

(60) Robinson FP, Gorman G, Slimmer LW, Yudkowsky R. Perceptions of effective and ineffective nurse-physician communication in hospitals. Nursing Forum 2010;45(5):206-216.

(61) Rabøl LI, McPhail MA, Østergaard D, Anderson HB, Mogensen T. Promoters and barriers in hospital team communication: A focus group study. Journal of Communication in Healthcare 2012;5(2):129-139.

(62) Carroll K, Iedema R, Kerridge R. Reshaping ICU ward round practices using video-reflexive ethnography. Qual Health Res 2008;18(3):380-390. 
(63) Rice K, Zwarenstein M, Gotlib Conn L, Kenaszchuk C, Russell A, Reeves S. An intervention to improve interprofessional collaboration and communications: A comparative qualitative study. J Interprof Care 2010;24(4):350-361.

(64) Reeves S, UK Centre for the Advancement of Interprofessional Education. Interprofessional teamwork for health and social care. Chichester, West Sussex, U.K: Wiley-Blackwell; 2010.

(65) Lingard L, Haber RJ. What do we mean by "relevance"? A clinical and rhetorical definition with implications for teaching and learning the case-presentation format. Acad Med 1999;74(10 Suppl):S124-S127. 


\section{SUMMARY}

This is a dissertation focused on internal medicine inpatient clinical teaching teams and the ways in which their communication practices support and constrain teams' ability to provide safe patient care and trainee education. In Canada, these teaching teams are referred to as clinical teaching units (CTUs). Despite recent changes to the structure and nature of training in medicine, CTUs continue to play an important role in the training of medical students and residents and in the delivery of medical care. Due to the nature of the CTU environment, team membership is constantly shifting. Thus, the quality of patient care becomes more a product of a team's collective competence than of any one individual's competence. Supporting this collective competence is a complex system of oral and written communication practices. This dissertation treats each of these practices as genres: they have recurring structures, use language to serve shared purposes and achieve particular social actions and are recognized as distinct practices by the members of the teams using them. This definition of genre is at the heart of this dissertation, which used the lens of Rhetorical Genre Theory (RGT) to explore the CTU context. While prior research had explored individual genres within this communication system, the genre system - set of connected genres linked to a common set of purposes - had not been studied. The goal of this dissertation was therefore to explore the CTU genre system and the ways in which its communication practices supported and constrained the team's ability to provide safe patient care and trainee education. This dissertation consists of seven chapters: two introductory chapters (chapters 12), four empirical studies (chapters 3-6), and a discussion (chapter 7).

Chapter 1 introduces the reader to the CTU context. It describes that in this setting, attending physicians support the education of medical students and residents by actively sharing patient care. As a consequence, it points out, quality of care is heavily reliant on the team's collective competence. While it acknowledges the critical role that individual competence plays, the chapter draws attention to the frequent changes in team membership and the burden they place on the team's ability to use its communication practices to support collective care. Other challenges that it identifies include the varying levels of learner experience, the dual roles of education and patient care, and patient complexity. The chapter then explores the current gaps in the literature and identifies that, to date, studies have largely focused on gaps in quality of care, on best practices in teaching, and on isolated elements of communication. Chapter 1 concludes with an acknowledgement of the need for a more nuanced study of how the CTU's communication practices support and constrain trainee education and the team's collective competence in providing quality patient care. 
Chapter 2 provides a general overview of rhetorical genre theory (RGT) and genre systems theory. It explains how RGT provides a valuable lens for studying communication practices because, rather than merely describing the characteristics of a genre, RGT draws attention to the social actions that a genre gives rise to. The chapter points out that by focusing on these social actions and how they function within a system of genres, RGT can help provide deep insights into systems of practice and the nuances of context and culture that help to shape them. It also reviews key concepts for studying genre systems; that is, how to study the relationships that exist between genres (intertextuality, recontextualization and uptake) and how to understand the social actions of genres within the system (exigence and social motive). Because RGT is neither a method nor associated with a specific methodology, Chapter 2 concludes with a brief summary of the three different methodologies used in the dissertation studies: multiple instrumental case study, constructivist grounded theory and consensus building.

Chapter 3 describes the first of four empirical studies and represents the foundational study of the dissertation. That first study explores the CTU admission genre system and identifies the underlying exigence that should drive the genre system from a patient care perspective. This exigence is referred to as Progressive Collaborative Refinement (PCR) and suggests that from the start of a patient's admission, the team's dialogue and documentation about the patient should capture the full progression of their thinking regarding all of the patient's active problems. The Chapter further suggests that PCR should be an iterative process that evolves as new information becomes available or as new insights and understandings are gained through review with more senior members of the team. PCR is described as predominantly visible through its absence rather than its consistent presence within the genre system. Therefore, this chapter reports on three forms of fragmentation - fragmented documentation, fragmented conceptualization, and fragmented continuity - all of which interact with each other and potentially constrain PCR.

Chapter 4 describes a study undertaken in response to the wide degree of variability of attending physician case review practices as identified in the study described in Chapter 3. It explains that prior research largely treats the different roles of the attending physician in isolation, focusing on supervisory teaching or on oversight and clinical care. In contrast, this study identifies four styles which take into account all three aspects of attending practice - patient care, trainee education and team oversight. Moreover, it points out that, rather than identifying a single practice, the four styles help illuminate how different attendings configure the roles in relation to each other and in response to the inherent tensions of the CTU and their own sense of priority related to each role. From a genre perspective, this study helps explain how different attending physicians influence the genre system and CTU team members' roles. The Chapter calls for more team dialogue regarding attending styles and the changing expectations that arise as a result of style variations between attendings at the time of changeover. 
Chapter 5 describes the third study which was designed to explore interruptions and their impact on the case review genre and PCR. The study reports that interruptions are an essential component of the case review genre, helping to both support patient care and trainee education. However, the chapter points out that depending on how and when they occur and how they are handled, interruptions can either support or hinder PCR. The key defining element it explains is the type of detours created by the interruption. It further describes best practices as interruptions that occur at the end of a particular presentation section rather than in the middle of a section, and where the interruption and subsequent detour are properly managed by the attending guiding the trainee back to where he/she left off prior to the detour.

Chapter 6 contains the final dissertation study which was focused on clinical reasoning tasks. This study addresses the question: "PCR about what?". In analyzing the transcripts from the PCR study, a lack of vocabulary for describing and assessing the purpose(s) being addressed during case reviews or admissions and progress notes had been identified. While it was possible to trace particular active problems identified by the team during their case review discussions, it was not possible to explore and compare how different genre variations allowed or constrained particular ways of thinking about each problem. This Chapter was the response to that problem. The Chapter describes a consensus building study that identified 24 possible reasoning tasks and it distinguishes them from how physicians reason (i.e., clinical reasoning) and clinical tasks (i.e., things physicians do when seeing patients such as taking histories and performing physical exams). The Chapter concludes by identifying the significance of the study findings for teaching, clinical practice and future research.

Chapter 7, begins with a section on reflexivity - a convention used in constructivist work in recognition of the importance placed on supporting readers to interpret the work by taking into consideration both the research findings and the researcher's relationship to them. The Chapter then moves on to explore the dissertation study findings from an RGT perspective. Moreover, rather than looking at the dissertation studies individually, it discusses them as a coherent group and demonstrates how each contributes to a growing understanding of the genre system: the exigencies that drive it; their relationship to each other; how the RGT concepts of intertextuality, recontextualization and uptake explain why the current genre system may fail to support PCR and; how contextual features including attending styles may all play a role supporting or constraining PCR. Building on these insights, the Chapter then discusses possible implications for clinical practice from the standpoint of the genre system, supervisory practices and junior trainee practices. The Chapter concludes with suggestions for possible future research related to PCR, supervisory styles and clinical reasoning tasks. 


\section{SAMENVATTING}

Dit is een proefschrift dat gericht is op teams die binnen de afdeling Interne Geneeskunde (IG) verantwoordelijk zijn voor zowel de zorg van opgenomen patiënten als het opleiden van coassistenten en aiossen*. In het bijzonder richt dit proefschrift zich op de vraag hoe hun communicatiegewoonten hun vermogen om veilige patiëntenzorg te verlenen en coassistenten/aiossen op te leiden, bevorderen en inperken. In Canada worden deze onderwijsteams clinical teaching units (CTUs), oftewel "klinische onderwijseenheden", genoemd. Ondanks het feit dat de structuur en aard van het medische onderwijs onlangs een aantal wijzigingen hebben ondergaan, spelen deze onderwijseenheden nog altijd een belangrijke rol in de opleiding van medische studenten en aiossen en in de medische zorgverlening. Vanwege de aard van hun omgeving, wisselt de samenstelling van deze onderwijsteams continu. Dit betekent ook dat de kwaliteit van de patiëntenzorg meer het resultaat is van de deskundigheid van het team als geheel, dan van de deskundigheid van één individu afzonderlijk. Aan deze gezamenlijke deskundigheid ligt een ingewikkeld systeem van mondelinge en schriftelijke communicatiegewoonten ten grondslag. Dit proefschrift behandelt elk van deze gewoonten als genres: ze worden gekenmerkt door terugkerende patronen, gebruiken taal om gezamenlijke doelen te bereiken en bepaalde sociale handelingen te volbrengen en worden door de teamleden die ze gebruiken erkend als uitgesproken gewoonten. Deze definitie van "genre" staat centraal in dit proefschrift dat door de lens van retorische genretheorie (RGT) de context van deze onderwijseenheden verkent. Hoewel voorgaand onderzoek zich toegespitst heeft op de aparte genres binnen dit communicatiestelsel, is het genresysteem, d.w.z. de aaneenschakeling van verschillende genres die door een aantal gezamenlijke doelen zijn verbonden, onbestudeerd gebleven. Het doel van dit proefschrift was dan ook om het genresysteem van deze onderwijseenheden te onderzoeken, en daarbij in te gaan op de vraag hoe de inherente communicatiegewoonten het vermogen van het team om veilige patiëntenzorg te verlenen en coassistenten/aiossen op te leiden, bevorderden en inperkten. Dit proefschrift bestaat uit zeven hoofdstukken, te weten: twee inleidende hoofstukken (hoofdstukken 1-2), vier empirische studies (hoofdstukken 3-6) en een discussie (hoofdstuk 7).

Hoofdstuk 1 maakt de lezer bekend met de CTU-context. Het beschrijft dat behandelend artsen in deze setting het leerproces van Geneeskundestudenten en aiossen ondersteunen door hen actief bij de patiëntenzorg te betrekken. Als gevolg daarvan, wordt uitgelegd, is de kwaliteit van de zorg sterk afhankelijk van de gezamenlijke deskundigheid van het team. Hoewel het de cruciale rol die individuele deskundigheid vervult erkent, vestigt het hoofdstuk de aandacht op de vele wis- 
selingen in teamsamenstelling en op het feit dat deze het vermogen van het team om middels hun communicatiegewoonten de verlening van gezamenlijke zorg te bevorderen, bemoeilijken. Andere uitdagingen die in dit hoofdstuk benoemd worden zijn de verschillende ervaringsniveaus van de leerling, de dubbele rol van opleider en patiëntenzorgverlener en patiëntcomplexiteit. Het hoofdstuk bespreekt vervolgens welke hiaten de literatuur momenteel kent en stelt vast dat studies zich tot op heden voornamelijk richtten op tekortkomingen in de kwaliteit van de zorg, op best practices in het onderwijs en op afzonderlijke elementen van communicatie. Aan het einde van hoofdstuk 1 wordt erkend dat er behoefte is aan een meer genuanceerde studie naar de vraag hoe de communicatiegewoonten van klinische onderwijseenheden het leerproces van coassistenten/aiossen en het gezamenlijke vermogen van het team om patiënten kwaliteitszorg te verlenen, bevorderen en inperken.

Hoofdstuk 2 geeft een algemeen overzicht van retorische genretheorie (RGT) en genresysteemtheorie. Er wordt uitgelegd hoe RGT een waardevolle lens biedt voor het bestuderen van communicatiegewoonten, omdat het in plaats van slechts een beschrijving te geven van de kenmerken van een genre de aandacht vestigt op de sociale handelingen waartoe een genre leidt. Het hoofdstuk wijst erop dat door te focussen op deze sociale handelingen en hun werking binnen een systeem van genres, RGT kan helpen om grondig inzicht te verschaffen in praktijksystemen en de contextuele en culturele nuances die deze systemen mede vorm geven. Daarnaast wordt een overzicht gegeven van de kernbegrippen die bij een studie naar genresystemen van belang zijn. Met andere woorden, hoe bestudeer je de verbanden die tussen genres bestaan (intertekstualiteit, recontextualisering en overdracht) en hoe kunnen we wijs uit de sociale handelingen van genres binnen het systeem (behoefte en sociale aanleiding)? Omdat RGT geen methode is, noch verband houdt met een specifieke methodologie, sluit hoofdstuk 2 af met een korte samenvatting van de drie verschillende methodologieën die in de proefschriftstudies gebruikt zijn: meervoudige geneste casestudy, constructivistische gefundeerde theorie en consensusvorming.

Hoofdstuk 3 beschrijft de eerste van vier empirische studies en legt de basis voor het proefschrift. Dit eerste hoofdstuk onderzoekt het door de klinische onderwijsteams gehanteerde genresysteem rondom "patiëntopname" en stelt vast welke onderliggende behoefte het genresysteem vanuit een patiëntenzorgperspectief in gang zou moeten zetten.

Deze behoefte wordt voortschrijdende, gezamenlijke uitwerking of PCR* genoemd, wat betekent dat de beraadslaging en documentatie van het team over de patiënt hun hele denkproces betreffende de actieve problemen van de patiënt zouden moeten weerspiegelen. Het hoofdstuk voert verder aan dat PCR een iteratief proces zou moeten zijn dat zich ontwikkelt naarmate er nieuwe informatie beschikbaar komt of nieuwe inzichten of kennis verkregen worden door ruggespraak met meer ervaren teamleden. PCR wordt omschreven als een fenomeen dat eerder zichtbaar 
is door haar dominante afwezigheid dan door haar consequente aanwezigheid binnen het genresysteem. Dit hoofdstuk doet daarom verslag van drie vormen van fragmentatie, nl. gefragmenteerde documentatie, gefragmenteerde beeldvorming en gefragmenteerde continuïteit, die allemaal met elkaar in wisselwerking staan en mogelijk afbreuk doen aan PCR.

Hoofdstuk 4 beschrijft een studie die verricht werd naar aanleiding van de grote verschillen die tijdens de in hoofdstuk 3 beschreven studie geconstateerd werden met betrekking tot de benadering van patiëntcasussen door behandelend artsen. Er wordt uitgelegd dat eerder onderzoek voornamelijk gemoeid was met het uitlichten van de verschillende rollen van de dienstdoende arts, en zich daarbij richtte op begeleidend opleiden óf op toezicht en klinische zorg. Deze studie, daarentegen, onderscheidt vier stijlen die alle drie de aspecten van een ziekenhuisdienst in acht nemen, nl. de zorg voor patiënten, het opleiden van coassistenten/aiossen en het houden van toezicht op het team. In plaats van een algemene werkwijze aan te duiden, wordt de lezer er verder op geattendeerd dat de vier stijlen inzicht verschaffen in de manier waarop verschillende behandelend artsen de rollen verdelen ten opzichte van elkaar, als reactie op spanningen binnen het team en volgens het belang dat zij zelf aan elke rol hechten. Vanuit een genreperspectief helpt deze studie te begrijpen hoe verschillende behandelend artsen het genresysteem en de rollen van de onderwijsteamleden beïnvloeden. Het hoofdstuk roept op tot meer teamoverleg over de werkstijlen en de veranderende verwachtingen die voortvloeien uit stijlverschillen tussen behandelend artsen ten tijde van de dienstwisseling.

Hoofdstuk 5 beschrijft de derde studie die ten doel had onderbrekingen en hun uitwerking op het genre rondom de patiëntbespreking en PCR nader te onderzoeken. De studie verhaalt dat onderbrekingen een belangrijk onderdeel uitmaken van dit genre, daar zij zowel de patiëntenzorg als het leerproces van de coassistent/aios bevorderen. In het hoofdstuk wordt echter benadrukt dat, afhankelijk van hoe en wanneer deze onderbrekingen plaatsvinden en hoe zij worden ondervangen, zij het PCR-proces ofwel kunnen bevorderen ofwel belemmeren. Er wordt uitgelegd dat deze uitkomst vooral afhangt van welke omweg door de onderbreking wordt ingeleid. Voorts worden best practices uitgelegd als onderbrekingen die pas na (in plaats van middenin) een bepaald deel van een presentatie plaatsvinden en die samen met de omweg die vervolgens wordt ingeslagen door de behandelend arts in goede banen worden geleid, opdat de leerling weer wordt teruggevoerd naar het moment van vóór de onderbreking.

Hoofdstuk 6 bevat de laatste studie van dit proefschrift die zich richtte op klinisch redeneertaken. In deze studie werd ingegaan op de vraag: "PCR, waarover?". Bij een analyse van de bij de PCR-studie verkregen transcripten werd geconstateerd dat men niet over voldoende vocabulaire beschikte om de kwestie(s) die tijdens een patiëntbespreking of opname en decursus aan de orde werd gesteld te beschrijven en beoordelen. Hoewel we bepaalde actieve problemen konden 
onderscheiden die tijdens de patiëntbesprekingen door het team werden geconstateerd, was het niet mogelijk om te onderzoeken en vergelijken hoe genreverschillen bepaalde probleembenaderingen faciliteerden of juist tegenwerkten. Dit hoofdstuk was het antwoord op dat probleem. Het hoofdstuk beschrijft een studie gebaseerd op consensusvorming waarbij 24 mogelijke redeneertaken werden vastgesteld die onderscheiden werden van hoe artsen redeneren (d.w.z. klinisch redeneren) en van klinische taken (d.w.z. dingen die artsen doen tijdens een consult, zoals anamneses afnemen en lichamelijk onderzoek verrichten). Aan het eind van het hoofdstuk wordt aangestipt hoe de studiebevindingen van belang kunnen zijn voor het onderwijs, de klinische praktijk en toekomstig onderzoek.

Hoofdstuk 7 begint met een paragraaf over reflexiviteit, een principe dat vaak wordt toegepast bij constructivistisch werk en waarbij de lezers worden gestimuleerd het werk te interpreteren door niet alleen de onderzoeksresultaten, maar ook de wijze waarop de onderzoeker zich daartoe verhoudt, in acht te nemen. Vervolgens worden in het hoofdstuk de onderzoeksresultaten van dit proefschrift bekeken vanuit een RGT-perspectief. In plaats van de studies in dit proefschrift als losse delen te beschouwen, worden deze bovendien behandeld als een samenhangend geheel en wordt aangetoond hoe elke studie bijdraagt aan een beter begrip van het genresysteem: de behoeften die het systeem aandrijven; hun onderlinge verhoudingen; hoe de RGT-concepten intertekstualiteit, recontextualisering en overdracht kunnen verklaren waarom het huidige genresysteem misschien niet erg bevorderlijk is voor het PCR-proces; en hoe contextuele kenmerken inclusief werkstijlen misschien allemaal helpen het PCR-proces te bevorderen of te beletten. Voortbouwend op deze inzichten wordt in het hoofdstuk vervolgens besproken welke potentiële gevolgen zij hebben voor de klinische praktijk vanuit het oogpunt van het genresysteem, voor supervisie en voor de inrichting van het onderwijs voor coassistenten/aiossen. Het hoofdstuk wordt afgesloten met aanbevelingen voor eventueel toekomstig onderzoek met betrekking tot PCR, supervisiestijlen en klinisch redeneertaken. 


\section{Valorization}

The research presented in this dissertation has several possible broad reaching implications. In my discussion section, I explored the implications for practice and future research and I will not replicate these here. However, as I have already done a considerable amount of knowledge translation work with regards to those implications, I will start this section by summarizing these. I will then turn to a brief exploration of three other areas: implications for clinical practice beyond the CTU, implications for patients and caregivers, and implications for electronic patient record developers.

\section{Knowledge dissemination}

While publication itself is an important component of knowledge dissemination, it is rarely sufficient in and of itself. In order to increase the potential uptake of ideas from my work into the relevant communities of practice in clinical practice and medical education, I have already taken several steps. The first was to increase the awareness of the work at the local, national and international levels. In my fields of medical education and internal medicine, this largely means presentations at conferences. Over the past few years, as data emerged from the various studies in this dissertation, I delivered 25 presentations at local, national and international conferences. At the national and international levels, these include the Canadian Conference on Medical Education, the Canadian Society for Internal Medicine and the Association of American Medical Colleges Research in Medical Education conference and the Association for Medical Education in Europe conference. At the local level, in addition to presenting the results at grand medical rounds and teaching rounds, I also took steps to ensure more local impact. In particular, I sit on numerous local committees related to the emergence of electronic health records at my institution and related to CTU restructuring. I also created several handouts that are widely used on the CTU to teach trainees how to create their admission, progress, and discharge summary notes. Additionally, I now give a yearly series of lectures and workshops to both medical students and residents on clinical reasoning and documentation. Finally, because our knowledge of how to influence change related to my research findings is a work in progress, I have begun several new research projects. 


\section{Implications for clinical practice beyond the CTU}

While my research has largely focused on the CTU, there is good reason to believe that the findings are relevant to other clinical areas. First, PCR appears relevant to all areas of medicine. Consider for example the primary care office setting. In this setting, similar to other areas of healthcare, patients continue to accumulate a large number of chronic medical illnesses as well as a considerable number of specialists and allied healthcare providers who follow and support them. From visit to visit across this potentially large group of healthcare providers, it is essential for PCR to occur to ensure quality care. Failing to do so undoubtedly leads to increased costs within the system and increased morbidity and mortality. While it has not been studied as such, it is quite likely (almost certain) that in the current Canadian Healthcare system, PCR is not the norm. One key example is the direction of information flow. For the most part, it is unidirectional; as specialists see patients in follow-up, they send a note to the patient's family physician. Apart from the initial consultation, family physicians do not send follow-up notes to specialists. Moreover, specialists do not necessarily send copies of their notes to each other even when they are sharing the care of a patient. And, when their patients get admitted to hospital, there exists no single health record from which medical teams can gather the relevant data on patients. Rather than refining, medical teams from numerous specialties are left re-creating, often incompletely, information about a patient's medical conditions and active problems.

The list of active problems clearly guides the team's work. The current clinical documentation standards, however, do not automatically support the differentiation between chronic active medical problems and past medical history. While much has been written about the increasing burden of illness played by chronic active conditions (see introduction), the standard genre of the medical record has not been configured to address this issue. Similarly, the standard teaching of history taking focuses the physician's attention on the chief complaint and the history of present illness, and not on an exploration of the list of active problems. This represents an excellent opportunity for innovation. Given the magnitude of the problem, regional and national healthcare planners constitute an important group of stakeholders to whom further knowledge dissemination could benefit.

My work on attending styles is also of likely benefit to other specialties outside the CTU such as other physician groups who organize themselves in clinical teaching teams. Key examples include consultation services, surgical services, and pediatric services. While local and specialty specific contextual features lead to further variations on the attending styles, the concepts themselves are likely quite applicable. In addition to further research on attendings styles in these different settings, interested groups could also use the existing description of styles for selfreflection and faculty development. Similarly, my work on interruptions and 
detours has broad applicability across the health education system. There is good reason to believe that a similar phenomenon takes places in most settings where trainees are involved in collecting and presenting patient data.

\section{Implications for Patients and Caregivers}

Coming from both my personal experiences as a caregiver and my professional experience as a clinician, I have no doubt that the concept of PCR has great relevance to patients and their caregivers. While there has been much written about poor experiences of patients and caregivers in the healthcare system, I suspect that few truly understand the magnitude of the problem or the ways in which they could play a role in supporting PCR. Below I summarize a few key ideas that emerged as a result of the PCR findings. I do not claim that these are novel in all settings; they may emerge in literatures outside of those supporting this work. In my local context, however, the suggestions I offer are novel.

Starting with medications, all patients should have an up-to-date list of all the medications that they are currently taking. Moreover, if these have changed over time, they should also have a list of discontinued medications and the rational for the discontinuation. To support this, patients should require the medical team to provide them with an updated list and rationale for all changes made prior to their discharge from hospital. Increasingly, patients are cared for by numerous healthcare professionals. Accordingly, along with their updated list of medications, they should have a list of all of the healthcare practitioners who currently support their care and the area of care they are supporting. This should be provided to all practitioners caring for them so as to facilitate inter and intra-professional sharing of information. With regards to chronic active problems, patients should also have a list of these along with a summary of the overall plan of care for each problem. A summary of key investigations and where they were performed would also be beneficial to the patient. Prior to discharge from hospital, the patient and/or their caregiver should require the healthcare team to review their list of problems and medications and provide them with any relevant updates that arose as a result of their hospital stay. From a commercialization standpoint, a quick online search reveals that there are already numerous vendors working on products to facilitate this type of communication.

\section{Implications for Electronic Medical Record Developers}

My research took place in a hybrid system of electronic and paper based records. More specifically, the electronic health record in the settings studied provided information on results of investigations, lists of current medication, and a limited 
set of dictated notes that include discharge summaries, consultation notes, and ambulatory clinic visit notes. It did not include, however, any form of cumulative patient profile or progress notes. Having viewed many commercial products over the past few years and reviewed some of the literature related to problems with active problem lists, I will offer some comments for the developers of these electronic systems.

Based largely on the results from the PCR study but also drawing on my work on clinical reasoning tasks as well as other research already reviewed in this dissertation, the most important component of any electronic medical record is the cumulative patient profile. While I would certainly suggest further research in this area, I anticipate that an electronic system that could allow for a fully integrated and actively updatable cumulative patient profile would lead to the greatest impact in supporting safer and more time-efficient patient care. Ideally, this would include the following key elements:

- A list for past medical history in which items could be selected as chronically active or acutely exacerbated. Any item selected would then automatically create the option for data entry related to three key types of information: baseline function, current status, and current plans of care.

- A list of new active problems. Given the known problems with active problem lists that are based on existing coding systems (see discussion in chapter 7), this list should allow for free text entry for problem labels that are updatable as new information becomes available. Sections should also be created for describing baseline status, current status, and current plans for the assessment and management of the problem. Given that not all active problems are based on medical diagnoses, there should also be optional sections that can be completed or created by allied health care professionals involved in the patient's care. A good example relates to issues of mobility or planning for discharge when the patient may be transitioning to an alternative living situation such as a nursing home.

- All active problems should include the name and contact information of the healthcare provider(s) involved in the ongoing care for that problem.

- For both the chronic active and acutely active problems listed, updating relevant sections of the cumulative patient profile should be part of the daily progress note. This would eliminate the problem of dropped items from the active problem list. If there is no update, they should simply be able to indicate that the status and plans are unchanged.

- Medication lists should not be static nor should they be restricted to current medications only. Providers need to know how a patient's dosing and list of medications have changed over time. At the time of discharge, it is essential 
that the medication list clearly and easily indicates all changes from the medication list prior to admission to hospital.

- At the time of discharge, the team should be able to review the cumulative patient profile and use it to generate the discharge summary. Again, this would reduce the amount of time spent creating discharge summaries and would reduce omission errors in the documentation. Very few new fields would be required for the discharge summary. The main updates required would be anticipating and documenting the plans for ongoing follow-up and management of each active problem addressed during the hospital stay.

- Prior to finalizing the discharge summary, teams should be prompted to confirm and update the list of providers that will receive a copy of the discharge summary. This should be a push function rather than relying on teams to selfgenerate the list.

While there are likely many other features of electronic records that could and should be improved upon, the suggestions above are directly linked to the research from this dissertation.

\section{Valorization Conclusions}

Reflecting on the opportunities for knowledge valorization arising from my dissertation work, the concept of PCR and what was learned about ways in which it is hindered and supported has the greatest potential for improving the quality of the healthcare system. In particular, those participating in the design of electronic medical records should pay careful attention to ways in which their products can support PCR, and not just billing and finances. As patients and their caregivers are key stakeholders, they too would benefit from better understanding the ways in which they can play a role in supporting PCR. Components of knowledge valorization arising from other findings from this dissertation are also important but currently are more limited in scope. For the most part, given my focus on exploring practice, their greatest potential lies in supporting faculty development, reflection on practice, and future research. 


\section{ACKNOWLEDGEMENTS}

Looking back on the past four years, I feel a tremendous sense of gratitude for the opportunity this $\mathrm{PhD}$ has afforded me and for all of the tremendous support I have received from my family, my friends, my colleagues, my institution and from SHE at Maastricht. Without question, I would not have gotten to this point without a whole lot of wonderful people doing all of the great things that they do!

To begin, I would like to thank my family. Michelle, you are simply the best partner anyone could ask for! Four kids make for a very, very busy household; I only ever felt your full support for tackling this crazy further training. Thank you so much for that, it made all of the difference. Rebecca, thanks for always wanting to know what I was studying, for wanting to sit and listen to my presentations and making me feel like my work mattered to you. I just love knowing that I have a, now 16 years old, daughter who thinks my work is cool. As for the rest of you guys, Sam, Jacob and Max, you're just great and fun and I thank you for always being there to remind me that weekends and evening are for family and not for work. P.s., if any of you boys are reading this acknowledgement, thanks for also growing up to be someone who would care to read your dad's thesis.

Next, I would like to thank my supervisory team. Wow, I am ever so appreciative of all that you have done in supporting me. I have learned so much from all of you. Lorelei, you set the bar for all other supervisors and mentors. I aspire to support my students as you have me and all the rest of us here at CERI. When you suggested that I pursue my PhD I had no idea where this journey would take me. However, looking back, I know with certainty that had you not planted that first seed, I would not likely be here now. Prior to working with you, I had been struggling for years to find a way to study the things that most interested me in medical education. Then, you gave me genre theory and a way forward became possible. I will never see the world in the same way again! Thank you! P.s. I have also loved the grammar lessons and will sorely miss them. It's another of the new vocabularies you gave me.

Tim, from the get go you were uber supportive. I don't think I know anyone who is as enthusiastic about their students as you are. At every point along the way you have supported and encouraged me. You also came to London and spent a week with me analysing data and exploring themes at one of those critical, early, junctures where I was still trying to figure things out. I will always cherish that wonderful week. I think it was during that week that progressive collaborative refinement was born. Just look at what has happened since! Thank you!

Jeroen, you were the wild card in my supervisory committee, when Tim told me that we needed another Maastricht supervisor to balance things out, I really had no 
idea what to expect. I am very grateful that you agreed to join our group. Despite our two programs of research having nothing in common, I always felt like you devoted so much time and attention to my work. At every step of the way you challenged me to make the work both rigorous and clear to all readers. Without question, the final products are much the better because of your feedback. I also have to thank you for being the one we could turn to for all matters Dutch! Knowing the rules matter. Thank you!

Georges, I can't believe we finally got to work together. Since starting my Master's degree fifteen years ago I have wanted to collaborate with you. While you may not remember this, I distinctly remember speaking to you early in my Master's degree about my concerns with the diagnostic focus of the clinical reasoning literature. I guess it takes a PhD to challenge something that big. Thank you for helping me find a way to start that conversation in the literature. Without your support, I don't think I could have found the right way to get that portion of my program of research off the ground. You have also been very supportive with the rest of this PhD. Coming from such a different research paradigm you constantly challenged me to look outward and see different possibilities. I have also benefitted from your insistence on precision of language and good grammar; many times you have slowed me down and helped ensure that the message we were creating was the right one. Thank you!

Along the way, I have also been blessed, and I continue to be blessed, by supportive leaders. In particular, I would like to highlight two of them who really helped make this PhD a possibility - David Hollomby and Carol Herbert. In my mind, the two of you will always be inseparable. You were both my firsts, first department chair and first dean. From the beginning, you both were so supportive. First you helped make our Group for the Advocacy \& Advancement of Medical/Dental Education Scholarship (GAMES) possible. Then, there was the Centre for Education Research \& Innovation. That was a game changer! Looking back, without question, this $\mathrm{PhD}$ was made possible by your willingness to believe in me and in your generosity in supporting and mentoring me along the way. I am ever so grateful to the both of you. Thank you!

Looking back, I am also grateful for the many special colleagues and friends across the country who have helped me find my place in medical education. Starting here at home, I would like to thank all of my friends and colleagues at CERI; you are an unbelievably supportive and generative community. Thanks you! Without question, the medical education community across Canada has got to be one of the most supportive and generative communities in the World. All of the friends and colleagues that I have met through the Canadian Association for Medical Education (CAME) and the Canadian Conference on Medical Education (CCME) have been a great support and inspiration for me. While I cannot possibly name you all, I think you know who you are. Thank you! 
I do want to thank one very special colleague, friend and mentor, Wayne Weston. Wayne, we first met when I moved to London to start my internal medicine fellowship and I attended a workshop you put on. What followed was a friendship that changed my life. You helped me during those formative years to find my voice in medical education. You also helped me to forge the community here at Western that has continued to sustain me. GAMES was our child and I will never forget that. While we only see each other occasionally, you continue to be one of my favorite medical education people ever. Nobody before, or since, has had the same enthusiasm, or patience, for sitting and just talking about medical education. I miss those talks. They were the start of many of the ideas that led to this PhD. Thank you!

It takes a whole lot of people to make great research happen. Along the way, I have had the great fortune to work with some truly remarkable research assistants and students. My first RA was Allan McDougall. Allan, from you I learned a whole lot about genre, about research and about the difference a good RA can make in supporting your work. Thank you! While you were a tough act to follow, I was ever so grateful to find Meredith Vanstone. Meredith, without you I never would have gotten the attending styles paper done. You are a great interviewer and I learned a lot from reading your transcripts. It was also because of you that we were able to include the McMaster attendings in the study. Thank you! Over the past two years, I have also had the privilege of Lisa Faden joining my team. Lisa, without question I was only able to finish my PhD in such a timely manner because of you. You were not only a great research associate, you were a fantastic collaborator and a friend. Thank you!

In terms of students, I could not have asked for a better group of people to work with. Steven Thomson was my first student volunteer. Steven, you helped me get my research off the ground. It was pilot data from our work that helped support my $\mathrm{PhD}$ application and the innovations grant that then supported my entire PhD. Thank you! Natasha Aziz then joined me for two summers to work on interruptions and detours. We did some great work together and through our shared publication, everyone knows it. Thank you! Then Dani Cadieux joined me for another two great summers. Dani, while you certainly have helped with this $\mathrm{PhD}$, you have also been instrumental in helping to define my post-PhD work. Our paper on student approaches to patient care follow-up is going to be much cited I am certain. Thank you! Two other students who I would like to thank are Noureen Huda and Salina Juma. Noureen and Salina both joined me during their residencies. As with Dani, your work, building on my thesis data, will go a long way in supporting a rich post-PhD program of research. In many ways, the studies you are both involved in could have gone into this thesis - it was my supervisors who told me to stop and get on with it. Noureen, it has also been such a pleasure working with you on your own Master's thesis and I am thrilled that we will be able to continue to collaborate together. Thank you! 
Early on in this PhD work, I was successfully awarded an Innovations grant from the Academic Medical Organization of Southwestern Ontario (AMOSO). This grant has largely supported the entirety of my PhD work. The grant not only supported the research work, it supported my time by funding me for one day/week to devote myself to the research. This gift of time made all the difference. There should be more grants like this one. Thank you!

Finally, I would like to end by acknowledging all of the many research participants. This has included medical students, residents and faculty colleagues. The type of research that I do requires a lot of trust on the part of the research participants. Thank you for believing I was worthy of that trust; without you I could not have done this work. Thank you!

Mark 


\section{CURRICULUM VITAE}

Mark Goldszmidt is an Associate Professor in the Division of Internal Medicine, Department of Medicine and Associate Director for the Center for Education Research \& Innovation at the Schulich School of Medicine \& Dentistry at Western University in London, Ontario, Canada. He graduated in medicine from McGill University in 1996 following which he completed his post-graduate residency in Internal Medicine at Queen's University, Kingston, Ontario, Canada and his fellowship in General Internal Medicine at Western University in London, Ontario, Canada.

Dr. Goldszmidt has been passionate about medical education since medical school. In 2003 he received his Masters of Health Professions Education from the University of Illinois at Chicago and he started his PhD with Maastricht University's School of Health Education in 2011. Dr. Goldszmidt has held numerous positions in medical education at the local, regional and national levels and spearheaded multiple innovations. He is most proud however of his involvement in the creation of the Centre for Education Research \& Innovation that emerged from his founding work with the Group for the Advocacy and Advancement of Medical Education Scholarship at the Schulich School of Medicine \& Dentistry. In recognition of his leadership in medical education, Dr. Goldszmidt received the GlaxoSmithKline Young Educators Award from the Association of Faculties of Medicine of Canada (2008), the New Educator Award from the Canadian Association for Medical Education (2008), and the 3M National Teaching Fellowship from the Society for Teaching and Learning in Higher Education (2013).

Outside of medicine, Dr. Goldszmidt's main passion is his family. With his wife Michelle and four children Rebecca, Sam, Jacob, and Max, he enjoys cooking, reading, skiing, and playing just about every sport imaginable that can somehow be squeezed into a living room! He and his family live in London, Ontario, Canada. 